\title{
Strengthening reproductive health services in Africa through Operations Research
}

Population Council

Follow this and additional works at: https://knowledgecommons.popcouncil.org/departments_sbsr-rh

Part of the Demography, Population, and Ecology Commons, Family, Life Course, and Society Commons, International Public Health Commons, and the Maternal and Child Health Commons How does access to this work benefit you? Let us know!

\section{Recommended Citation}

"Strengthening reproductive health services in Africa through operations research," Africa Operations Research and Technical Assistance Project II Final Report. New York: Population Council, 1999. 


\section{Strengthening Reproductive Health Services in Africa through Operations Research}

Africa Operations Research and Technical Assistance Project II

Final Report
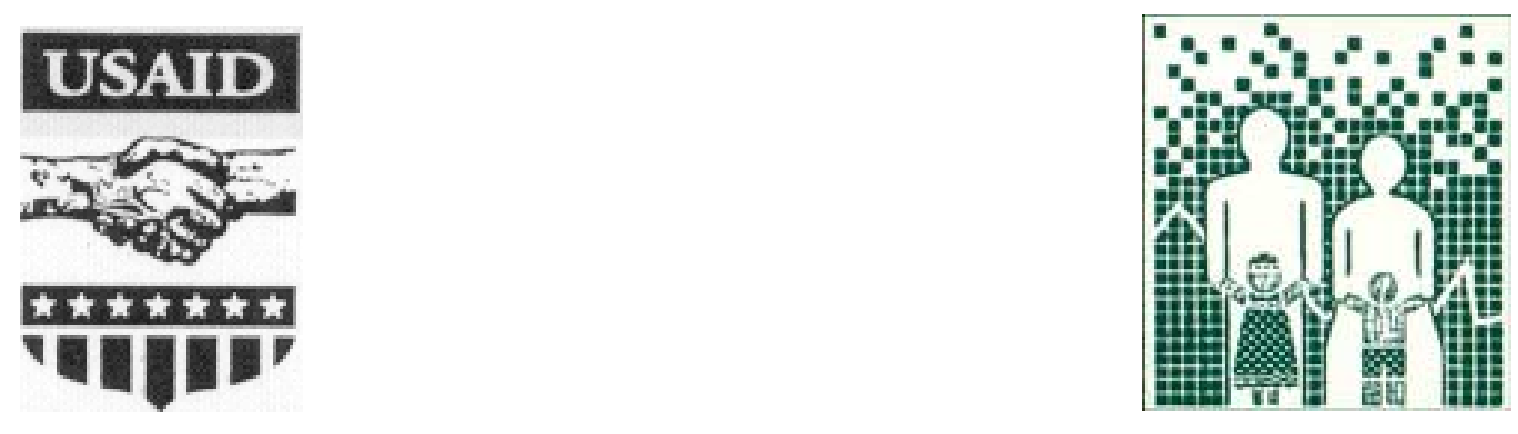


\section{The Population Council}

The Population Council seeks to help improve the well-being and reproductive health of current and future generations around the world and to help achieve a humane, equitable, and sustainable balance between people and resources. The Council analyzes population issues and trends; conducts biomedical research to develop new contraceptives; works with public and private agencies to improve the quality and outreach of family planning and reproductive health services; helps governments to influence demographic behavior; communicates the results of research in the population field to appropriate audiences; and helps build research capacities in developing countries. The Council, a nonprofit, nongovernmental research organization established in 1952, has a multinational Board of Trustees; its New York headquarters supports a global network of regional and country offices.

\section{Africa OR/TA Project II}

The overall objectives of the Africa OR/TA Project II are to broaden understanding of how to improve family planning services in Sub-Saharan Africa, and to apply operations research and technical assistance to improve services by:

- Increasing access to a full range of family planning services and methods;

- Developing service delivery strategies that are client-oriented and acceptable to various population groups;

- Improve the operations of programs to make them more efficient and financially sustainable;

- Improving the quality of services;

- Strengthening the capabilities of family planning program managers to use operations research to diagnose and solve delivery problems.

This report was supported by The Population Council's Africa Operations Research and Technical Assistance Project II. The Africa OR/TA Project II was funded by the U.S. Agency for International Development (A.I.D), Office of Population Contract No. CCC-3030-C-00-3008-00, Strategies for Improving Family Planning Service Delivery. 


\section{TABLE OF CONTENTS}

PAGE

Introduction

Africa Operations Research and Technical Assistance Project II 8

Summary of activities completed $\quad 9$

Location of project activities 11

Quality Of Care In MCH/Family Planning Clinics 13

Findings form Situation Analysis studies 13

Indicators of readiness and quality 16

$\begin{array}{ll}\text { Determinants of the quality of family planning services } & 18\end{array}$

Provider-imposed restrictions on access to family planning methods 19

Unrealized and missed opportunities in family planning services $\quad 20$

Differences in quality of family planning services in urban and rural areas 22

Changes in quality of service overtime $\quad 22$

Operations Research studies on quality of care clinics 23

Resource page on quality of care in clinics 26

Increasing Access To Reproductive Health

Services Through Community Based Services Delivery 29

Testing CBD deliver through field stations 30

What information and services can CBD agents provide? $\quad 33$

What role can $\mathrm{CBD}$ agents play in providing information
and services to their communities?

How productive are CBD agents, and which factors affect their performance? $\quad 35$

Factors determining agent performance 36

What costs are involved in providing information

and services through a CBD program? 38

What impact can be expected of a CBD program? 39

How Operations Research has strengthened CBD program? 41

Resource page on Community Based Service Delivery

Integration Of STI/HIV Information And Services In MCH/FP Programs

Is there need to offer RTI/HIV information and treatment services

to women attending MCH/FP clinics? $\quad 45$

Are STI and/or HIVIAIDS services currently provided at MCH/FP clinics?

Are MCH/FP programs and facilities prepared to provide STI

and/or HIVIAIDS services?

48

Are service providers in MCH/FP clinics prepared to provide STI

and HIVIAIDS services? $\quad 49$

What quality of STI and HIV information and services are MCH/FP

clients actually receiving? $\quad 50$

Are partners of clients treated for STIs at MCH/FP clinics also treated? 51

Are antenatal clients routinely tested and treated for syphilis at clinics 52

What are clients perceptions about integrating STI, HIV/AIDS and MCH/FP services? 52

What role can CBD agents play in the provision of STI and HIVIAIDS information and services? 53

How effective are existing procedures for detecting and managing STIs in MCH/FP clients? 53

Does the use of a standardized checklist improve the quality of an integrated approach? 57

How has Operations Research strengthened integration of STI/HIV and family planning services 58

Resource page on STI/HIV and MCH/FP information and services 59 
How extensive is the problem of incomplete abortion?

What are the characteristics of women seeking treatment of incompetence abortion? 62

How is emergency treatment best provided? 63

How best can family planning services be provided to Postabortion patients? 64

Implications for the routine implementation of Postabortion care 65

How has Operations Research helped in improving Postabortion care 66

$\begin{array}{ll}\text { Resource page on Postabortion Care } & 67\end{array}$

Reaching Adolescents With Information And Services 69

What do we know about the sexual and reproductive behavior of adolescents? 70

Contraceptive use: Do adolescents protect themselves?

Alternative approaches to reaching adolescents $\quad 72$

Resource page on reaching adolescents through information and services $\quad 75$

Strengthening The Role Of Men As Partners In Reproductive Health 77

Male involvement in family planing $\quad 78$

$\begin{array}{ll}\text { Men and STI/HIV } & 79\end{array}$

How can "Male friendly" RH services be organized $\quad 80$

Making services "Male friendly"

Resource page on strengthening the role of men as partners in reproductive health 82

Introducing Emergency Contraception To Expand Method Choice 83

Introducing emergency contraception in Zambia 83

Access to emergency contraception services $\quad 84$

Does use of emergency contraception encourage women to

abandon routine family planning methods? $\quad 86$

Does use of emergency contraception encourage the adoption of more

Is routine follow-up of emergency contraception users necessary?

How has Operation Research facilitated the introduction of emergency contraception 88

Resource page on emergency contraception 88

Female Genital Cutting $\quad 89$

Prevalence of FGC in Sahelian countries $\quad 90$

$\begin{array}{ll}\text { Complications associated with FGC } & 91\end{array}$

Attitudes and behaviors of clinic and community health workers concerning FGC 92

$\begin{array}{ll}\text { Community views on FGC } & 93\end{array}$

To what extent have interventions currently in place been able to bring about change? 94

How has Operations Research contributed to reducing the practice of FGC 96

Resource page on FGC

Building Capacity For Operations Research 99

Development and improvement of research methods $\quad 100$

Strengthening the capacity to plan, manage and evaluate service delivery programs 105

$\begin{array}{ll}\text { Activities of the Botswana Youth Empowerment Project(YEP) } & 107\end{array}$

$\begin{array}{ll}\text { Resource page on Capacity Building } & 109\end{array}$

$\begin{array}{ll}\text { Appendices } & 111-137\end{array}$ 


\section{Africa ORTAProject Countries}

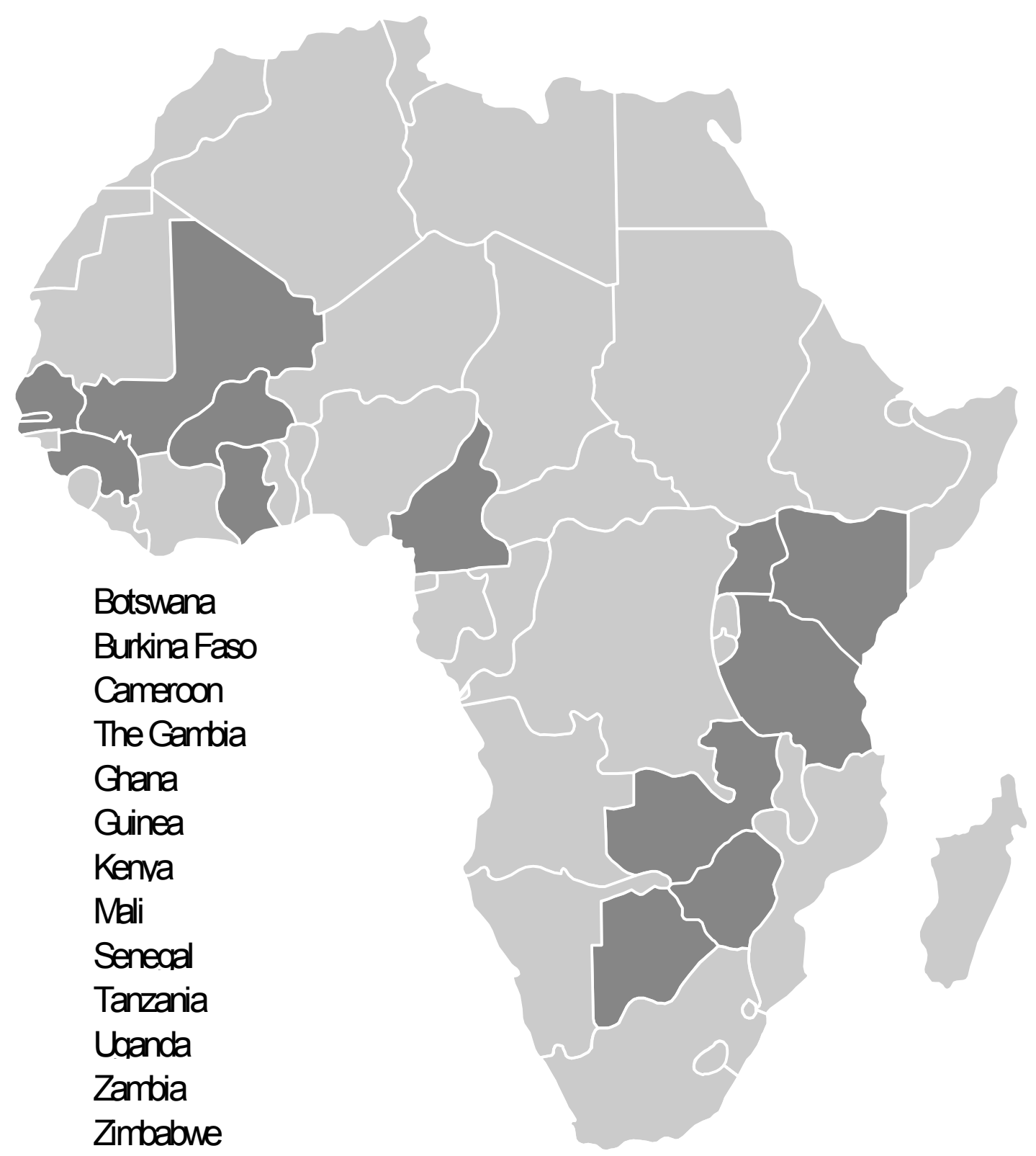




\section{INTRODUCTION}

The health status of women, men and children in Sub-Saharan Africa remains the poorest in the world. Moreover, virtually every country in the region is suffering mediocre economic growth or economic decline, thereby reducing the ability of their health care systems to respond adequately and increasing dependence on external donor assistance.

In terms of reproductive health specifically, the region is faced with high levels of unwanted fertility; high levels of maternal, child and infant morbidity and mortality; and an almost exponential growth in HIV prevalence. Access to and quality of reproductive health services remain poor in most countries, thereby maintaining unmet need for even the most basic reproductive health services.

Despite this gloomy background, reproductive health services in Africa are receiving tremendous and critically-focussed attention from governments, NGOs, donors and technical assistance organizations. Spurred on largely by the "Program of Action" emerging from the 1994 Cairo (ICPD) conference, most service delivery organizations in the region, both public and private are actively looking for ways to increase the proportion of the population having easy access to basic reproductive health services, to improve the quality of these services and to increase the efficiency of the systems providing these services. In many countries, this is also being done within the broader framework of health sector reform, with its emphasis on sustainability and decentralization.

"MCH/FP programs, which have traditionally and narrowly served the needs of women (and usually married and/or pregnant adult women), have the potential to also serve other clients, notably the male partners of these women and sexually active adolescents..."

Moreover, there has been growing recognition that a program providing reproductive health information and services needs to offer them in an integrated fashion, not only for the convenience of the consumer and the efficiency of the program, but also because of the inter-related nature of many reproductive health issues. For example, sexual intercourse can result in both pregnancy and infection. While pregnancy may or may not be desired depending on circumstances, a sexually transmitted infection is never desirable. Hence, the situations of individuals and couples' need to be considered whenever counseling is given for contraceptive or disease prevention services.

There has also been increased awareness that Maternal and Child Health/Family Planning (MCH/FP) programs, which have traditionally and narrowly served the needs of women (and usually married and/or pregnant adult women), have the potential to also serve other clients, notably the male partners of these women and sexually active adolescents. 
The (belated) realization thatfertility regulation, pregnancy and child-raising are not, and should not, be the sole responsibility of women is forcing managers to look for ways in which to broaden the reach of their programs to actively encourage and facilitate the involvement of men as partners in all aspects of reproduction and reproductive health.

Furthermore, the increased number of unmarried adolescents who are sexually active, and the trend towards earlier initiation of sexual activity, requires that programs must reduce the considerable social, administrative and economic barriers facing adolescents needing access to reproductive health and services.

The challenges facing reproductive health programs in sub-Saharan Africa are, therefore, numerous and varied. While seeking to increase coverage, improve quality and enhance efficiency, managers must do so within a context of decentralization of responsibility for resource management and program implementation. In addition, they must expand the range of services offered, and increase the type of people they serve. In short, policymakers and program managers are having to review, redirect and restructure $\mathrm{MCH} / \mathrm{FP}$ programs that have been in place for as many as 25 years.

Operations Research (OR) has a crucial role to play in such a situation. There are no right or wrong ways of going about such a redirection and in restructuring, each program manager needs to learn what is feasible, what is effective and what is efficient. And while intuition and experience can be drawn upon to guide this process, it is essential that the "better practices" that emerge as programs try out these new approaches to service delivery are documented with supportive empirical evidence and communicated widely throughout the region.

The newness of such practices means also that it is essential for programs to test alternative ways on a pilot basis before going to scale if they are to avoid what could be expensive mistakes. For example, the promotion of syndromic management of vaginal discharge among family planning clients, and the building of youth centers as means of reaching adolescents with reproductive health services, are just two examples of intuitively pleasing reproductive health strategies that have since been found wanting.

\section{Africa Operations Research and Technical Assistance Project II}

The program of OR supported by USAID is one technical assistance mechanism available to program managers and policymakers to assist them in pilot-testing innovative and alternative strategies when restructuring their programs. OR uses social science and other research methods to provide decision makers with empirically-based and scientifically-valid answers to service delivery problems.

The Africa Operations Research and Technical Assistance (OR/ TA) Project II was the successor to the Africa OR/TA Project (19881993), which was also implemented by the Population Council. 
This project was itself the successor of a ten-year program of USAID-supported OR in Africa implemented by Columbia University (1978-1988). The objective of the Africa OR/TA Project II was to broaden understanding of how to improve family planning and other reproductive health services in sub-Saharan Africa through applying operations research and technical assistance by:

- Increasing access to a full range of family planning services and methods;

- Developing service delivery strategies that are client-oriented and acceptable to various special population groups;

- Improving the operations of programs to make them more efficient and financially sustainable;

- Improving the quality of existing services;

- Strengthening the capabilities of family planning program managers to use operations research to diagnose and solve service delivery problems.

The Africa OR/TA Project II was implemented from October 1993 to December 1998. During that period, the Project employed 11 professional staff and supported four Fellows from ten African countries, itself a contribution to strengthening the research capacity available in the region (see Appendix 1 for a list of staff). At various times staff were based in offices located in Kenya, Senegal, Botswana, Burkina Faso, Mali, Tanzania and the United States.

The Project rarely implemented OR activities on its own, the vast majority of activities being direct collaborations with national, regional and international organizations. Appendices 2 and 3 list the 46 national and 44 international organizations with which the Africa OR/TA Project II collaborated, usually in a supportive role.

\section{Summary of Activities Completed}

The Africa OR/TA Project II implemented three broad types of activities. First and foremost, it supported 47 OR studies that contributed to a greater understanding of how to strengthen family planning and other reproductive health services. These studies were of three types.

- Diagnostic studies were used to assess the nature and extent of a reproductive health or service delivery problem. One specific type of diagnostic study, which formed a substantial proportion of the Project's portfolio of activities, was the Situation Analysis approach to describing the functioning and quality of services at reproductive health clinics.

- Evaluative studies were used to evaluate on-going innovative reproductive health interventions. One drawback with evaluative studies is that they are generally restricted to using non-experimental research designs, but they have the advantage of being a less costly means of assessing service delivery interventions than the more rigorous prospective intervention studies. 
- Intervention studies were used to test, usually through a quasi-experimental research design, the effectiveness of service delivery interventions explicitly designed to address a specific service delivery problem. They have the advantage of producing the most scientifically valid results but usually require more resources. Wherever possible, such studies were undertaken jointly with another technical assistance organization supporting the intervention itself.

Second, the Project allocated a substantial proportion of its human and financial resources to addressing its fifth objective, that is, building the capacity of African institutions and individuals to conduct and use operations research. Altogether, 24 capacity-building projects were implemented. These included:

- Training workshops in operations research methods;

- Workshops for strategic planning and project management;

- Network development to link organizations with similar interests;

- Conferences for disseminating OR results;

- Support for the development of skills in innovative research methods , especially Situation Analyses, participatory research and costing of reproductive health services.

Third, the Project allocated a considerable amount of human and financial resources to providing technical assistance, totalling 1,431 person days. This assistance was in addition to, and separate from the assistance normally provided as part of the support for implementing the OR and capacity-building projects described above.

By far the largest proportion of this assistance was for capacitybuilding, although almost one fifth of staff time spent on technical assistance was directed towards activities aimed at reducing the practice of Female Genital Cutting (FGC). 


\section{Location of Project Activities}

The Africa OR/TA Project II supported activities in 13 countries throughout sub-Saharan Africa. In addition, a number of activities were inter-regional in nature. The table below describes the distribution of activities by country and by type. A full listing of the activities supported in each country is given in Appendix 4 .

\section{Table of Africa Activities}

\begin{tabular}{lcccccc}
\multicolumn{1}{c}{ Country } & $\begin{array}{c}\text { Evaluative/ } \\
\text { Intervention }\end{array}$ & $\begin{array}{c}\text { Situation } \\
\text { Analysis }\end{array}$ & Diagnostic & $\begin{array}{c}\text { Capacity- } \\
\text { building }\end{array}$ & $\begin{array}{c}\text { Technical } \\
\text { assistance }\end{array}$ & $\begin{array}{c}\text { Total } \\
\text { activities }\end{array}$ \\
\hline Botswana & 1 & 1 & & 6 & 1 & 9 \\
Burkina Faso & 2 & 1 & 4 & & 7 & 14 \\
Cameroon & 1 & 1 & & & & 1 \\
Gambia & 5 & 1 & 2 & 1 & 2 & 1 \\
Ghana & 1 & & & & 11 \\
Guinea & 3 & 1 & 2 & 1 & 5 & 1 \\
Kenya & 2 & & & 1 & 2 & 12 \\
Mali & 2 & 3 & & 2 & 8 & 15 \\
Senegal & 2 & & 1 & 1 & 4 & 8 \\
Tanzania & 3 & 1 & 3 & 2 & 1 & 10 \\
Zambia & 2 & 1 & & 1 & & 4 \\
Zimbabwe & 1 & & & 8 & 2 & 11 \\
Regional & & & & 1 & 1 & 2 \\
Interregional & 24 & 11 & 12 & 24 & 33 & 104 \\
\hline TOTAL & & & & & & 5 \\
\hline
\end{tabular}




\section{Quality of Care in MCH/ Family Planning Clinics}

Since the late 1980s, there has been increasing recognition worldwide of the importance of service quality in family planning and reproductive health programs for improving the attractiveness of clinics as sources of services, and for enhancing the likelihood of women and couples achieving their reproductive goals. However, uncertainties about how program managers can implement "quality" continue to pose a challenge, not only to policymakers and managers, but also to those involved with service delivery research.

For example, "what is quality?"; "what should be considered a reasonable standard of quality to offer?"; and "what effect does quality of services received have on women's reproductive behavior?" are questions that the Africa OR/TA Project II addressed. The findings presented here are derived from two sources of information: national Situation Analyses studies; and operations research studies on specific aspects of service quality.

\section{Findings from Situation Analysis Studies}

The Africa OR/TA Project II supported 12 national Situation Analyses studies in the following countries: Botswana, Burkina Faso, Cameroon, Ghana, Guinea, Kenya, Senegal (three studies), Zambia, Zanzibar/Tanzania and Zimbabwe. The Project also provided technical assistance for Situation Analysis studies undertaken by other organizations in two regions of Mali (implemented by CERPOD); in the Mbeya Region of Tanzania (implemented by British Council/DFID); and in the cities of Mombasa, Blantyre and Bulawayo (implemented by the JSI/SEATS Project).

These studies measured and evaluated the functioning and quality of family planning and selected reproductive health services provided in clinics in each country. The Situation Analysis approach was first developed by the Africa OR/TA Project in 1989, and a handbook, including examples of data collection instruments and guidelines for study implementation, was prepared by staff from the Africa OR/TA Project II and colleagues from the Population Council (see Miller et al. 1997).

The results from these studies have been used to strengthen specific program subsystems and to guide and evaluate policies and programs within each of these countries as shown in the following tables. 
Using Results From Situation Analysis Studies To Strenghthen Program Subsystems

\begin{tabular}{|c|c|c|}
\hline Country & Date & Utilization of Results \\
\hline Botswana & 1995 & $\begin{array}{l}\text { Task Force established to review client record forms, service provider } \\
\text { guidelines and IEC materials after weaknesses identified by study. } \\
\text { Training course in logistics management. } \\
\text { Supervisory checklist for integrated services; will be tested on a } \\
\text { pilot basis as an OR study. }\end{array}$ \\
\hline Burkina Faso & $\begin{array}{l}1991 \\
1995\end{array}$ & $\begin{array}{l}\text { New training curricula and materials for training providers in counseling } \\
\text { developed by } \mathrm{MOH} \text {. } \\
\text { 'Reference guide' on contraceptive methods developed to improve } \\
\text { information provided. } \\
\text { Data analyzed by Geselischaft for Technische Zussammenarbeit (GTZ) to } \\
\text { strengthen services at clinics it supports. } \\
\text { Guide for undertaking a training needs assessment developed by } \\
\text { Program for International Training in Health (INTRAH). } \\
\text { IEC materials on contraceptives developed by Johns Hopkins university/ } \\
\text { Population Communication Services. } \\
\text { Findings used by Family Planning Service Expansion and Technical Support } \\
\text { (SEATS) Project to advise the MOH on a program of integration. }\end{array}$ \\
\hline Ghana & $\begin{array}{l}1993 \\
1997\end{array}$ & $\begin{array}{l}\text { Results of items on training used by the Johns Hopkins Program for } \\
\text { International Education in Reproductive Health } \\
\text { implementation of revised curriculum. }\end{array}$ \\
\hline Kenya & $\begin{array}{l}1990 \\
1991 \\
1995\end{array}$ & $\begin{array}{l}\text { Results used by Nairobi City Commission (NCC) and Pathfinder to } \\
\text { assess and strengthen infection control, counseling and IEC } \\
\text { activities. } \\
\text { Decision made by Pathfinder to support clinic strengthening in all } 44 \\
\text { NCC clinics, rather than } 10 \text { as originally planned. } \\
\text { Results disseminated to six provinces and used by managers to plan } \\
\text { improvements at subprovince level. }\end{array}$ \\
\hline Senegal & $\begin{array}{l}1994 \\
1998\end{array}$ & $\begin{array}{l}\text { Decentralized dissemination led to rapid training sessions for } \\
\text { improving providers' attitudes and beliefs about contraception. } \\
\text { Training manual developed for managing contraceptive supplies. }\end{array}$ \\
\hline Zanzibar & 1991 & $\begin{array}{l}\text { Equipment found missing at specific facilities purchased by } \mathrm{MOH} \text {. } \\
\text { Management and supervision courses added to program. }\end{array}$ \\
\hline Zimbabwe & $\begin{array}{l}1991 \\
1996\end{array}$ & $\begin{array}{l}\text { Basic family planning training curriculum revised by Zimbabwe National } \\
\text { Family Planning Council (ZNFPC) to encourage full counselling on } \\
\text { methods. } \\
\text { Counseling skills training module developed, with special emphasis } \\
\text { on long-term and permanent methods. } \\
\text { Interpersonal commmunications training module developed. } \\
\text { Checklist developed to improve follow-up visits to continuing clients. } \\
\text { Selection criteria for those being trained in family planning revised to } \\
\text { ensure that all clinics have at least one provider trained in family planning. } \\
\text { Decentralised training initiated at district level to increase number of staff } \\
\text { trained in family planning. } \\
\text { Increased attention and resourcs allocated to training doctor-nurse } \\
\text { teams of sterilization and IUD services. } \\
\text { Frequency of refresher training increased through training of provincial } \\
\text { staff. } \\
\text { System for distributing IEC materials to provinces improved. } \\
\text { Health Information Form improved, with training provided in completion } \\
\text { of the family planning component to improve service statistics. } \\
\text { Proposal developed for study to train providers in Reproductive Tract } \\
\text { Infection (RTI) management with IUD clients; proposal funded and } \\
\text { supported by JHPIEGO. } \\
\text { Pilot study to test depot-holder approach as alternative CBD strategy } \\
\text { developed and implemented. }\end{array}$ \\
\hline
\end{tabular}


Using Results From Situation Analysis Studies To Guide And Evaluate Policies And Programs

\begin{tabular}{|c|c|c|}
\hline Country & Date & Utilization of Results \\
\hline Botswana & 1995 & $\begin{array}{l}\text { Reproductive health section of Government of } \\
\text { Botswana 5-year National Development Plan } \\
\text { formulated. } \\
\text { Indicators for monitoring integrated reproductive } \\
\text { health services developed. } \\
\text { Data used by USAID as baseline measure for evaluat } \\
\text { ing its bilateral BOTSPA integrated services project. } \\
\text { United Nations Population Fund (UNFPA) 5-year } \\
\text { Project Review and Strategy Development Plan } \\
\text { developed. }\end{array}$ \\
\hline Burkina Faso & 1991 & $\begin{array}{l}\text { Comparative analysis of results from } 1991 \text { and } 1995 \\
\text { studies funded by UNFPA, as was a regional-level } \\
\text { analysis of the } 1995 \text { data, to guide joint planning with } \\
\text { the MOH. } \\
\text { Results used by MOH to guide World Bank-funded } \\
\text { decentralization process. }\end{array}$ \\
\hline Ghana & 1993 & $\begin{array}{l}\text { Results used by FHI to assess adherence by providers } \\
\text { to new } 1997 \text { standards and guidelines. }\end{array}$ \\
\hline Kenya & $\begin{array}{r}1990 \\
1991 \\
1995\end{array}$ & $\begin{array}{l}\text { Study report used by program managers to identify } \\
\text { specific resource needs in discussions with donors. } \\
\text { MOH Reproductive Health Strategy developed. } \\
\text { National Implementation Plan for Family Planning } \\
\text { Program (I995 - 2000) developed. } \\
\text { Data used by Marie Stopes International to develop } \\
\text { proposals for the World Bank. }\end{array}$ \\
\hline Senegal & $\begin{array}{l}1994 \\
1998\end{array}$ & $\begin{array}{l}1996 \text { National Action Plan developed. } \\
\text { Fees policy reviewed and standardized nationwide. } \\
\text { Standards and guidelines finalized. } \\
\text { Provision of injectables begun by International } \\
\text { PlannedParenthood Federation (IPPF) affiliate. } \\
\text { Data used as baseline for USAID bilateral Child } \\
\text { Health/Family Planning project implemented by } \\
\text { Management Sciences for Health (MSH). }\end{array}$ \\
\hline Zambia & 1997 & $\begin{array}{l}\text { Data used as baseline for evaluating: } \\
\text { i. USAID bilateral clinic-strengthening project } \\
\text { implemented by John Snow Incorporated (JSI). } \\
\text { ii. USAID Child Health Project. } \\
\text { iii. UNFPA reproductive health care project in } 10 \\
\text { districts. } \\
\text { iv. MOH Lusaka health program. }\end{array}$ \\
\hline Zanzibar & 1994 & Next 5-year program with UNFPA funding developed. \\
\hline Zimbabwe & $\begin{array}{l}1991 \\
1996\end{array}$ & $\begin{array}{l}\text { 1997-2001 national reproductive health program } \\
\text { developed. } \\
\text { Changes in program since } 1991 \text { assessed. }\end{array}$ \\
\hline
\end{tabular}


Given the large amount of information generated through these studies, Project staff undertook a number of secondary analyses of the datasets from 12 of the Situation Analysis studies undertaken in Africa since 1989 (eight of

Information collected through situation analysis studies has been used for many purposes including:

- Diagnosing and strengthening program readiness and service quality:

- Analyzing and explaining quality of care:

- Evaluating national programs over time:

- Developing and validating indicators of service delivery:

- Evaluating specific interventions in $\mathrm{MCH}$ / FP clinics: which were supported under this current project). These analyses synthesized the results from visits to 2,475 clinics and included interviews with 4,699 providers and observations of 7,067 client-provider observations.

The purpose of these analyses was to provide program managers, technical assistance organizations and donors with a comprehensive review of what is actually happening in $\mathrm{MCH} / \mathrm{FP}$ clinics throughout Africa.

The analyses have been brought together into a single volume entitled Clinic-Based Family Planning and Reproductive Health Services in Africa: Findings from Situation Analysis Studies, copies of which are available free of charge from the Population Council. The key findings are presented below.

\section{Indicators of Readiness and Quality}

An assessment of the readiness and quality of family planning services in sub-Saharan Africa can be constructed from the series of more than 100 indicators that have been measured in most of the 12 Situation Analysis studies (see Appendix 5).

The Situation Analysis methodology in no way measures every aspect of quality, nor is it free from various biases. The results are informative, nonetheless, and the following conclusions can be drawn from a review of these indicators.

In general, the maturity of the family planning program alone predicts much of the quality of family planning services. Overall, Botswana and Zimbabwe, with two of the most mature and well funded programs in sub-Saharan Africa, fare relatively well on many indicators, while the opposite is true for some of the less

"Many of the stronger points of family planning and reproductive health services in sub-Sahara Africa are their readiness to provide services." developed programs. However, program maturity in no way determines all of the results. The size of the population of women of reproductive age served, the method mix of each country, the quality and extent of training pro-

grams and even the various cultures all directly affect service quality. 
The infrastructure of most clinics, especially in urban areas, is adequate, and many have the equipment required for basic family planning services. Moreover, the pattern of methods offered is in some ways quite appropriate (the one serious problem being the lack of full availability of condoms in some countries), and stockout rates for most methods appear generally to be under control, excepting injectables.

Several strengths are also evident in the quality of services given to clients. The physical assessment of new family planning clients (e.g. weight, blood pressure, LMP and medical history), is carried out fairly consistently as required in most delivery guidelines but not necessarily essential. The quality of administering injections is quite high in most countries, especially with regard to aseptic procedures-an important finding given the increasing use of injectables in many contexts. Also, across all the study sites, the vast majority of clients are given revisit dates, thereby encouraging continuity of method use.

The overall weaknesses of the programs revolve mainly around family planning counseling, asepsis and STD/HIV integration. With regard to counseling, two aspects must be considered: information taken from clients about reproductive intentions, breast-feeding status and other concerns and information given to clients about the method accepted and STD risk. In both of these aspects, counseling is broadly lacking across all study sites. These activities are particularly important because they are directly related to client satisfaction, appropriateness of method selected, continuity of use and STD/HIV risk.

Information, Education and Communication (IEC) materials are extremely uncommon in most contexts; even where present they are not usually used with clients. This nonuse of existing IEC materials represents missed opportunities to communicate effectively with clients about their methods.

"Family planning clients are by definition sexually active, so they are at risk of STDs and HIV, but most programs do not adequately address this risk."

The issue of asepsis also stands out as an area of concern. Many examination rooms do not have adequate water for washing hands or equipment, and handwashing and/or glove use are not practiced consistently during pelvic exams, even where water and gloves are available. In some cases, clients undergoing pelvic exams are given no protection whatsoever against cross-infection from other clients.

Moreover, sterile instruments were not used for all observed IUD insertions. Because STD and HIV prevalence is so high in many of the study contexts, there can be no margin for error allowed on asepsis, so even the smallest lapses should be viewed as extremely serious.

Some of the Situation Analyses were carried out before the ICPD in Cairo, at which the importance of STD/HIV integration with family planning services was stressed. 
Nonetheless, the results presented here reveal the great distance that many sub-Saharan African programs must travel to reach full integration. To begin with, the availability of condoms in some places is quite low; even where they are available in most SDPS, they are often not discussed with clients with respect to either family planning or prevention of STD/HIV transmission. Moreover, clients are rarely told how their method relates to STD transmission or screened for STD symptoms.

Many of these observed strengths and weaknesses depend on the actions of staff, who are charged with the actual provision of family planning services. In turn, it is the responsibility of family planning programs to train providers adequately so their actions will result in high-quality care. The results of staff interviews show that family planning has in fact been integrated into many basic training courses, so most of the newer providers are trained. In addition, many programs appear recently to have been increasing their refresher training programs in IEC/counseling.

\section{Determinants of the Quality of Family Planning Services}

\section{Clinic readiness}

Using data from the 1995 national Situation Analysis study conducted in Kenya, the relationship between the readiness of a facility to deliver family planning services (in terms of staff training, infrastructure, equipment and supplies) and the quality of services received by clients was analyzed. The analysis led to the following conclusions:

- If a provider has not been trained specifically in the long-term or permanent contraceptive methods (such as Norplant ${ }^{\circledR}$ implants and female sterilization), they are less likely to mention these methods to clients than providers who have received such training. General family planning training does not have the same impact on counseling and is not associated with better technical competence.

- If a clinic has IUDs, Norplant ${ }^{\circledR}$ implants and spermicides available, providers are more likely to discuss them with clients.

- Providers trained in IEC, NFP and LAM are likely to discuss more types of methods with clients and to give more information on the accepted method, possibly because training in these methods puts a strong emphasis on thorough counseling.

- Clients attending clinics where samples of contraceptives and anatomical models are available as counseling aides are more likely to be given detailed counseling about their accepted method than clients who attend clinics where these aides do not exist.

- The availability of medical equipment, such as blood pressure machines, at a clinic appears to motivate providers to use that equipment for assessing possible medical contraindications to certain contraceptive methods, although care must be taken not to encourage their use unnecessarily. 


\section{Client characteristics}

A client's personal characteristics appear to influence the way family planning services are provided. Providers use a client's individual characteristics not only to identify the most suitable method but also to restrict access to contraception (see later). Married women are more likely than unmarried women to hear about a greater range of methods (and especially progestin-only pills, condoms and IUDs). Likewise, women with none or one child are more likely to hear about all methods (except female sterilization) than women with two or more children.

A client's characteristics have no influence on whether a provider tells her about the advantages and side effects of a method or about her ability to switch methods. In other words, all women are equally likely to receive (or not) this information. There is an association, however, between the client's educational level, and other information given to her about the accepted method.

Clients with primary or secondary education are many times more likely than clients with no education to be told about how to use a method, its disadvantages and how to manage a problem. Likewise, clients under the age of 20 years and (albeit to a lesser extent) unmarried are less likely to receive this information.

\section{Provider-imposed Restrictions on Access to Family Planning Methods}

Situation Analyses studies contain data on provider attitudes and behaviors and measure the extent to which providers impose various restrictions on the availability of contraceptive methods. A review of five recent and comparable studies (in Botswana, Burkina Faso, Kenya, Senegal and Zanzibar) looked at staff-imposed restrictions and compared them with their country's service protocols. The analysis showed that:

- In all five countries, marital status restrictions are imposed most commonly in prescribing IUDs and female sterilization and least commonly when providing condoms.

\begin{abstract}
"A family planning client who is married and has none or one child is more likely to be told about a wide range of different methods."
\end{abstract}

- An unmarried woman in

Botswana, Burkina Faso or Senegal has an easier time obtaining contraception than a married woman who does not have her husband's consent. With the exception of female sterilization, however, none of the countries has a policy requiring husband's consent for any method, implying that providers are imposing this barrier on their own initiative.

- A considerable proportion of providers impose parity requirements for the provision of IUDs and injectables. This is not surprising given that restrictions on IUDs are required by policy in Burkina Faso, Kenya and Zanzibar. In Kenya, however, where the providers were the most restrictive in terms of parity require- 
ments, methods such as condoms were also significantly restricted on the basis of parity, even though the country's service protocol did not require such restrictions.

- Providers generally appear to impose age restrictions according to the types of women they feel should use each method. Thus for combined pills and condoms, the average minimum age required is 15-17 years; for IUDs, injectables and Norplant ${ }^{\circledR}$ implants, the requirement is 17-27 years; and for female sterilization, it is 35 years or over.

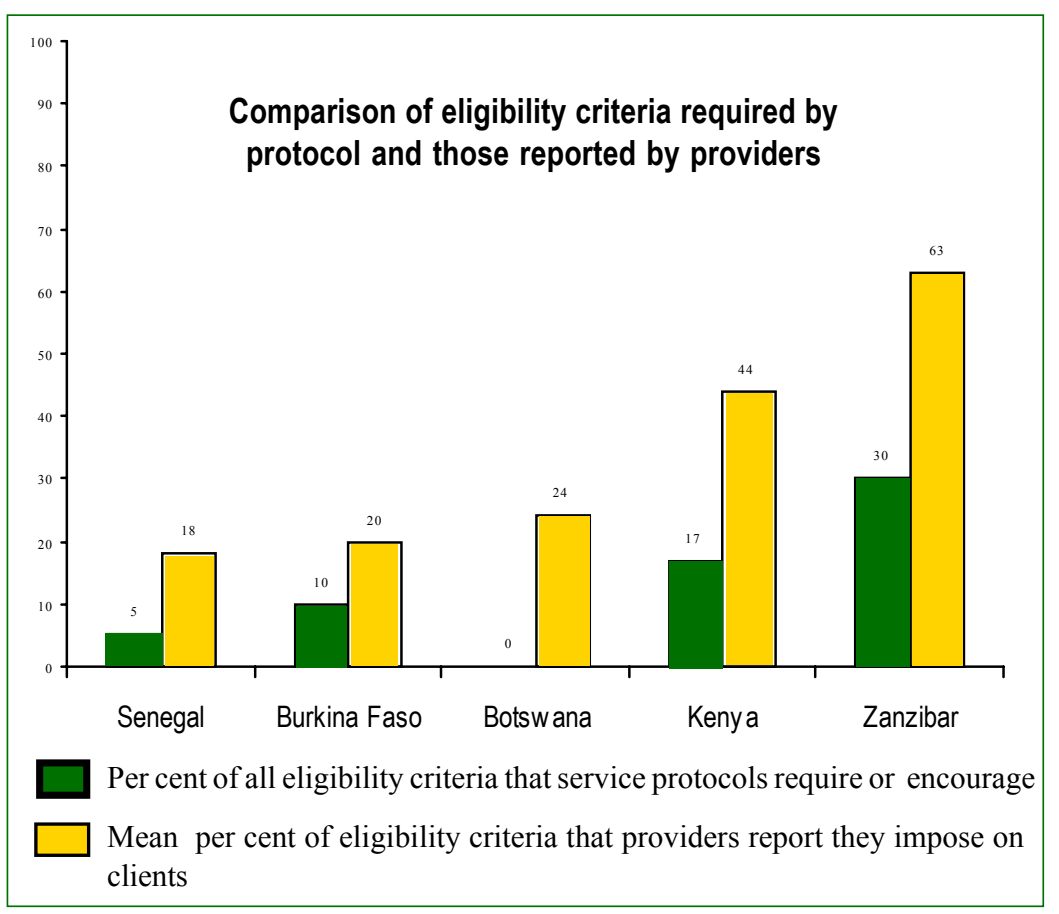

Apart from female sterilization in three countries, and the IUD in Senegal, the service protocols in these countries have no such age requirements. Moreover, international guidelines place no strict age requirements on any method.

- As shown in the chart, in each of the five countries, providers on average impose twice as many eligibility criteria as are required or encouraged by national guidelines.

Overall, it can be concluded that providers' attitudes and behavior play a significant role in the way services are provided and in the restrictions imposed on particular methods. Revised service protocols and training programs may remove the concerns about clients' well-being, but addressing broader societal and cultural concerns will require more careful attention.

\section{Unrealized and Missed Opportunities in Family Planning Services}

The 1994 International Conference on Population and Development in Cairo set forth the broad challenge of ensuring that clients receive an adequate quality of care. In light of this emphasis, the question arises as to whether the resources exist to meet this objective. Additional technological and financial inputs are often necessary to incorporate closely related reproductive health services into the scope of existing family planning programs.

An analysis of data from Botswana, Burkina Faso, Kenya, Senegal and Zambia, however, suggests that substantial opportunities exist already to increase the quality of care and its contribution to clients' reproductive health, simply by using available resources more effectively. For example, the following actions could be taken with no need for additional resources:

Increase method choice The number of contraceptive options offered to new clients seeking to space pregnancies is consistently fewer than the number of spacing methods physically present in 
the clinic. This unnecessarily restricts clients' ability to choose and take home the most appropriate or desirable method.

Use existing IEC materials during client counseling: Providers generally do not make use of available information, education and communication (IEC) materials which could improve clients' understanding and assist them in making more fully informed decisions.

Spend more time with clients to give comprehensive service: The majority of providers see three or fewer clients (including both family planning and maternal and child health clients) per day, suggesting that a significant amount of staff time may be available to increase the duration of consultations, improve the quality of information given and expand the number of reproductive health services offered.

Use available water and gloves to protect against risk of infection: Providers commonly make use of equipment such as blood pressure machines and uterine sounds when available. However, they often fail to follow asepsis procedures during pelvic exams, even when clean water and gloves are available in the exam room. They thus put their clients at unnecessary risk of infection.

Ask about a client's social context and sexual relationships: Providers frequently do not inquire about the client's sexual behavior (e.g., the number and frequency of partners, and whether the partner is included in the decision to seek contraception). They are thus unable to assess contraindications for a given method or recommend methods appropriate to the client's situation.

\section{Always discuss the ability of a con- traceptive method to prevent STIs:} The ability of a given method to protect against sexually transmitted infections, and in particular the dualprotection benefit of condoms, is rarely discussed during consultations (for example, only 4 per cent of cli-

Cumulative per cent of clients who experienced a choice of methods and who were told about their selected method

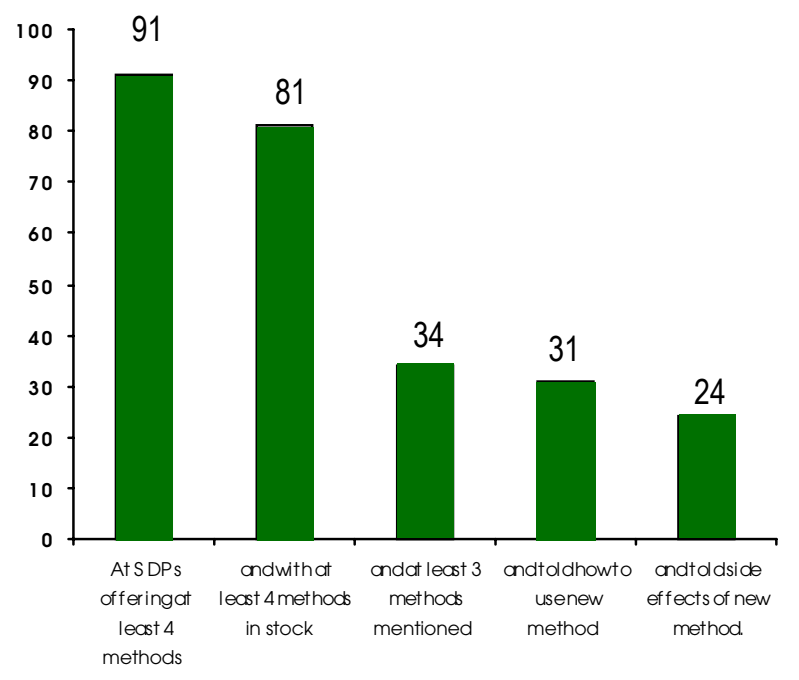
ents in Zimbabwe knew of the dualprotection message in relation to condoms).

Taking advantage of these unused resources will arguably increase the efficiency of resource use but will not be fully costfree. It will require establishing appropriate protocols that define the minimum information to be given to clients, give meaning to offering a full choice of methods and identify safety of services as a clear priority. It will also be necessary to shift the emphasis of staff training to higher-quality services and to being sensitive to clients' expressed needs. The supervisory program will thus support and evaluate providers in these areas. 


\section{Differences in Quality of Family Planning Services in Urban and Rural Areas}

Sub-Saharan Africa currently has the highest rate of urban growth in the world. As a result, the infrastructure in cities, and particularly that of urban health systems,

Providers can substantially raise the quality of services through such practical measures as improving information exchange and observing proper asepsis procedures. In addition, in many clinics a significant amount of staff time appears to be untapped and could be harnessed to broaden the scope of services. is becoming increasingly strained. However, urban areas also enjoy a number of advantages which, it may be assumed, could facilitate higher quality of services than those found in rural areas for example, a greater concentration of trained personnel, larger health facilities and shorter supply routes.

To test the validity of this assumption, a comparison was undertaken of the quality of family planning services in urban and rural areas in six countries: Botswana, Burkina Faso, Ghana, Kenya, Zanzibar and Zimbabwe. The data led to the following conclusions:

- For indicators related to clinic infrastructure (such as availability of electricity and water), urban clinics show a clear advantage.

- Almost half or more of the indicators of readiness, including staffing, accessibility of services, logistics, equipment, supervision, IEC materials and contraceptive methods offered, show little or no difference between urban and rural clinics.

- There is little difference between the quality of care offered at urban and rural clinics as shown in the following page, with only Burkina Faso and Kenya showing any noticeable advantages in urban clinics. Indeed, in Senegal there is a slight advantage to the rural clinics.

- The quality and frequency of counseling and information exchange appear to be similar among urban and rural clinics within each country, and the technical competence of providers appears to be roughly equal as well.

\section{Changes in Quality of Services Over Time}

In a number of sub-Saharan African countries (Burkina Faso, Ghana, Kenya, Senegal and Zimbabwe), two or more Situation Analysis studies have been carried out several years apart. Comparison of the results from these studies can indicate whether changes in service quality have occurred in the interval. This comparison can also serve an evaluative function if service quality interventions have been introduced between the two studies (as was the case in Senegal).

Although each comparison is country-specific, several overall conclusions about how family planning and reproductive health services are changing over time can be drawn: 
- The choice of methods available shows slight or partial improvements in all countries. These improvements take the form of availability of an expanded range of methods, increased number of methods mentioned to clients during counseling and/or larger numbers of clients being asked their method preference.

- All countries are making some progress in increasing the availability of IUDs, Norplant ${ }^{\circledR}$ implants and/or permanent methods. At clinics that offer these methods, not all elements required to provide the methods (e.g. training, equipment, technical competence and counseling) are fully in place in any of the countries, but efforts are moving in that direction.

- The quality of family planning counseling is generally low. More seriously, it appears to be declining or stagnant in each country except Senegal, where clients are hearing about more methods and getting more information about methods. This particular element of quality is suffering markedly more than technical competence, and it does not appear to be directly related to any training interventions that have happened during the interval.

- The few indicators that address the integration of STI/HIV services into the programs either declined or remained constant over time. Given the high prevalence of STIs and HIV in these countries, there is urgency to take action on these findings.

These comparisons testify to the complexities of programs to achieve real increases in quality of care. Improvements in the readiness of a program do not necessarily translate to improvements in the quality of care delivered, even if the changes are in the form of increased training or supervision. These comparisons are limited in their ability to serve as rigorous evaluations of program interventions because they lack an experimental design. As additional facility-based studies are undertaken on a more regular basis in the future (for example, through the USAID-funded MEASURE Program), the opportunity presents itself to design such evaluations more rigorously.

\section{Operations Research Studies on Quality of Care in Clinics}

\section{Clients' Perceptions and Definitions of Quality of Care}

Most definitions of quality of care (e.g., the Bruce-Jain Framework and IPPF's "Rights of the Client") have been established by professionals with expertise in the field. While this is a perfectly valid approach, there has been little effort to validate these definitions from the point of those actually providing or using the services. An OR study undertaken in Kenya used qualitative research methods (focus group discussions, in-depth interviews and simulated clients) to explore the meaning

Efforts by program managers to attract more clients to clinics for family planning services may have to focus equal attention on costs, accessibility and offering medical exams as on counseling and infrastructure. 
of quality of care to clients and providers. The study included both urban and rural clinics, and private sector and NGO clinics.

The study used content analysis to determine how frequently an element was mentioned and the strength of feeling expressed. Two elements were identified by both providers and clients as being central to any definition of quality: cost and client's proximity to the clinic. In addition, clients mentioned counseling on side effects and the availability of a range of methods as important, whereas providers mentioned availability of supplies and equipment, and performing a medical exam. Rated slightly less high, but seen by both groups as fairly important, were providers' attitudes to clients and the waiting time spent.

These results suggest that a definition of quality of care that primarily emphasizes client-provider interaction may not fully incorporate the clients' or providers' perspectives on what is important in providing clinic-based services.

\section{Exposure to Family Planning Information during MCH/FP Visits}

A study undertaken in Kenya sought to find out whether women were given family planning information during visits for antenatal care and/or infant health care and whether this exposure influenced the likelihood of their subsequently using family planning. The study included 1,834 women interviewed while attending 28 health facilities for $\mathrm{MCH}$ or family planning reasons.

The women were asked about antenatal visits during their last pregnancy. Almost half the women who had been to the clinic for antenatal care indicated that they had been given family planning coun-

Exposing women to information about family planning during antenatal visits, whether through provider counseling, seeing IEC materials or discussions with other women, doubles the likelihood that they will use family planning. seling during their antenatal visits. Older and married women were more likely than younger, single women to have received such counseling, as were those with higher levels of education.

Moreover, women who wanted no more children were more likely to be counseled on family planning than women who did want more children.

Women were also asked whether they had started using family planning after the pregnancy. The likelihood of a woman using family planning increased by 2.13 times if she reported having received family planning counseling during antenatal visits, by 2.04 times if she had discussed family planning with other women while at the clinic and by 1.94 times if she reported having seen IEC materials on family planning during antenatal visits. 


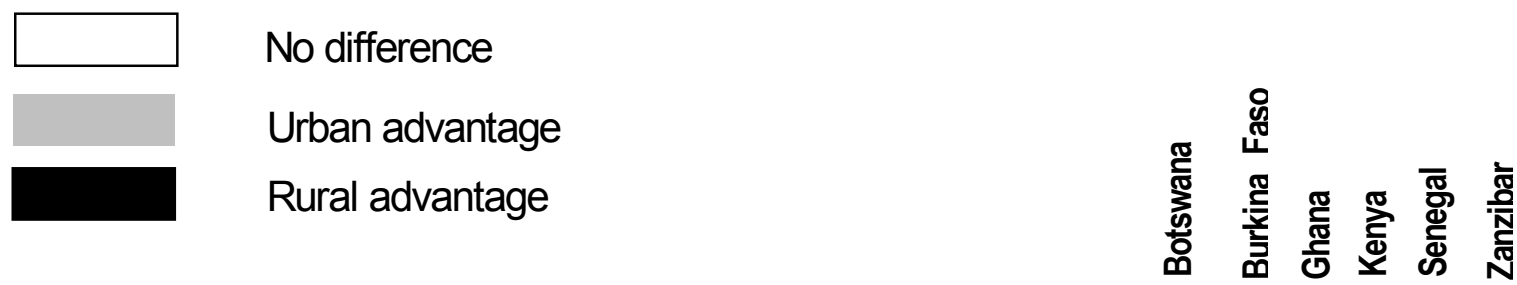

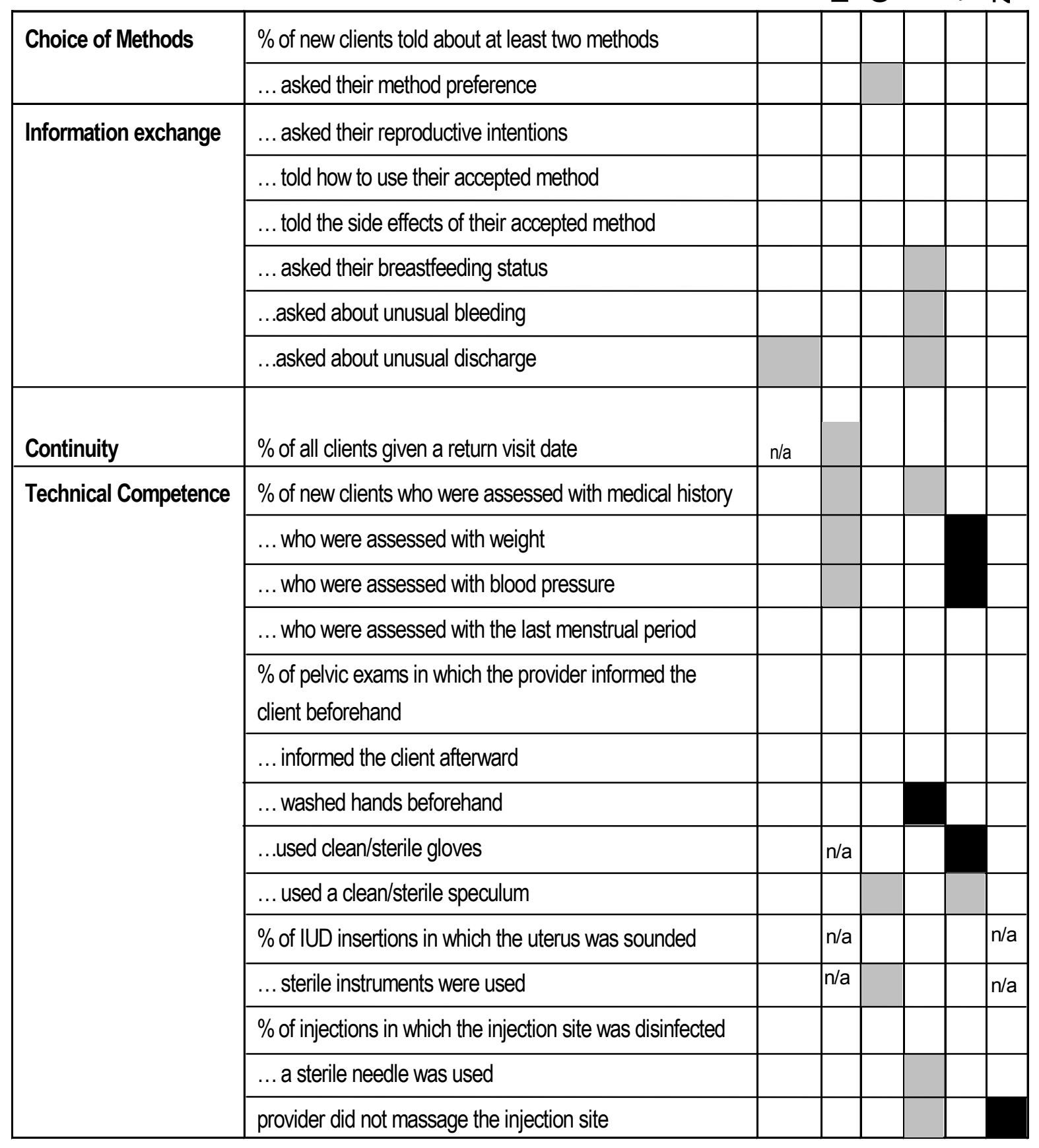

${ }^{*} p<0.05$ 


\section{Resources Available From The Africa OR/TA Project II On Quality Of Care In Clinics}

Askew, Ian. 1994. Distinguishing between quality assurance mechanisms and quality assessment techniques. Health Policy and Planning 9(3): 274-277.

Askew, Ian. 1998. Using Situation Analysis to improve reproductive health programs, Chapter 4 in Miller, Kate, Robert Miller, Ian Askew, Marjorie Horn and Lewis Ndhlovu (eds) Clinic-Based Family Planning and Reproductive Health Services in Africa: Findings from Situation Analysis Studies, Population Council, New York.

Askew, Ian, Barbara Mensch, and Alfred Adewuyi. 1994. Indicators for measuring the quality of family planning services in Nigeria. Studies in Family Planning 25(5): 268-283.

Askew, Ian, Kate Miller, and Barbara Mensch. 1995. Key indicators for measurement of quality of family planning services. Paper presented at The EVALUATION Project's Service Delivery Working Group meeting, Washington, D.C., 5 October.

Baakile, Benjamin, Baker Ndugga Maggwa, Lucy Maribe, and Robert A. Miller. 1996. A Situation Analysis of the maternal and child health/family planning (MCH/FP) program in Botswana. Prepared by the Africa OR/TA Project II in cooperation with the Ministry of Health MCH/FP Unit, Family Health Division. Gaborone, Botswana, July.

Bamba, Azara, Brice Millogo, Jeanne Nougtara, Youssouf Ouédraogo, Placide Tapsoba and Inoussa Kaboré. 1996. Deuxième Analyse Situationnelle du Program de Planification Familiale au Burkina Faso, Prepared by the Africa OR/TA Project II in cooperation with the Ministère de la Santé, de l'Action Sociale et de la Famille, Ouagadougou, Burkina Faso, July.

Central Statistical Office, 1998. Zambia Situation Analysis Report, 1997. Lusaka, Zambia, May.

Diop, Marième, Isseu Touré, Nafissatou Diop, Diouratié Sanogo, and Aristide Aplogan. 1995. Analyse Situationnelle du système de prestation de services de planification familiale au Sénégal. Prepared by the Africa OR/TA Project II in cooperation with the Ministère de la Santé et de l'Action Sociale, and Program National de Planification Familiale. Dakar, Sénégal, February. [In French and English; French version also available by region]

Dube Hazel M.B, Caroline S. Marangwanda and Lewis Ndhlovu. 1998. As Assessment of The Zimbabwe Family Planning Program: Results from the 1996 Situation Analysis Study. The Africa OR/TA Project II, Nairobi, Kenya, May.

Family Health Project. 1995. Mbeya Family Health Project Situation Analysis study. Report of Technical Assistance provided by the Africa OR/TA Project II to The British Council and UK Overseas Development Administration Family Health Project, Mbeya, Tanzania, December.

Fisher, Andrew and Kate Miller.1996. Conditions required at SDPs to deliver quality family planning services: Why so many do so little. Paper presented at the annual meeting of the American Public Health Association, New York, New York, 17-21 November.

Laboratoire de Santé Communautaire. 1998. Comparing quality of Reproductive Health Services before and after clinic-strengthening activities: A case study in rural Burkina Faso. Laboratorie de Santé Communautaire du Bazega, Ouagadougou, Burkina Faso. December. Ouagadougou, Burkina Faso.

Maggwa, Baker N., Ityai Muvandi, Martin Gorosh, et al. 1995. Findings from the subSaharan Africa urban family planning study: Mombasa City report. Report of Technical Assistance provided by the Africa OR/TA Project II to the SEATS Project. John Snow Inc., Washington, D.C., March.

Maggwa, Baker N., Ityai Muvandi, Martin Gorosh, et al. 1995. Findings from the subSaharan Africa urban family planning study: Blantyre City report. Report of Technical Assistance provided by the Africa OR/TA Project II to the SEATS Project. John Snow Inc., Washington, D.C., March.

Mapunda, Patiens and the Africa OR/TA Project II. 1996. The Zanzibar Family Planning Situation Analysis Study. Ministry of Health, Zanzibar, Tanzania, and the Africa OR/TA Project II, Nairobi, Kenya, May. 
Mbodji, Fara. 1996. Analyse Situationnelle des services de planification familiale dans les régions de Koulikoro et Sikasso, Mali. Report of Technical Assistance provided by the Africa OR/TA Project II to the Center d'Etudes et de Recherche sur la Population pour le Développement (CERPOD), Bamako, Mali, August.

Mensch, Barbara, Robert Miller, and Vincent Miller. 1994. Focusing on quality with Situation Analysis. Planned Parenthood Challenges 2, London: International Planned Parenthood Federation.

Miller, Kate, and Diouratié Sanogo. 1997. Analyse Secondaire: Développement des indicateurs pour les managers. Presentation at Francophone Africa program managers' workshop on 'Analysis and Utilization of Situation Analysis studies, " Population Council, Dakar, Senegal, 9-14 June.

Miller, Kate, Heidi Jones, Carolyn Vogel, Martin Gorosh and Melinda Ojermark. 1997. Urban and rural family planning/STD services in sub-Saharan Africa: does service quality really differ? Presentation notes. Paper presented at the $125^{\text {th }}$ annual meeting of the American Public Health Association, Indianapolis, Indiana, 9-13 November.

Miller, Kate, Lewis Ndhlovu and Naomi Rutenberg. 1997. How does 'readiness' to provide family planning services affect the quality of services delivered. The relationship between functional capacity and quality of care in three sub-Saharan African countries. Poster session at the $125^{\text {th }}$ annual meeting of the American Public Health Association, Indianapolis, Indiana, 9-13 November.

Miller, Kate, Robert Miller, Goli Fassihian and Heidi Jones. 1997. How do providers restrict access to family planning methods? Results from five African countries. Paper presented at the $125^{\text {th }}$ annual meeting of the American Public Health Association, Indianapolis, Indiana, 9-13 November.

Miller, Kate, Robert Miller, Ian Askew, Marjorie Horn and Lewis Ndhlovu (eds). 1998. Clinic-Based Family Planning and Reproductive Health Services in Africa: Findings from Situation Analysis Studies, Population Council, New York.

Miller, Robert, Kate Miller, Lewis Ndhlovu, Julie Solo and Ominde Achola. 1996. A comparison of the 1995 and 1989 Kenya Situation Analysis findings. Paper presented at the annual meeting of the American Public Health Association, New York, New York, 17-21 November.

Miller, Robert, Kate Miller, Lewis Ndhlovu, Julie Solo, and Ominde Achola. 1996. A comparison of the 1995 and 1989 Kenya Situation Analysis study findings. African Journal of Fertility, Sexuality, and Reproductive Health 1(2):162-168.

Miller, Robert, Andrew Fisher, Kate Miller, Lewis Ndhlovu, Ndugga Maggwa, Ian Askew, Diouratié Sanogo and Placide Tapsoba. 1997. The Situation Analysis Approach to Assessing Family Planning and Reproductive Health Services: A Handbook, Population Council, New York.

Ministère de la Santé, Africa OR/TA Project II and Projet Santé Familiale et Prévention du SIDA. 1998. Analyse Situationnelle du Système de Prestation de Services de Santé de la Reproduction au Cameroon, Africa OR/TA Project II, Population Council, Dakar, Senegal. December.

Ministère de la Santé, Africa OR/TA Project II, USAID and BASICS. 1998. Analyse Situationnelle de Programmes de Santé de la Reproduction. Africa OR/TA Project II, Population Council, Dakar, Senegal. December.

Muvandi, Ityai, Baker Ndugga Maggwa, Martin Gorosh, et al. 1995. Findings from the subSaharan Africa urban family planning study: Bulawayo City report. Report of Technical Assistance provided by the Africa OR/TA Project II to the SEATS Project. John Snow Inc., Washington, D.C., March.

Ndhlovu, Lewis. 1994. Quality of care in family planning service delivery in Kenya: Clients' and providers' perspectives. Paper presented at the Conference on Quality of Health Care for Women. Budapest, Hungary, 15-17 October.

Ndhlovu, Lewis. 1995. Quality of care in family planning service delivery in Kenya: clients' and providers' perspectives. Summary report. Africa OR/TA Project II, Nairobi, Kenya, August.

Ndhlovu, Lewis. 1996. Including the users' perspective: how clients define quality. Paper presented at a workshop on "Strengthening the Utilization of Situation Analysis for Planning, Managing and Evaluating Reproductive Health Services," Population Council, Nairobi, Kenya, 29-31 May.

Ndhlovu, Lewis. 1997. The route from MCH to family planning: Why do women switch health facilities in the Kenyan MCH/FP program? Paper presented at the $125^{\text {th }}$ annual meeting of the American Public Health Association, Indianapolis, Indiana, 9-13 November. 
Ndhlovu, Lewis. 1999. Quality of Care and the Utilisation of MCH and FP Services at Kenyan Health Facilities, Africa OR/TA Project II, Nairobi, Kenya. February.

Ndhlovu, Lewis and Ominde Achola. 1996. Maternal and Child Health visits to health facilities in Kenya: A "missed opportunity" for family planning and reproductive health education. Paper presented at the annual meeting of the American Public Health Association, New York, New York, 17-21 November.

Ndhlovu, Lewis, Julie Solo, Robert Miller, Kate Miller and Achola Ominde. 1997. An assessment of clinic-based family planning services in Kenya: Results from the 1995 Situation Analysis study. The Africa OR/TA Project II, Nairobi, Kenya, January.

Ndhlovu, Lewis and Jane Chege. 1997. Family planning services in Nairobi: Report of a workshop for strengthening the utilization of findings from research studies of clinic and community based family planning services of the Nairobi City Council. The Africa OR/TA Project II, Nairobi, Kenya, September.

Programme National de Planification Familiale and the Africa OR/TA Project II. 1999. Etude Expérientale sur 'Effet des Stratégies d'Amélioration de la Qualité sur le taux de Continuité de Services de Planification Familiale au Sénégal. Africa OR/TA Project II, Population Council, Dakar, Senegal. March.

Sanogo, Diouratié, Nafissatou Diop, Adiartou Ndiaye, Mady Cissé, Cheikh Bamba Diop and Bineta Mbow. 1998. Evolution des Services de Santé de la Reproduction et Planification Familiale de 1994 à 1998. Ministère de la Santé and Africa OR/TA Project II, Population Council, Dakar Senegal. December.

Stein, Karen. 1996. Service quality among women receiving MCH and family planning services. African Journal of Fertility, Sexuality, and Reproductive Health 1(2):146-152. 


\section{Increasing Access to RH Services through Community-Based Service Delivery}

Health care facilities (including hospitals, clinics and health posts) are the most common source of family planning and other reproductive health services in sub-Saharan Africa. However, the distances to clinics in sparsely-populated rural areas, the overcrowding of clinics in urban areas, the often inadequate quality of care available and the medical environment of clinics themselves are some of the reasons why access to reproductive health services is limited for many potential service users in the region.

Consequently, several programs have developed and are implementing non-clinic-based alternatives for providing these services. These include: delivering contraceptive services at the market and workplaces, as well as through traditional birth attendants and healers; training male and religious opinion leaders and adolescent peer leaders to inform and educate their communities about reproductive health services and social marketing.

The alternatives most frequently implemented in Africa are Community-Based Distribution (CBD) programs. These programs vary greatly in structure and function but consist essentially of a cadre of "agents" who work within their communities to educate community members about family planning and other services, and who distribute or sell contraceptive and selected health care commodities. The agents are usually (but not always) supported by a clinic-based program that provides access to a broader range of reproductive health services and are normally selected by and answerable to the community in which they live.

The Africa OR/TA Project II supported studies in seven countries that evaluated on-going CBD programs and tested new approaches to providing community-based services as follows:

- A test of the impact on family planning and fertility behavior of relocating nurses from clinics and creating a cadre of community agents, jointly and alone, in Ghana.

- A test of the effect of creating a cadre of community agents on family planning and other reproductive health behaviors, and a comparison with the effectiveness of a clinic-strengthening intervention, jointly and alone, in Burkina Faso.

- A documentary review and field-based assessment of the functioning, determinants of effectiveness and cost-effectiveness of seven large-scale CBD programs in Kenya. 
- An assessment of the functioning, determinants of effectiveness and cost-effectiveness of three major CBD programs in Tanzania.

- A comparison of community-based strategies that focus primarily on demand creation with those that also include community-based delivery of services in the Gambia.

- A Situation Analysis of the functioning and quality of care provided by the CBD program in Zimbabwe.

- Technical assistance for developing policy guidelines on CBD for the MOH in Senegal.

In addition, a large-scale community-based program for reaching adolescents with reproductive health information and services was supported in Zambia; the results from this study are reported in the section on adolescent reproductive health.

Rather than describe the findings from each individual study see list at the end of chapter), a synthesis of the key lessons learned is provided, together with examples of how these OR studies have contributed to strengthening CBD programs in the region.

\section{Testing CBD Delivery through Field Stations}

The OR studies in Ghana and Burkina Faso were part of larger research activities into community-based health services being undertaken at government health research field stations. Such field stations have produced "documentation series" of unpublished reports describing many aspects of the community-based health service delivery projects.

In Ghana, the Africa OR/TA Project II supported the establishment of the Community Health and Family Planning (CHFP) Project, which is being implemented by the Navrongo Health Research Centre (NHRC) of the Ministry of Health. Through on-going support from USAID, Rockefeller Foundation and several other donors, the Population Council's Policy Research Division is continuing support for the CHFP Project so that the long-term impact of community-based services on family planning and fertility behavior can be evaluated for the first time in an African setting.

In Burkina Faso, the Africa OR/TA Project II has been supporting the Ministry of Health to establish a health research field station, termed the Laboratoire de Santé Communautaire (LSC), in Bazèga province. The LSC is directed by the Direction de la Sante Familiale (DSF) of the $\mathrm{MOH}$, but all activities are implemented by a partnership of organizations including the DSF, the Unite d'Enseignement et de Recherche en Demographie (UERD) of the University of Ouagadougou, Mwangaza (a community development NGO) and the Population Council's office in Ouagadougou. 


\section{Community Health and Family Planning Project Navrongo Health Research Centre}

Objective:

To test the impact of reorganizing basic health care services from clinic to community-based on the fertility and mortality of a rural population.

\section{Service delivery interventions tested:}

Relocating community health nurses from the clinic to community health compounds (constructed by the communities), and providing them with a motorcycle, basic medications and commodities so that they can provide family planning and other primary health care information and services by visiting women in their compounds.

Assembling village health committees that recruit and supervise mostly male volunteer health promoters, termed Yezura Zenna ( $Y Z s)$. These volunteers undertake health education, dispense essential drugs for malaria, diarrhea, etc. and condoms. They also make referrals.

\section{Design:}

A factorial experimental design that compares the impact of service delivery interventions, individually and jointly, through five "cells":

1. $Y Z s+$ clinic upgrading

2. Mobile nurses + clinic upgrading

3. YZs and mobile nurses + clinic upgrading

4. Clinic upgrading only

5. Pure control area (existing services).

\section{Research systems:}

Demographic Surveillance System - collects vital events data from every individual every 3 months

Annual panel survey - a DHS-type survey conducted every year for a sample of 1,860 family compounds

- Service statistics from nurses - collected through special service record forms completed during each home visit and computerized

Qualitative research - using a variety of methods, data are collected routinely to monitor social reactions to the interventions

- Special studies - discrete studies undertaken to address specific reproductive health issues, e.g. FGC, perceptions of reproductive tract morbidity, Norplant ${ }^{\circledR}$ implants, integration of STI services, etc. 


\section{Service à la Base Communautaire Laboratoire de Santé Communautaire du Bazèga}

\section{Objectives:}

To test the impact of improving the quality of care in clinics and introducing community volunteer agents on family planning behavior.

\section{Service delivery interventions tested:}

- Upgrading clinic equipment, supplies and staff skills

- Introducing community-based volunteer agents to sell pills, condoms and spermicides, basic medications for malaria, diarrhea, etc., and education on STIs and FGC.

\section{Design:}

A quasi-experimental design that compares the effect of these two interventions with two comparison zones:

1. Clinic strengthening only

2. Clinic strengthening plus $C B D$ program

3. Comparison with existing NGO community-based health program

4. Pure control (existing services).

\section{Research systems:}

Bi-annual panel survey - a DHS-type survey conducted alternate years for a sample of 1,900 women and 1,600 men.

- Service statistics - monthly record forms designed for nonliterate agents to collect information on commodities sold and meetings held by topic.

- Qualitative research - diagnostic studies to better understand the socio-cultural context for service delivery

- Special studies - discrete studies undertaken to address specific reproductive health issues, e.g., FGC, perceptions of reproductive tract morbidity. 
The first major study undertaken by the LSC has been the development and testing of a CBD program that seeks to offer a range of reproductive health information and services. The lessons learned from this experimental study are currently being assessed and the Population Council, with assistance from USAID, UNFPA and the Gates Foundation, will support a follow-on study to test a revised model for community-based services.

\section{What Information and Services can CBD Agents Provide?}

The primary function of all $\mathrm{CBD}$ agents and the unifying characteristic of all the CBD programs assessed has been informing and educating clients about family planning in general and about contraceptive methods in particular. Agents in all CBD programs also supply or sell condoms and spermicides, and many are allowed to supply or sell oral contraceptives, although they must also refer these clients for an examination.

Agents in the Navrongo and Bazega programs sell some basic medicines, such as analgesics, malaria pills and oral rehydration therapy (ORT), and keep a share of the income generated from this as a partial incentive. In addition, the agents in the Navrongo program organize mass child immunization sessions attended by a team from the local clinic.

Given the seriousness of the HIV pandemic and the high prevalence of STIs, most CBD programs in Africa now train their agents to inform and educate clients on STI/HIV symptoms, means of transmission and prevention and refer them to the clinic for diagnosis and treatment if symptoms are suspected. Although communities have welcomed this additional service when introduced, the agents' knowledge of STIs was found to be generally poor and they feel their training is inadequate. Refresher training is clearly essential.

Many agents were found to spend time on activities that are not recorded. For example, in Tanzania more than 20 per cent of an agent's time is spent informing and referring clients on reproductive health issues other than family planning. Their record keeping and reporting procedures, however, are organized around the number of family planning clients served and the couple years of

\section{Should CBD agents provide oral contraceptives?}

Allowing CBD agents to provide oral contraceptives can be controversial. In Burkina Faso, Kenya, Tanzania and Zimbabwe, agents are allowed to provide low-dose combined and progestin-only pills to new and continuing clients.

For most programs, CBD agents use a checklist to screen for contraindications among their pill clients, and new pill clients are referred to a clinic for a medical check-up before being re-supplied. The Ghana $\mathrm{MOH}$ has recently approved pill distribution by CBD agents, but it was important for the Navrongo program managers to first pilot-test the addition of pills to agents' activities; the study is currently on-going.

Similar pilot studies were also necessary in Kenya and Mali; both studies successfully proved that CBD agents are as competent as nurses in screening pill clients and in giving adequate and appropriate information to pill users. 
protection (CYP) provided. This clearly points to a need for redesigning the recordkeeping and reporting systems so that agents can be supervised and evaluated in relation to the multipurpose role which they have.

In Tanzania and Kenya, it was found that agents who provide a broader range of health services are more productive overall, and are better accepted in their communities because they are seen as meeting a range of needs beyond simply family planning.

Some activities may not be appropriate for CBD agents, however. For example, in other countries (e.g. Bangladesh, Guatemala, Peru) CBD agents have successfully been trained to offer injectable contraceptives. In Kenya, the MOH considered but then rejected using OR to test the introduction of the injectable as a CBD-provided method.

The CBD agents in Burkina Faso were trained in sensitizing communities on the complications associated with female genital cutting (FGC). An assessment after six months, however, indicated that many of the agents felt uncomfortable with this function because they were actually supportive of the practice.

\section{What Role can CBD Agents Play in Providing Information and Services to their Communities?}

Catchment area surveys of seven CBD programs in Kenya revealed that $\mathrm{CBD}$ agents play an active role as providers of information and services within their communities. One-half of the women and men in the agents' catchment areas knew of the agent, and one-quarter of women and one-fifth of men had ever met directly with the agent. Similar proportions were found in both the Navrongo and Bazèga studies, suggesting that such levels of coverage are what can be typically expected in CBD programs.

These proportions may disappoint some program managers. They suggest that programs can and should promote the presence of their agents more vigorously within communities as well as motivate them to reach more people. To do this might require reducing the size of catchment area populations served by individual agents, and basing the estimation of appropriate workloads on more realistic levels of agent activity, especially for voluntary, part-time agents.

In Kenya, it was found that in communities served by a CBD program, 44 per cent of women using the pill get their supply from the CBD agent. Moreover, among those men who use the condom and who know the CBD agent, this person is the source of supply for the majority.

Clearly, CBD agents can be an important source of supply and/ or motivation to use contraception. In the Navrongo and Bazèga programs, use of modern contraceptives increased over and above that achieved through the existing clinics in areas served by CBD agents, implying that the addition of a CBD program will increase overall contraceptive use rather than replace an existing source. 
Agents are often the main source of family planning information, especially among men, although not the first source (this tends to be clinics and the media). Although it is difficult to measure the quality of information communicated, agents in the Kenyan programs universally showed only moderate levels of knowledge about prescribing the pill and instructing condom use. Consequently, agents should be given contraceptive update training regularly.

\section{How Productive are CBD Agents, and which Factors Affect their Performance?}

The following chart illustrates the wide variation in the annual number of new, revisit and referral clients served per CBD agent that can be found between programs, even in the same country. Using the average number of all clients served as an indicator of performance, the following factors were analysed in terms of their influence on agent performance.

Average number of clients served annually per CBD agent

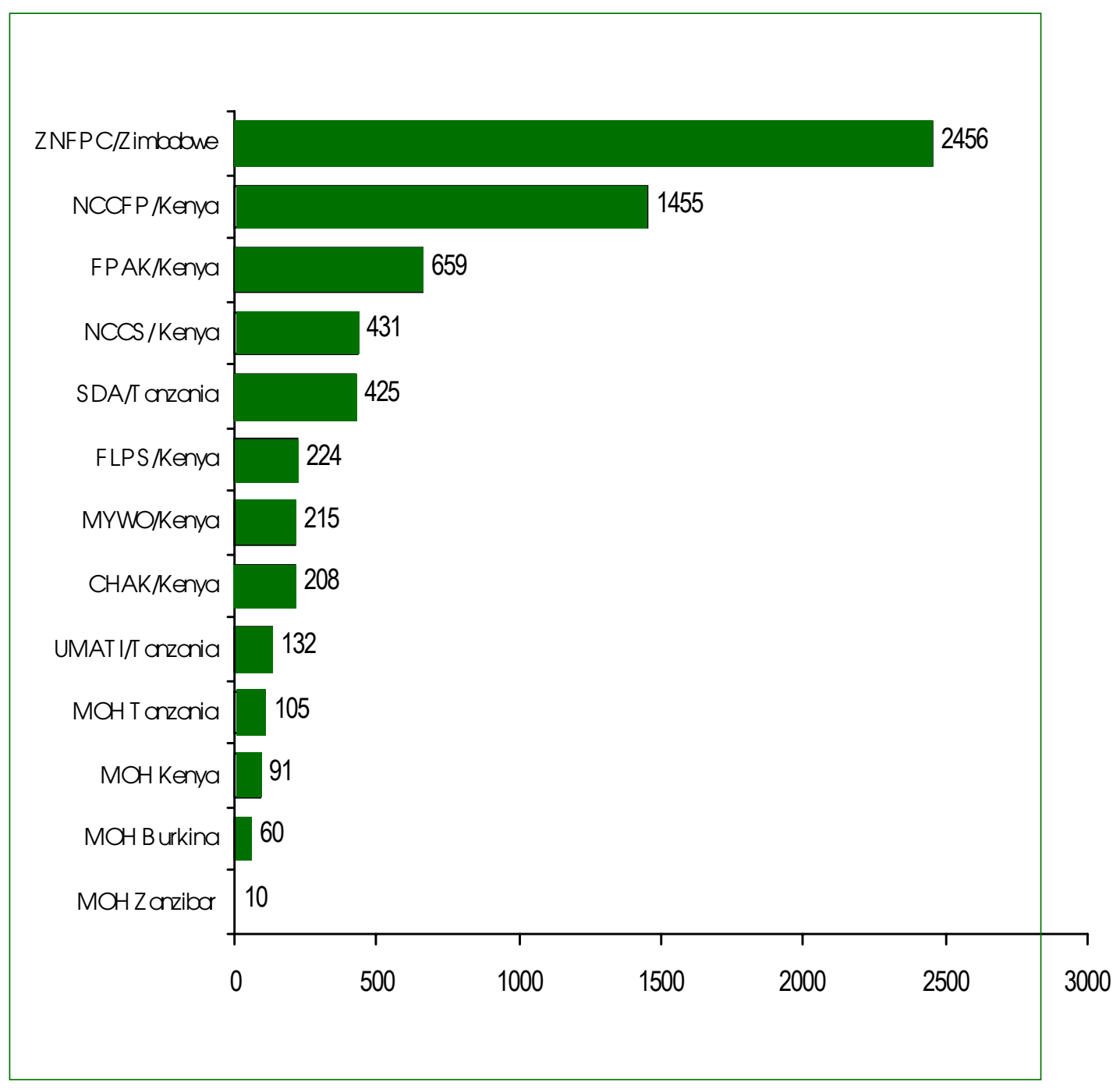




\section{Factors Determining Agent Performance}

\section{Type of program}

As the previous chart illustrates, agents in the programs run by NGOs (e.g. FPAK, SDA, FLPS, MYWO, CHAK, UMATI) or by Nairobi City Council (NCCFP, NCCS) outperform the agents in all the $\mathrm{MOH}$ programs. However, this finding masks the fact that the $\mathrm{MOH}$ programs all use agents who are wholly voluntary, whereas the other programs provide either tangible incentives such as travel allowances, or employ their agents full-time. Moreover, the two programs with by far the most productive agents (ZNFPC and NCCFP) are both public sector but employ their agents on a fulltime, salaried basis. The ZNFPC program operates in both urban and rural areas, whereas the NCCFP program operates only in urban Nairobi.

Comparisons between the performance of CBD and clinic programs are difficult to make. Some insights have been gained, however, from an analysis of the church-based CHAK program in Kenya that has both CBD agents and hospitals operating in the same catchment areas. The $527 \mathrm{CBD}$ agents served more new and revisit family planning clients than the 21

As would be expected, it was found in the Kenya, Tanzania and Burkina Faso programs that female CBD agents are more effective at providing the pill to women, and male agents are more effective at providing condoms to men. Consequently, CBD programs should try to ensure a balance to increase their ability to involve men as partners in family planning. hospitals. They also generated more CYP for pills, condoms and spermicides than the hospitals, but overall the hospitals provided more CYP because they are also able to provide other types of contraceptives, i.e., long-term and permanent methods.

\section{Location of program}

Agents working for the same program but in areas with a higher contraceptive prevalence were found to serve slightly more clients on average than those in areas with a lower prevalence. In both Kenya and Tanzania, however, it was found that agents working in areas with lower contraceptive prevalence could be motivated to perform as well as or better than those in the high prevalence areas.

Being well-supervised, having support from their communities and/or receiving a financial allowance or participating in an income-generating activity appear to be the motivating factors. For example, the program of the IPPF-affiliate in Kenya (FPAK) operates primarily in rural areas, and yet its agents outperform two of the three urban CBD programs in Nairobi (NCCS and FLPS). It was also found in Kenya that, for agents receiving an allowance, a higher level of payment does not automatically lead to higher productivity.

Rural programs in Kenya provide most of their CYP through the pill, but in urban programs the distribution between methods is either more even or in favor of the condom, possibly because they serve more men. 


\section{Agent's personal characteristics}

In Kenya, it was found that an agent's age, educational level, marital status and religion made little difference to productivity. The average age was 37 years, 90 per cent were married and at least one half of agents had secondary or tertiary education.

Although many CBD programs originally recruited female agents only, the demonstrated success of men as CBD agents has led to a concerted effort by many programs to recruit males. For example, in the Navrongo program, virtually all CBD agents are male because the program is explicitly using this strategy for reaching men with messages about family planning. These male agents complement a parallel program to reach women through community-based nurses.

\section{Incentives/motivation}

The studies in Kenya and Tanzania confirmed the expectation that those agents receiving a salary generally make more client visits than those receiving an allowance, and agents with an allowance perform better than those receiving only nonmonetary incentives.

Agents tend to be more productive and are committed for a longer duration when they have monthly individual and/or group supervisory meetings, when their community plays an active role in managing the program and when they are satisfied with their jobs. Community participation has proved particularly important when setting up CBD programs in rural areas with little apparent demand for family planning, for example, in the Navrongo program.

\section{Type of clients served}

In virtually all CBD programs, agents serve more continuing clients than new or referral clients. This is not surprising because most clinic-based family planning programs also do the same. Agents for three of the programs in Kenya did see more new than revisit condom clients, however. This may be because these programs serve as first or onetime sources but may not be the preferred regular source for condom clients, a role probably better fulfilled by a social marketing program.

Agents also provide more CYP through the methods they actually supply (i.e.,. pills and condoms) than through referrals for clinical methods. Although the largest number of referrals is for clients wanting the injectable, clients referred for sterilization generate a higher level of CYP.

To achieve one couple year of protection, a client in Kenya has to meet with an agent between five to eight times per year because of restrictions on the number of commodities that can be provided at each visit. CBD programs that give contraceptives for free normally restrict the number of pill cycles and condoms an agent can supply at one meeting, thus increasing the number of visits needed.

\section{A single indicator for measuring} agent productivity (e.g. number of family planning clients served, or (YP) is not helpful when agents are expected to be multipurpose. 
The Tanzania study showed that CBD agents can spend significant proportions of their time communicating information about and referring clients for other reproductive health services, activities that are not normally recorded and cannot be reflected through indicators of family planning commodities. If managers want to use a single indicator, the number of "clients served for all reproductive health services" may be a better performance indicator.

\section{What Costs are Involved in Providing Information and Services through a CBD Program?}

The costs of seven CBD programs in Kenya and three programs in Tanzania were measured and compared in terms of their cost structures and cost-effectiveness. Different methods were used for each analysis because the studies had different objectives, and so the results are not comparable across the two countries. However, these studies mark the first time such data have been collected in Africa and so provide valuable insights.

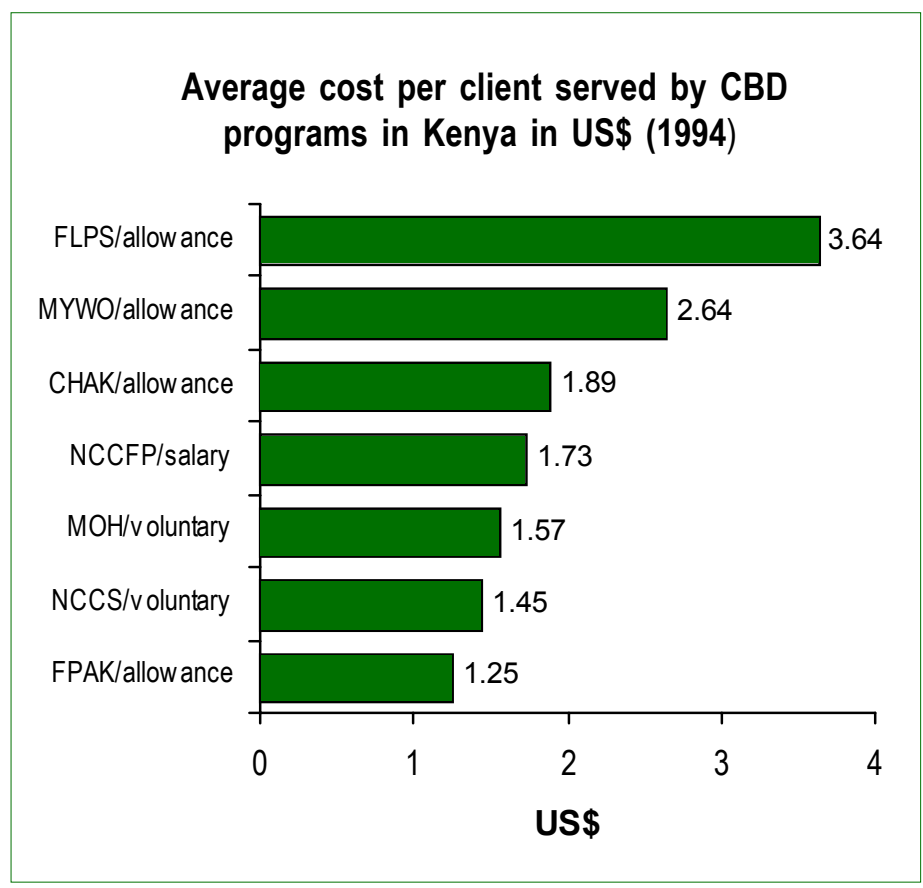

As would be expected, programs with the highest annual cost per agent were those that used salaried, full-time agents, and those with the lowest costs per agent were those that used volunteers. Because the costs per agent and their productivity are directly related, it is preferable to compare programs by their cost-effectiveness ratio to get a better idea of which models are more efficient.

The cost per client served for most of the programs in Kenya were generally similar, whether agents were voluntary, received an allowance or were salaried. This suggests that different CBD models can be made to work with similar levels of efficiency, regardless of the type of incentives provided to the agents.

For this reason, agent remuneration must not be considered in isolation from the overall cost structure for a CBD program. Spending less on motivating an individual agent does not necessarily reduce the overall cost of the program, as such programs often invest relatively more resources in training and supervision. If a program is using voluntary agents, however, a model that has many agents serving a small number of clients can lead to a good cost-effectiveness ratio, as has been achieved by the Kenyan $\mathrm{MOH}$ program and the UMATI program in Tanzania.

In both Tanzania and Kenya, the programs that give only nonmonetary incentives to their voluntary agents tend to spend higher proportions of their budget on supervisors and other staff and on training and administrative costs. 
For example, although the direct cost of the agents is zero in the two programs using volunteers, these programs allocate relatively larger proportions of their budgets to supervisory program staff.

\section{What Impact can be Expected of a CBD Program?}

CBD programs are expected to increase demand for family planning by reducing social and cultural opposition to its practice, as well as to satisfy unmet need for contraceptive services themselves. Both types of impact are most commonly evaluated by an increase in contraceptive prevalence in a CBD program's catchment areas over time. Ultimately, it is expected that this will lead to a reduction in fertility.

Findings from an OR study of a community-based program undertaken in the Gambia suggest that by focusing intensively on addressing sociocultural perceptions of family planning, social barriers to the use of family planning, especially among men, can be reduced and concurrently the use of contraception increased.

The study in the Gambia compared two interventions for increasing family planning demand: training traditional birth attendants (TBAs) and other respected women in the community to discuss family planning among the women of their own extended family; and holding village meetings, targeted for men (but attended by both men and women) and led by male religious leaders to promote the fact that the Islamic religion supports birth spacing and is not against the use of modern contraceptive methods. Both strategies have increased significantly the prevalence of use in the areas receiving these interventions, supporting the idea that CBD programs can increase demand for family planning.

The Navrongo program in Ghana also demonstrates that systematically addressing the concerns of men through communitybased information strategies can greatly increase the acceptability and use of modern contraceptives. As shown on the right, the male CBD agents appear to have had a significant effect on the use of family planning in their catchment areas, both where they function on their own and in conjunction with the mobile nurse.

Data from the Bazèga program also show that contraceptive use can be increased through a community-based program, despite the program suffering from some implementation problems (including low levels of supervision and incomplete recordkeeping) that have limited its potential impact.

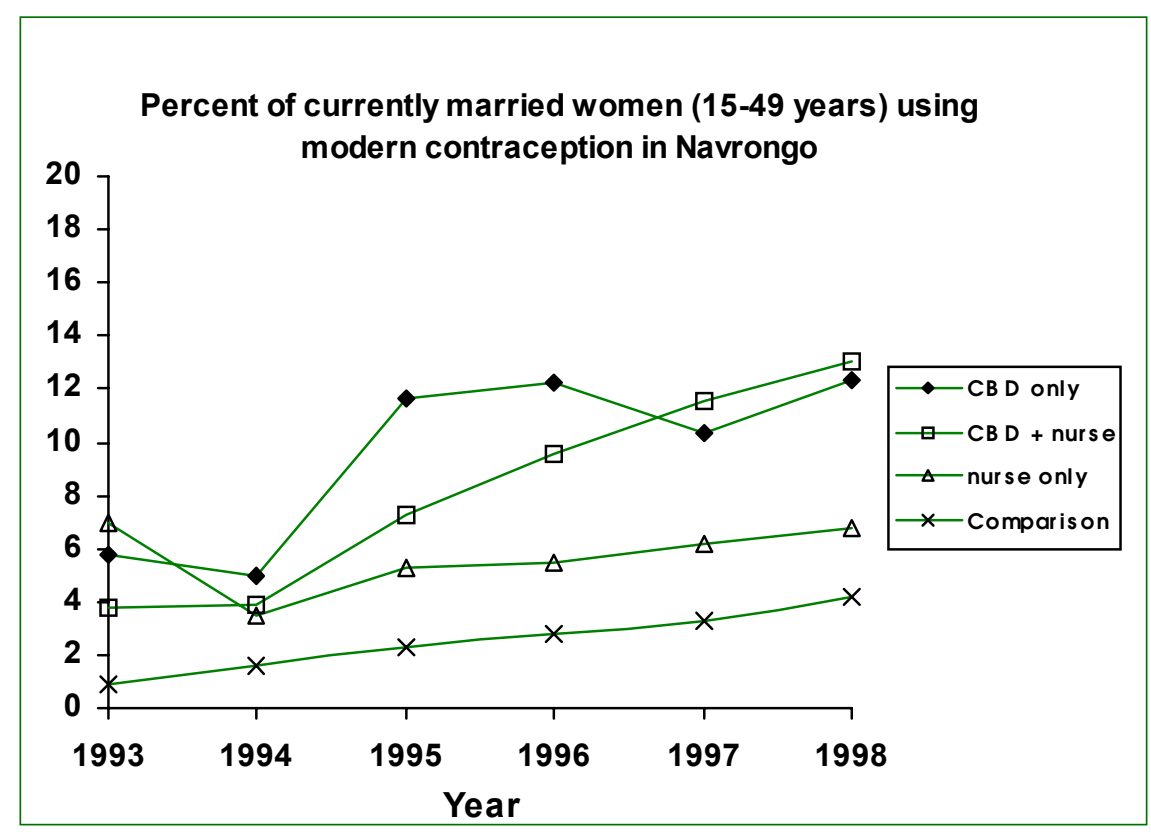


As the graph below indicates, prevalence has doubled in the areas that are served by CBD agents and that have also had their clinics strengthened, compared with a smaller increase in areas where clinics alone have been strengthened. No change in prevalence has occurred in the comparison and control areas, suggesting that both interventions have been important in raising demand for, as well as supplying a need for family planning in these communities.

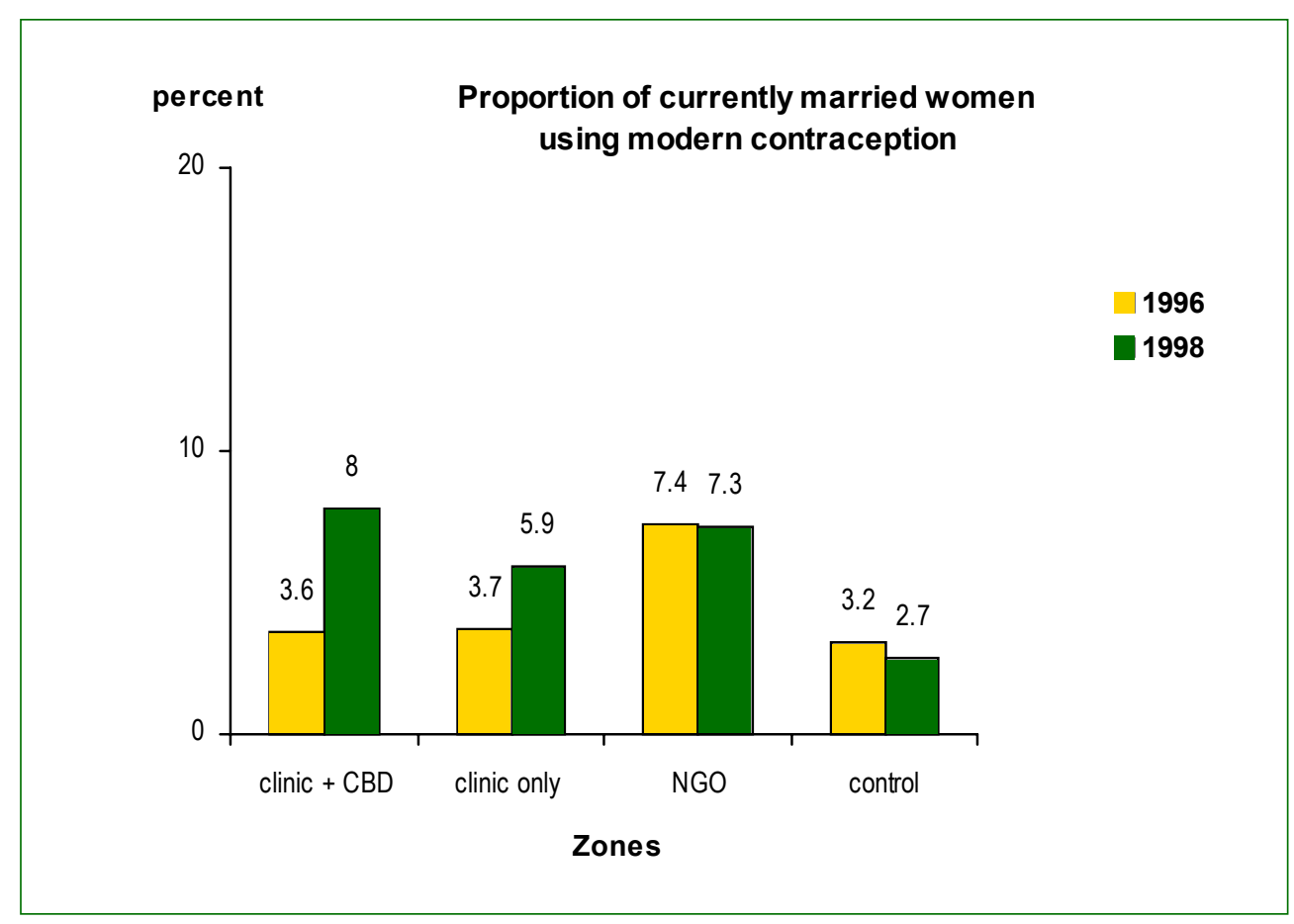

The Navrongo and Bazèga field stations are measuring the impact of the community-based services over a five-year period using systematic data collection systems (i.e. panel surveys and service statistics). Consequently, they will be able to evaluate whether these CBD programs have influenced not only family planning practices but also fertility intentions and behavior.

Already, a slight decrease in the total fertility rate of about half a birth per woman has been detected in the experimental areas of the Navrongo program compared with the control area. 


\section{How has Operations Research strengthened CBD programs?}

Ghana: The CHFP Project at Navrongo was established by the MOH to enable it to address some of the weaknesses found with previous public-sector community-based health programs. The results from this study have convinced the $\mathrm{MOH}$ of the need to allow and encourage districts to use experiment with community-based approaches within the context of decentralization and health sector reform. As a result, a scaling-up plan has been developed by the MOH (funding by USAID) in which Navrongo will support districts from the three northern regions in their efforts to develop similar communit-based programs through a research and action based approach. If this proves successful, the approach will be replicated nationwide.

Burkina Faso: Experience with the Bazèga CBD program has encouraged the $\mathrm{MOH}$ in Burkina Faso to recommend to provincial level health program managers that they consider introducing community-based programs, and funding is being sought from the World Bank for this. The Population Council will continue to support further development of this program through testing an expanded scope for the agents' role so that they provide STI, antenatal and child health information and services.

Kenya: Within Kenya, the results were disseminated individually to each of the organizations whose CBD programs had been assessed. The Family Planning Association of Kenya and the Nairobi City Council took immediate action to re-structure elements of their programs based on these findings. Internationally, the results were presented at many meetings and conferences and have been used to inform organizations planning to introduce new CBD programs or to assess ongoing programs.

Gambia: Although the OR study was undertaken by an NGO (Save the Children/USA), the $\mathrm{MOH}$ participated in the study throughout and has adopted the training strategies. Two other NGOs (GFPA and World View) also replicated aspects of the interventions in other divisions of the country. Visitors from Burkina Faso, Cameroon, Egypt, Mali and Uganda came to learn about this approach.

Senegal: Technical assistance provided to the Programme National de Planification Familiale (PNPF) led to the development of a national policy guidelines document on CBD. Subsequently, the PNPF has requested FRONTIERS to assist it in developing and testing a public-sector CBD program using the OR approach. USAID/Senegal has allocated funding for this activity.

Tanzania: The results are being used by both the public and non-governmental sectors. The Tanzania Ministry of Health is designing a CBD strategy, and the USAID Mission has recommended that the Ministry utilise the findings of the OR study to inform the strategy design. JOICFP and IPPF supported an Africa-wide workshop in Tanzania for designing guidelines on how CBD programs they support should address program sustainability. JOICFP, which co-supports the UMATI CBD program, drew heavily from the findings of the Tanzania OR study when drafting the workshop report on CBD sustainability.

Zimbabwe: Results from the Situation Analysis study contributed to ZNFPC's decision to review and redirect its CBD program so that it can reach men, offer a wider range of contraceptives and more actively educate communities on STIs, including HIV/AIDS. Subsequently, ZNFPC has requested FRONTIERS to assist it in first undertaking a thorough assessment of the CBD program, and then developing and testing alternative models for reaching men and preventing and managing STIs and HIV/AIDS. USAID/Zimbabwe has allocated funding for this activity. 


\section{Resources Available from the Africa OR/TA Project II on Community-Based Service Delivery}

Askew, Ian and Jane Chege. 1996. Impact and effectiveness of CBD models in Kenya: what factors account for variance in program achievements? Paper presented at the annual meeting of the American Public Health Association, New York, New York, 17-21 November.

Bamba, Azara, Jeanne Nougtara, Jean-Baptiste Koama and Youssouf Ouadraogo. 1996. Etude pour tester l'expansion de l'utilisation des Accoucheuses Villageoises pour les prestations de services de SMI/PF/NUT dans cinq provinces du Burkina Faso: Enquete de base. A report of Technical Assistance provided by the Africa OR/TA Project II to the Ministère de la Santé, de l'Action Sociale et de la Famille and UNFPA / Burkina Faso, Ouagadougou, Burkina Faso, May.

Binka, Fred, Alex Nazzar and James Phillips. 1994. The Navrongo Community Health and Family Planning Project. Paper presented at the 122nd annual meeting of the American Public Health Association, Washington, D.C., 30 October-3 November.

Binka, Fred, Alex Nazzar, and James Phillips. 1995. The Navrongo community health and family planning project. Studies in Family Planning 26(3): 121-139.

Chege, Jane and Ian Askew. 1997. An assessment of community-based family planning programs in Kenya. Africa OR/TA Project II, Nairobi, Kenya, January.

Chege, Jane, Naomi Rutenberg, Andrew Thompson and Barbara Janowitz. 1998. Factors affecting the outputs and costs of Community Based Distribution of family planning services in Tanzania. Africa OR/TA Project II Nairobi, Kenya, May.

Debpuur, Cornelius, Alex Nazzar, James Phillips, Pierre Ngom and Fred Binka. 1999. The impact of family planning service provision on reproductive preferences, knowledge and use of modern contraceptives, Paper presented at the annual meeting of the Population Association of America, New York, New York, 25-27 March.

Gouedé, Nicholas. 1997. On the road to reproductive health: A day in the life of a community health worker. Populi 24(2):8-10.

Laboratoire de Santé Communautaire. 1998. Rapport d'Evaluation: Evaluation de la Stratégie de Distribution à Base Communuataire. Laboratorie de Santé Communautaire du Bazega, Ouagadougou, Burkina Faso. December.

Luck, Margaret, Diane Nell, Ebrima Jarjou and Marc Michelson. 1996. Contributions of demand mobilization and contraceptive availability to increased contraceptive prevalence: Issues for replication. Save the Children Federation, The Gambia Field Office, Banjul, The Gambia. September.

Mundy, Jacqueline and Ian Askew. 1994. Current experiences with community-based distribution of family planning in Kenya: A review prepared for USAID/Kenya. A report of Technical Assistance provided by the Africa OR/TA Project II to USAID/Kenya. The Africa OR/TA Project II, Nairobi, Kenya, September. [In English and French]

Nazzar, Alex, Philip Adongo, Fred Binka, James Phillips and Cornelius Debpuur. 1995. Developing a culturally appropriate family planning program for the Navrongo experiment. Studies in Family Planning 26(6): 307-324.

Nazzar, Alex, Philip Adongo, Fred N. Binka et al. 1994. The Navrongo Community Health and Family Planning Project phase I trial: Developing community participation in community health. Paper presented at the 122nd annual meeting of the American Public Health Association, Washington, D.C., 30 October-3 November.

Nazzar, Alex, Philip Adongo, Fred N. Binka et al. 1995. Involving a traditional community in strategic planning: The Navrongo Community Health and Family Planning Project pilot study. Paper presented at the annual meeting of the Population Association of America, San Francisco, California, 6-8 April.

Phillips, James, Ian Askew, Alex Nazzar, Placide Tapsoba, and Fred Binka. 1996. Moving health and family planning services from clinics into rural communities: Results from a pilot study in Navrongo, Northern Ghana. Paper presented at the annual meeting of the American Public Health Association, New York, New York, 17-21 November. 
Sanogo, Diouratié. 1995. Role des leaders d'opinion (LO) dans la promotion et la prestation des services de sante et de planifacation familiale en milieu rural au Cameroun. Paper presented at the Conference Regionale Francophone sur l'Amelioration de l'Accessibilite et la Qualite des Services de Sante de la Reproduction et de Planification Familiale. Ouagadougou, Burkina Faso, 12-18 March.

Tapsoba, Placide, Alex Nazzar, Olivia Aglah and Robert Alirigia. 1996. Making the Bamako Initiative work: The Navrongo experience. Paper presented at the annual meeting of the American Public Health Association, New York, New York, 17-21 November. 


\section{4}

\section{Integration Of STI/HIV Information And Services In MCH/FP Programs}

The integration of Sexually Transmitted Infection (STI) and HIV/ AIDS information and services into existing MCH/FP programs has been strongly supported in recent years following recommendations from the 1994 Cairo ICPD. Moreover, it is now widely accepted that early detection and management of STIs can reduce the incidence of HIV infection.

Thus there are powerful incentives to increase efforts to broaden the capacity of $\mathrm{MCH} / \mathrm{FP}$ programs to provide STI prevention and management information and services for their clients, both as a comprehensive reproductive health service and as a preventive measure for reducing the transmission of HIV.

As shown in the table on the following page, the Africa OR/TA Project II, in collaboration with several agencies in the region, undertook a number of OR studies to assess the preparedness of programs to provide STI, HIV/AIDS and MCH/FP services using an integrated approach. These diagnostic studies were then followed by intervention studies to test ways of improving the existing approaches to implementing integrated services.

\section{Is there Need to Offer RTI/HIV Information and Treat- ment Services to Women Attending MCH/FP Clinics?}

OR studies conducted in Kenya and Zimbabwe show that more than half of the women attending clinics for family planning or antenatal services have a reproductive tract infection (RTI). Among these women, non-sexually transmitted infections (i.e. candidiasis and bacterial vaginosis) are much more prevalent than sexually transmitted infections (STIs) such as gonorrhea, chlamydia and trichomoniasis.

Because of their more serious effects on women's and infants" health, most efforts to integrate RTI detection and treatment services have focused on sexually transmitted infections. However, these data suggest that programs aimed at improving women's reproductive health should also consider ways of detecting and treating non-sexually transmitted RTIs, given their widespread prevalence and the inconvenience and suffering they can cause many women. 


\begin{tabular}{|c|c|}
\hline ACTIVITY TYPE & LOCATION \\
\hline $\begin{array}{l}\text { Situation Analysis studies of } \\
\text { integration at clinics of STI/HIV } \\
\text { information and services in } \\
\text { national MCH/FP programs }\end{array}$ & $\begin{array}{l}\text { - Botswana } \\
\text { - Ghana } \\
\text { - Kenya } \\
\text { - Tanzania/Mbeya region } \\
\text { - Zambia } \\
\text { - Zimbabwe }\end{array}$ \\
\hline $\begin{array}{l}\text { Case studies of programs } \\
\text { providing MCH/FP, STI and HIVIAIDS } \\
\text { services using an integrated approach }\end{array}$ & $\begin{array}{l}\text { Mkomani Clinic Society,Mombasa Kenya } \\
\text { (BOTSPA), Botswana } \\
\text { - Nakuru Municipal Council clinics, } \\
\text { Kenya } \\
\text { - Family Life Education Program, } \\
\text { Busoga diocese, Uganda }\end{array}$ \\
\hline $\begin{array}{l}\text { Assessments of integration of STI/HIV } \\
\text { information and services in } \\
\text { community-based programs }\end{array}$ & $\begin{array}{l}\text { Kenya (seven CBD programs) } \\
\text { Community Health and Family Plan } \\
\text { ning Project, Navrongo, Ghana } \\
\text { Community-Based Reproductive Health } \\
\text { Services, Bazèga, Burkina Faso }\end{array}$ \\
\hline $\begin{array}{l}\text { Qualitative studies of perceptions } \\
\text { towards RTIs and health-seeking } \\
\text { behavior }\end{array}$ & $\begin{array}{l}\text { - Navrongo, Ghana } \\
\text { - Bazèga, Burkina Faso }\end{array}$ \\
\hline $\begin{array}{l}\text { Measuring the prevalence of RTIs } \\
\text { among } \mathrm{MCH} / \mathrm{FP} \text { clients }\end{array}$ & $\begin{array}{l}\text { Nakuru Municipal Council clinics, } \\
\text { Kenya } \\
\text { Zimbabwe National Family Planning } \\
\text { Council clinics, Zimbabwe }\end{array}$ \\
\hline $\begin{array}{l}\text { Evaluating the effectiveness of STI } \\
\text { syndromic management among } \\
\text { MCH/FP clients, and testing strategies } \\
\text { to improve this strategy }\end{array}$ & $\begin{array}{l}\text { Nakuru Municipal Council clinics, } \\
\text { Kenya } \\
\text { Zimbabwe National Family Planning } \\
\text { Council clinics, Zimbabwe }\end{array}$ \\
\hline $\begin{array}{l}\text { Assessment of resource utilization } \\
\text { and cost-effectiveness of integrated } \\
\text { programs }\end{array}$ & $\begin{array}{l}\text { Nakuru Municipal Council clinics, } \\
\text { Kenya } \\
\text { Zimbabwe National Family Planning } \\
\text { Council clinics, Zimbabwe }\end{array}$ \\
\hline
\end{tabular}


Prevalence of Reproductive Tract Infections (RTIs) among family planning and antenatal clients in Kenya and Zimbabwe

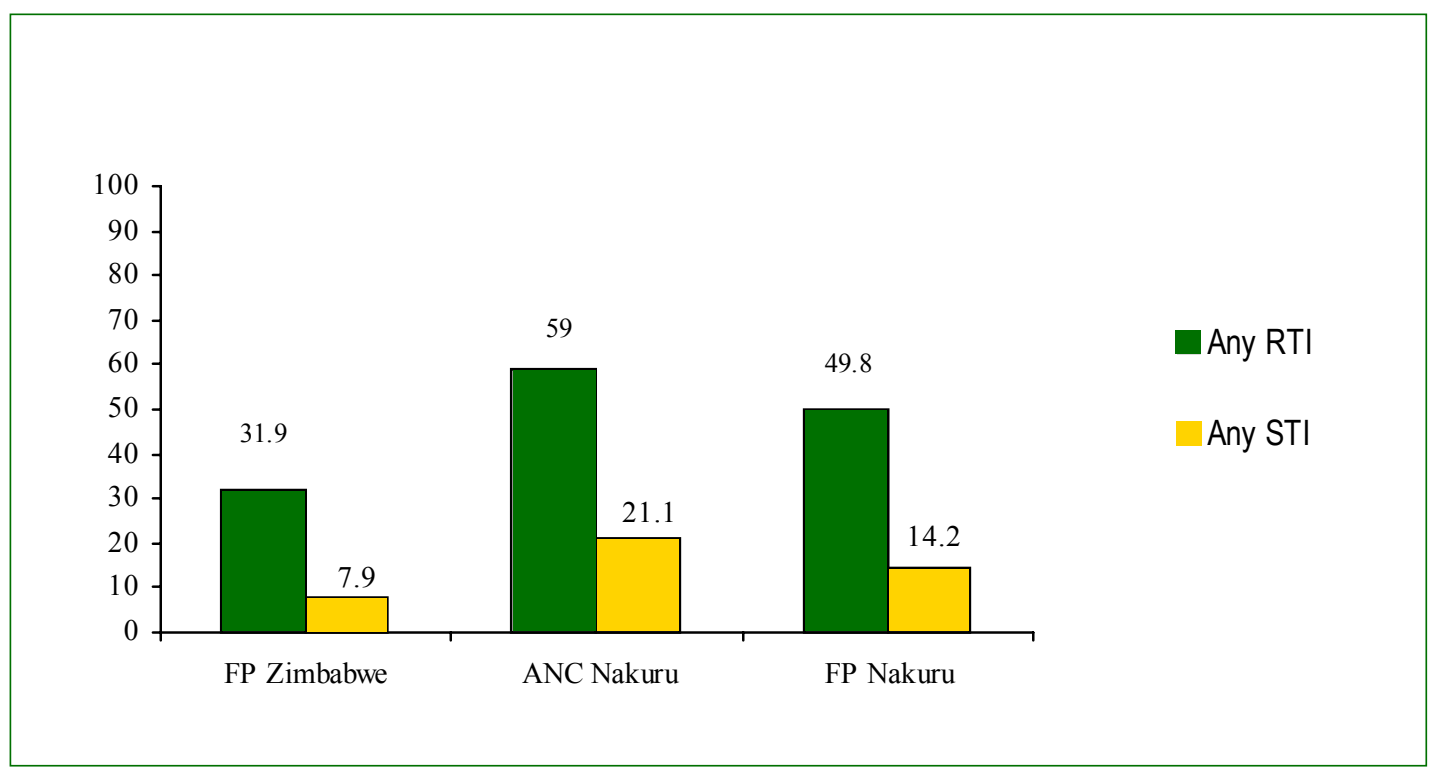

Moreover, recent evidence linking bacterial vaginosis with increased likelihood of sexual transmission of HIV and the difficulty in distinguishing between this and other vaginal infections suggest that program managers may need to consider vaginitis as being as important to detect and treat as the sexually transmitted infections.

Knowledge about signs, symptoms, risk factors and ways of preventing sexually transmitted infections is scanty among women attending $\mathrm{MCH} / \mathrm{FP}$ clinics. Less than one-fifth of clients attending $\mathrm{MCH} / \mathrm{FP}$ clinics were aware that HIV infection could be transmitted through blood transfusion or from mother to baby. Nearly half of these women did not consider condom use an effective protection against STIs and HIV/ AIDS.

In rural communities of northern Ghana, both men and women have many beliefs concerning the cause of STIs. In addition to having sex with multiple partners and infidelity, God's will, lack of hygiene, insect bites and inadequate or poor diets are cited as possible causes.

Because of their perceptions of the causes of STIs, many individuals seek treatment from a traditional healer the first choice. It is only when the traditional remedies have failed that they seek medical help from health facilities.
Decisions on whether to integrate STI and MCH/FP services that are based on the prevalence of STIs alone may deny access to care for the large number of women with non-sexually transmitted infections.

Given the emerging information that bacterial vaginosis may be associated with pelvic inflammatory disease and increased risk for HIV infection, greater attention may need to be paid to managing vaginitis.

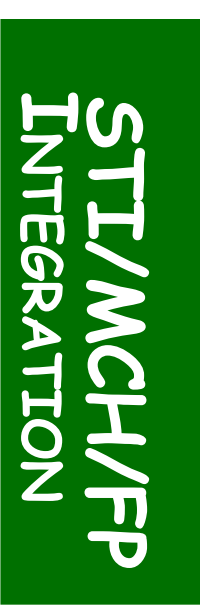




\section{Are MCH/FP Clinics Currently Providing STI and/or HIVIAIDS Services?}

Data from Situation Analysis studies in the region show that many $\mathrm{MCH} / \mathrm{FP}$ programs in the region are already providing STI and/or HIV/AIDS information and services using an integrated approach, albeit to varying degrees. For example, 69 per cent of facilities claim to offer STI management services and 49 per cent HIV management services. Findings from case studies suggest that clinic-based programs in the region are adopting integration strategies that seek to include four major service components:

\section{Major components of integration strategies used by MCH/FP clinic-based programs}

- STI case finding, diagnosis and treatment among family planning clients and to a lesser extent antenatal clients attending $\mathrm{MCH} / \mathrm{FP}$ clinics;

- Communication of messages to clients about prevention of STIs and HIV transmission and good health-seeking behavior;

- Screening and treatment of syphilis among antenatal clients;

- Voluntary counseling and testing for clients suspected of having HIV.

Situation Analyses studies in five countries found that although many $\mathrm{MCH} / \mathrm{FP}$ facilities were offering STI and HIV/AIDS services, few clients were actually receiving these services. In Ghana, Zambia and Zimbabwe, clinics were found, on average, to provide STI services to one client per day and HIV/AIDS services to one client per month, although huge variations were found. Moreover, fewer than half of one per cent of family planning and $\mathrm{MCH}$ clients interviewed reported having received an STI or HIV service during their visit. Given the levels of infection indicated above, there would appear to be much scope for greater utilization of these services.

\section{Are MCH/FP Programs and Facilities Prepared to Provide STI and/or HIVIAIDS Services?}

If clinics are claiming to offer integrated services, are they ready and able to do so? One of the justifications for service integration is that the basic physical environment, equipment, supplies and IEC materials required to provide STI and HIV/AIDS services are similar to those required for $\mathrm{MCH} / \mathrm{FP}$ services, and that $\mathrm{MCH} / \mathrm{FP}$ 
clinics already have most of these in place. However, Situation

Analysis studies and case studies indicate that:

- Although wall posters with STI and HIV/

AIDS messages were available at more than two-thirds of the health facilities in five countries, other materials essential for individual education and counseling (flipcharts and brochures) were rarely available. Also group health talks - a useful strategy for communicating health information to clients in busy clinics and populations with low literacy rates, were rarely given at the $\mathrm{MCH} / \mathrm{FP}$ clinics.

- Fewer than half of the facilities in the programs studied had all four essential items of equipment and supplies required to perform a pelvic examination (directable source of light, at least one speculum, gloves and antiseptic lotion) - an essential step in assessing clients for STIs.

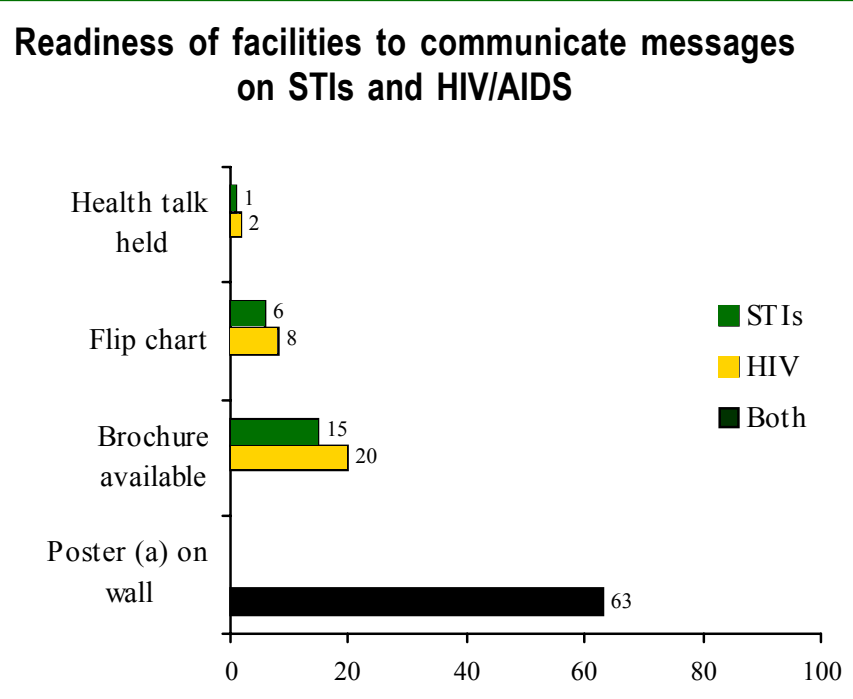

(a) no distinction was made between posters describing STIs and HIVIAIDS when the data were collected

- A significant number of $\mathrm{MCH} / \mathrm{FP}$ clin-

ics do not have the first-line drugs recommended in their country guidelines for treating STIs. As a result, service providers often have to use alternative medication that may not be as effective. Availability of drugs at the health facilities is influenced by both the resources to purchase the drugs and the logistics to ensure appropriate distribution.

- Most programs have revised their family planning guidelines and service standards to include STI and HIV/AIDS services and other reproductive health issues. However, these documents are often not available at health facilities, and most service providers are unaware of their existence or of the revisions.

- None of the programs have undertaken revisions of their forms for collecting service statistics (for example, client record cards, daily registers and service statistics summary forms) to cater for the additional information required in the management of STIs and HIV/AIDS. The absence of checklists, client record forms and reporting forms that reflect and support an integrated rather than specialized approach to interacting with the client has been blamed by providers themselves as contributing towards their inability to implement a fully integrated approach.

\section{Are Service Providers in MCH/FP Clinics Prepared to Provide STI and HIVIAIDS Services?}

Staff providing $\mathrm{MCH} / \mathrm{FP}$ services are thought to already have most of the basic skills required for offering an integrated service, and they are assumed to be willing and able to provide information and services for STI and HIV/AIDS routinely. However, certin conditions exist: 
- The majority of service providers in $\mathrm{MCH} / \mathrm{FP}$ clinics have not attended a post-basic or refresher course on STI and HIV/AIDS management. Basic training of service providers rarely includes STI and HIV/AIDS management, and most providers were trained many years ago. Moreover, the skills required for managing STIs and HIV/AIDS change rapidly; hence there is an urgent need for in-service training programs for providers. It is neccessary to establish systems that facilitate more frequent refresher and updated courses.

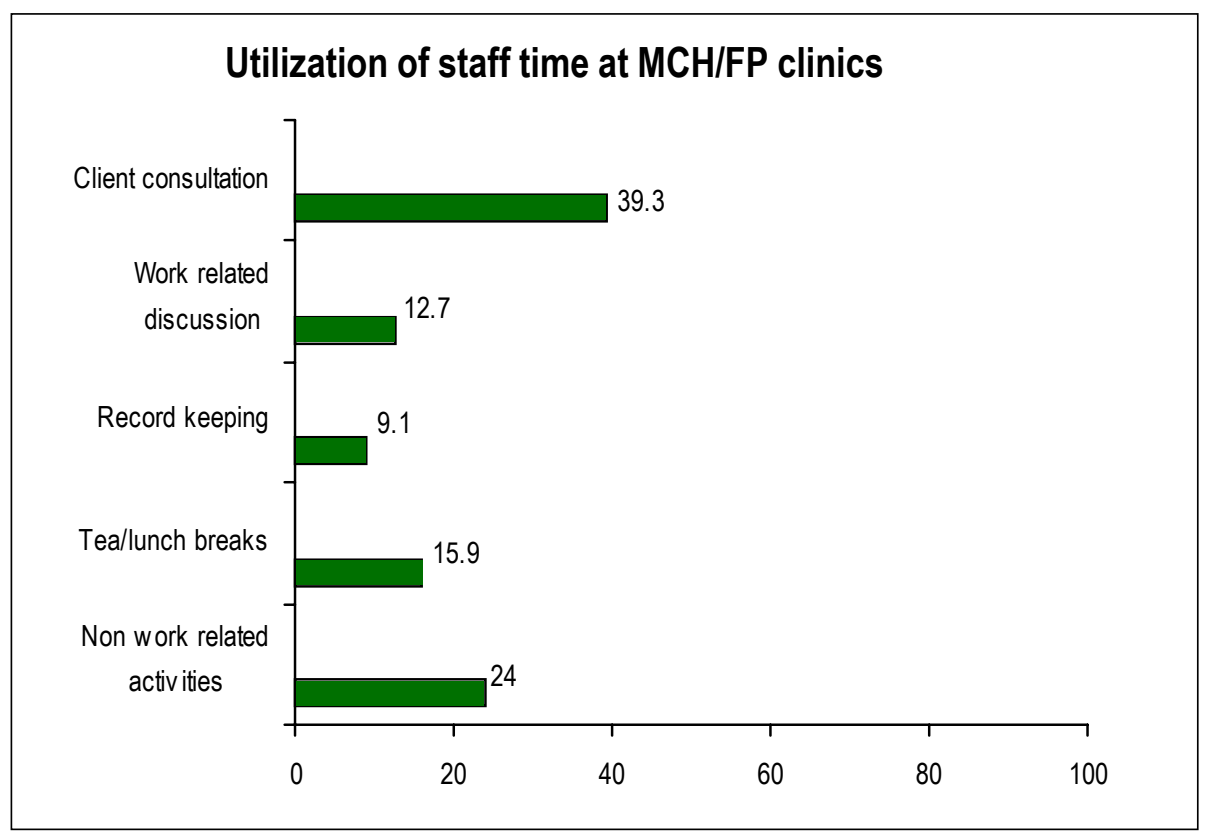

- STI and HIV risk assessment involves asking clients questions about their sexual behavior, that of their partners and other personal behavior. Although up to two-fifths of service providers feel comfortable asking clients about these issues, one-fifth do not feel at all comfortable. Training and appropriate supervision to address these concerns will be required.

- Service providers often cite heavy client loads and lack of time as major hindrances to the provision of good quality and integrated services. A time motion study carried out for one family planning program revealed that staff spent up to one-half of their official working time on tea/lunch breaks and non-work related activities. Moreover, most $\mathrm{MCH} / \mathrm{FP}$ clients are served in the morning only, with the clinics being under-utilized in the afternoons.

- The study also showed that risk assessment and counseling for STIs and HIV/AIDS did not substantially increase the duration of consultations with new family planning clients, repeat clients attending for their annual check-up, or clients using a method but having a problem. Consequently, time may not be a constraint to adding STI services to existing $\mathrm{MCH} / \mathrm{FP}$ programs. What may be required is a re-organization of staff time and work schedules.

\section{What Quality of STI and HIV Information and Services are MCH/FP Clients Actually Receiving?}

STI and HIV risk assessment, history taking and pelvic examination are rarely and inconsistently undertaken for $\mathrm{MCH} / \mathrm{FP}$ clients. However, the proportion of clients for whom these procedures are undertaken are higher for those programs where service providers have attended a post-basic and/or refresher course in the management of STIs. Thus, a concerted effort to improve integration does appear to have some effect, but more attention is needed to ensure that these procedures are routinely undertaken. 
Proportion of new family planning clients asked risk assessment questions

\begin{tabular}{|l|c|c|c|c|c|}
\hline & \multicolumn{1}{|c|}{$\begin{array}{c}\text { Marital } \\
\text { Status }\end{array}$} & $\begin{array}{c}\text { Number of } \\
\text { new partners } \\
\text { in last year }\end{array}$ & $\begin{array}{c}\text { Concerns } \\
\text { about STls }\end{array}$ & $\begin{array}{c}\text { Sexual } \\
\text { relations }\end{array}$ & $\begin{array}{c}\text { History of } \\
\text { STIs }\end{array}$ \\
\hline Botswana & 52 & 9 & 18 & $\mathrm{n} / \mathrm{a}$ & 20 \\
\hline Ghana & 75 & 21 & 12 & 30 & 13 \\
\hline Kenya & $\mathrm{n} / \mathrm{a}$ & 14 & 19 & 36 & 12 \\
\hline Zambia & 74 & 5 & 13 & 5 & $\mathrm{n} / \mathrm{a}$ \\
\hline Zimbabwe & 68 & 16 & & & 15 \\
\hline
\end{tabular}

$\mathrm{MCH} / \mathrm{FP}$ clients are rarely informed about STIs and HIV/AIDS during clinic consultations. In the five Situation Analysis studies, the proportion of new family planning clients with whom STIs were discussed ranges from 40 per cent in Zambia to 12 per cent in Kenya, and the proportion with whom HIV/AIDS was discussed ranged from 21 per cent in Botswana to 2 per cent in Zimbabwe.

For those who were informed, the emphasis was on condom use, but symptoms, signs, risk factors, complications and modes of transmission of STIs and HIV infection were rarely discussed.

Although the majority of new family planning clients receiving services at $\mathrm{MCH} / \mathrm{FP}$ clinics are informed about the role of condoms in preventing pregnancies, few are given information about their role in preventing STIs and HIV/ AIDS. Those who received a "dual protection" message (i.e., that a condom can protect against both pregnancy and infection) ranged from 4 per cent in Zimbabwe to 31 per cent in Botswana.
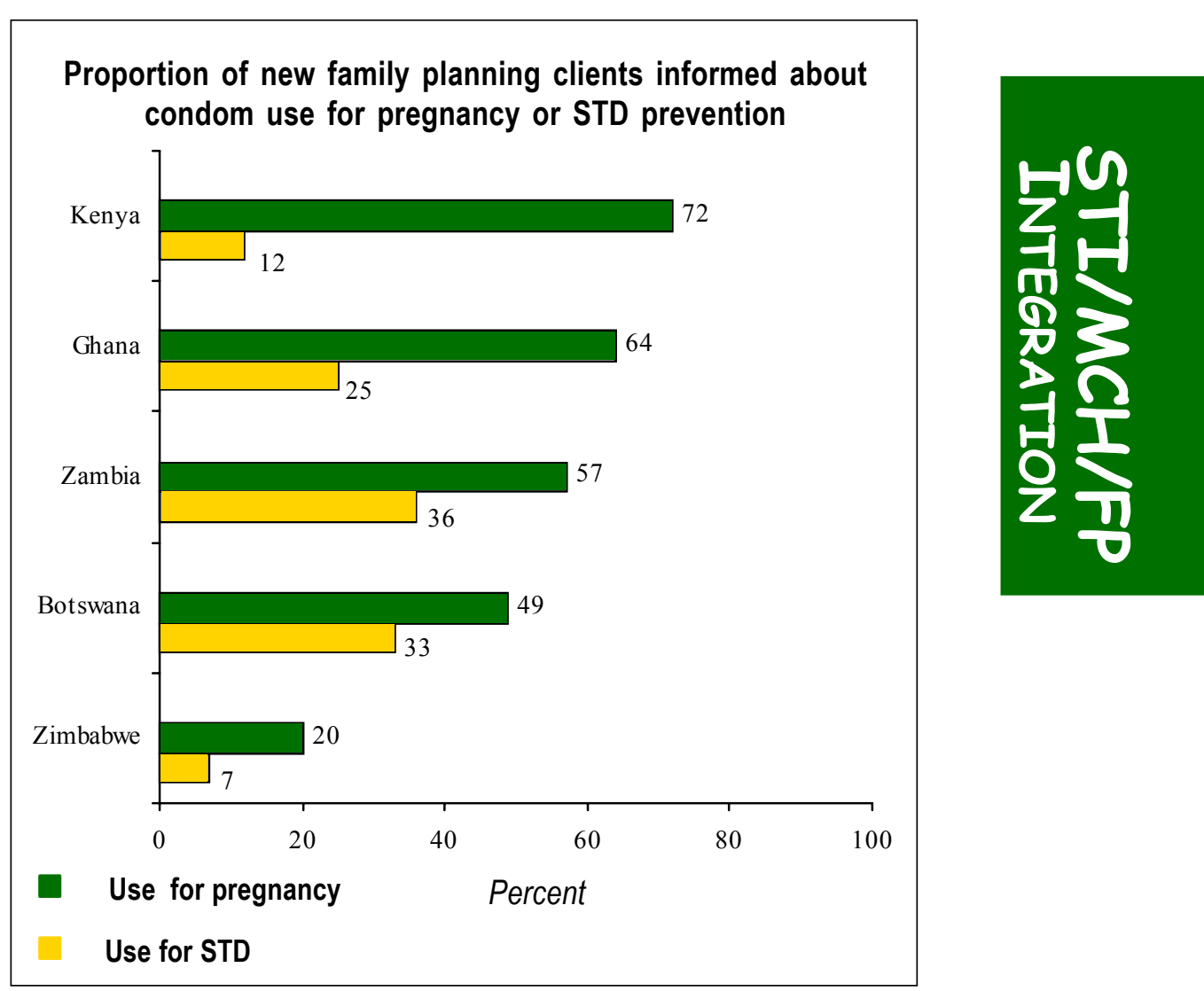


\section{Are Partners of Clients Treated for STIs at MCH/FP Clinics also Treated?}

Partner notification and treatment are essential components of STI management to prevent re-infection. However, data from two programs show that less than one-third of the sexual partners of family planning clients treated for STIs come for treatment, even when steps are taken to encourage them to do so. However, the case studies show that staff rarely inform clients treated for STIs about the importance and need to get their partners treated.

Partner notification and treatment are also complicated by the use of syndromic management of STIs in women. Most women diagnosed syndromically as having an abnormal vaginal discharge do not actually have a sexually transmitted infection (although they may have a naturally occurring infection).

Therefore, great care needs to be taken in handling cases where it is not completely clear whether the infection was acquired through sexual transmission or not. Unfortunately, the use of syndromes (such as vaginal discharge) for the identification and management of reproductive tract infections does not make such a distinction.

\section{Are Antenatal Clients routinely Tested and Treated for Syphilis at Clinics?}

As noted earlier, one particular STI, syphilis, has been given special attention because of its impact on the health and survival of pregnant women and their babies. Consequently, syphilis testing and treatment for pregnant women is mandated in almost all countries because of its proven cost-effectiveness.

Data collected from two programs in Kenya indicate, however, that between 27 and 52 per cent of antenatal clients are being tested. Even when testing is done, not all women return for the results and treatment. In one program, of the 31 women tested and proving positive, only 18 returned for treatment; an even smaller number of their contacts were treated. Use of procedures that require more than one visit or referral to another clinic and the costs clients have to pay for the test are some of the reasons given for the poor performance of this intervention.

\section{What are Clients' Perceptions about Integrating STI, HIVIAIDS and MCH/FP Services?}

Clients cite poor staff attitudes, stigmatization associated with STIs, fear of social rejection, poor confidentiality and the cost of obtaining services as the major reasons for not utilizing MCH/FP facilities for STI information and services.
The majority of $\mathrm{MCH} / \mathrm{FP}$ clients indicated that they are comfortable about being asked questions regarding their sexual behavior and that of their partners. Moreover, when clients participating in a study that involved detailed risk assessment, history taking, a pelvic examination and laboratory 
testing were asked to name what they appreciated most about their consultation, 70 per cent named pelvic examinations and having a laboratory test.

The clients felt that these were helpful in determining their health status. These findings suggest that, contrary to popular perceptions that clients do not like being asked about their sexual behavior and/or receiving intrusive pelvic examinations, the majority of $\mathrm{MCH} / \mathrm{FP}$ clients do appreciate these procedures and would welcome a more comprehensive reproductive health consultation.

\section{What Role can CBD Agents Play in the Provision of STI and HIVIAIDS Information and Services?}

Many CBD programs in the region are reviewing the scopes of work for their agents, to expand their role beyond family planning to include other reproductive health services, especially education, counseling and referral for STI and HIV/AIDS services. Although most CBDs are knowledgeable about family planning, their knowledge of STIs and HIV/ AIDS is relatively poor.

For example in two programs, many CBDs were found to have poor knowledge of most of the common symptoms of STIs, and in many cases their level of knowledge was not significantly different from that of the clients they served.

CBD agents are usually respected and trusted members of the communities they serve, and may be related to or friends with many of their clients. Some CBD agents saw this as a handicap to discussing STIs, and especially when an infection is suspected, with their clients. This factor needs to be taken into account when reviewing their responsibilities to include STIs management beyond education.

\section{How Effective are Existing Procedures for Detecting and Managing STIs in MCH/FP Clients?}

Two OR studies supported findings from other studies in the region that many women with laboratory evidence of an RTI did not have any symptoms of abnormal vaginal discharge when asked their history and/or during clinical examination. The study in Kenya found that 49 per cent of asymptomatic family planning clients and 56 per cent of asymptomatic antenatal clients had laboratory evidence of an RTI. The Zimbabwe study found that 29 per cent of asymptomatic family planning clients had a positive lab test for an RTI. For these asymptomatic women, the syndromic approach cannot be used to detect and manage their infection. 
These studies also showed that many women who complained of an abnormal vaginal discharge or were found to have one on examination did not have any infection on laboratory testing. In Kenya for example, 33 per cent of the antenatal clients and 46 per cent of the family planning clients with a vaginal discharge symptom and/or clinically determined sign did not have laboratory evidence of an infection. Among family planning clients in Zimbabwe, the proportion was even higher at 64 per cent. Thus diagnosing and treating these women according to their symptoms has led to overtreatment and represents wasted resources.

Observations of client-provider interactions showed that even when clients have symptoms or signs suggestive of an infection (as described by the national syndromic management algorithms), clinic staff do not always make a diagnosis as described in these algorithms. This was so despite the refresher training in syndromic management the staff received at the beginning of the two OR studies. Consequently, if the syndromic approach is going to be used, great care must be taken to make sure that the training is effective and that supervision maintains compliance with protocol guidelines.

Many programs in the region (e.g. in Kenya) recommend that women presenting with vaginal discharge and/or found to have vaginal discharge on examination should be treated for vaginitis (e.g. trichomoniasis, candida or bacterial vaginosis) first. They are requested to then come back after seven days to assess clinical progress, and if no improvements are found the client is then treated for cervicitis.

In the Kenya study, however, 48 per cent of family planning clients and 38 per cent of antenatal clients with a vaginal discharge were found not to have vaginitis. Moreover, among those women who did have vaginitis, 88 per cent of family planning clients and 67 per cent of antenatal clients did not have the vaginal discharge symptom. Using the presence of vaginal discharge symptom and/or sign as a predictor of vaginitis, therefore, leads not only to many women who need to be treated being missed, but also to over-treating many women who do not have such infections

In addition, the studies found that fewer than one-half of the women did not come back for the follow-up visit regardless of their infection status. Therefore, many women requiring a change in their treatment will be missed when this approach is used.

Given this problem with follow-up and the seriousness of cervical infections, other programs in the region (including Zimbabwe) recommend that all women presenting with or found to have a vaginal discharge should be treated for gonorrhea and chlamydia, that is, for cervicitis. The two studies show, however, that this leads to many women without a cervical infection being prescribed antibiotics. For example, fewer than 15 per cent of clients with vaginal discharge were found to have laboratory evidence of cervicitis. 


\section{Effectiveness of symptoms and/or signs in predicting RTls among clients seeking STI services from a family planning clinic}

\begin{tabular}{|l|l|l|l|c|}
\hline \multirow{2}{*}{ CLINICAL INFORMATION } & TYPE OF RTI & \multicolumn{3}{|c|}{ EFFECTIVENESS I N PREDICTING RTIS } \\
\hline & & Sensitivity & Specificity & $\begin{array}{c}\text { Positive } \\
\text { predictive } \\
\text { value }\end{array}$ \\
\hline Vaginal discharge symptom & & & & 9 \\
& Cervicitis & 72 & 41 & 34 \\
\hline \multirow{2}{*}{ Vaginal discharge sign } & Vaginitis & 69 & 44 & 10 \\
& Cervicitis & 62 & 55 & 38 \\
\hline \multirow{2}{*}{ Vaginal discharge symptom and sign } & Cervicitis & 55 & 60 & 11 \\
& Vaginitis & 40 & 70 & 41 \\
\hline \multirow{2}{*}{ Lower abdominal pain } & Cervicitis & 86 & 26 & 8 \\
& Vaginitis & 68 & 22 & 27 \\
\hline
\end{tabular}

Moreover, many women with a cervical infection did not have vaginal discharge symptom and/or sign (88 per cent and 61 per cent for antenatal and family planning clients respectively in Kenya, and 40 per cent in Zimbabwe). As with vaginitis, therefore, the presence of vaginal discharge symptom and/or sign as a predictor leads to both over and under-treatment.

The syndromic approach was developed for use when clients visit clinics explicitly seeking STI treatment rather than for screening clients attending $\mathrm{MCH} / \mathrm{FP}$ clinics. The two OR studies show that the syndromes for vaginal discharge and lower abdominal pain have statistically strong sensitivity for detecting cervical infections among clients who actively seek STI services, but they have very poor specificity and positive predictive values. This means, therefore, that the overall effectiveness of the syndromic approach is poor, even for those clients who are actively seeking treatment for a suspected STI.

Three major factors appear to contribute to this ineffectiveness. First, most women have poor knowledge of STI symptoms, and many are asymptomatic and/or have no clinical signs even when they have an infection. Research is urgently needed to find out whether improving women's knowledge and ability to identify symptoms will improve their health-seeking behavior, thereby increasing the effectiveness of the syndromic approach.

Second, as seen above, the symptoms and/or signs used in the existing algorithms for syndromic management have been shown not be effective in predicting whether or not a women has an infection, due to their poor sensitivity, specificity and positive predictive values. The Africa OR/

Using vaginal discharge as a means of detecting infections and deciding treatment of is not effective among women attending $\mathrm{MCH} / \mathrm{FP}$ clinics regardless of their primary reason for the clinic visit. 
Kenya and Zimbabwe to determine whether adding risk assessment to the client consultation would improve the effectiveness of detecting and managing STIs (see below).

Third, staff were found to not always follow the service delivery guidelines for screening and managing $\mathrm{MCH} / \mathrm{FP}$ clients for possible infections, even when there is sufficient information from history-taking and clinical examination to suggest the possibility of an infection.

The studies in Kenya and Zimbabwe also tested whether using a checklist would improve the provider's capacity to correctly implement the standard procedures for an integrated approach (see below).

\section{Can the effectiveness of the syndromic approach be improved by adding risk assessment?}

Adding risk assessment has been proposed as a means for improving the effectiveness of the syndromic approach for detecting infections among $\mathrm{MCH} / \mathrm{FP}$ clients who present without symptoms. A risk assessment is relatively simple to undertake - it requires the provider to ask the women a number of questions about her and her partners' behavior, the answers to which may indicate that she is at increased risk of contracting an STI. The factors most commonly included are: multiple sex part-

Given the low prevalence of both STIs and risk factors among MCH/FP clients, the addition of risk assessment to the syndromic approach does not result in any substantial improvements on its sensitivity, specificity and positive predictive values. ners; current or past STIs; perception of STI risk; and staying away from partner.

For these two OR studies, the objective was to find out whether it was possible to establish a small number of questions that would significantly improve the ability of providers to detect and manage $\mathrm{MCH} / \mathrm{FP}$ clients with STIs. To do this, a set of 23 risk factors was identified from the literature and through expert knowledge of the local situation.

Researchers interviewed clients after their consultation to obtain information about each of these factors. These data were then analyzed in relation to whether or not the woman was actually infected, as indicated by a laboratory test. From this analysis, a reduced set of six key risk factors was identified as being those most likely to predict an infection. The findings were as follows:

- The factors that are usually considered to be indicative of increased risk were uncommon among women attending $\mathrm{MCH} / \mathrm{FP}$ clinics in Kenya and Zimbabwe.

- Strengthening the algorithm by combining selected information from the client's medical history, a clinical examination and risk assessment leads to a small improvement in the effectiveness of the algorithms to correctly identify clients with a cervical infection (the positive predictive value). There is also a small improvement for identifying those without a cervical infection (the 
specificity). However, the ability of the algorithm to identify cervical infections in a pool of clients known to be positive (its sensitivity) remained low.

\section{Does the Use of a Standardized Checklist Improve the Quality of an Integrated Approach?}

A major reason identified by staff for their not systematically assessing and counseling MCH/FP clients on STI/HIV was the lack of a checklist and recordkeeping system that would facilitate an integrated consultation.

Drawing from this finding, the studies in Kenya and Zimbabwe developed and introduced an integrated checklist to be used by clinic staff during history taking, clinical examination and STI/ $\mathrm{HIV}$ risk assessment for all $\mathrm{MCH} / \mathrm{FP}$ clients. The checklist included 23 STI/HIV risk factor items and 13 counseling and information items that a provider should discuss with a client, and allowed space for the information obtained to be recorded. The results of this study showed that:

- Although staff found it difficult and time consuming at first to use the checklist, they gradually accepted it as part of their routine procedure for collecting information from and giving information to their clients. With time, the staff reported that the checklist enabled them to

The introduction of a standardized and inte-
grated checklist was acceptable to both clinic
staff and clients, and lead to significant im-
provements in the quality of care provided to
clients.
spend the time with clients more efficiently, and were thus able to build a better rapport, collect more detailed information required for proper diagnosis and management, and to counsel their clients in a more systematic manner.

- Clients felt that service providers were now spending more time with them and providing a more thorough examination, resulting in a better understanding of their problems.

- Both the staff and clients felt comfortable with the risk assessment questions. One reason given by the clients was that the questions on sexual behavior gave them the opportunity to think about and re-examine their own lives.

- Following the introduction of the checklist, the vast majority of clients $(78-99 \%)$ were now receiving systematic counseling on key STIs and HIV/AIDS topics. The quality of information given on family planning also improved significantly. 


\section{How has Operations Research Strengthened Integration of STI/HIV and Family Planning Services?}

Kenya: Two case studies undertaken in Kenya helped to identify weaknesses in the strategies used to integrate STI and family planning services. The strategy had focussed on training staff in syndromic management and providing STI-dedicated drug kits. The research found that the training did not cover the essential skills required by the providers, the MIS had not been revised to facilitate recording and reporting of information needed for providing and monitoring integrated programs, prescribing policies had not been reviewed to allow the trained nurses to prescribe STI drugs, indicators of program performance had not been reviewed to include STI and HIV services and there were no job aides to assist the providers providing services using an integrated approach. The two programs have already reviewed their training curricula and MIS to cover those areas found to be deficient by the studies, and have also reviewed their cost recovery strategies.

Results from these studies contributed to the inclusion of a section on the integration of STI/HIV/AIDS control into the MCH/FP program within the revised National Reproductive Health/Family Planning Policy Guidelines and Standards for Service Providers. The findings also led to national debate on the prescribing policies that currently do not allow nurses to prescribe STI drugs. The matter was taken up by parliament and changes in legislation to allow the nurse to prescribe have been approved.

Uganda: Results from the case study helped the program in identifying its requirements and were used to inform and solicit support from donors. The program was able to get the MOH to provide KEPI fridges to some of their clinics, they were able to get more equipment and drugs from donors using the study findings to back up their requests. The program reviewed its training curriculum to cover areas in which the study found the staff to be deficient. Client flow and privacy were found to be a problem in many of the facilities and structural adjustments were required. The program used these results to convince the communities to undertake the necessary structural adjustments and to put billboards at the clinics to inform clients of the availability of STI/HIV services.

Botswana: The MCH/FP unit has utilized the results to more accurately define areas in their program that need attention. For example, the trainers from the Botswana Population Assistance (BOTSPA) Project used the results to revise the training curriculum for nurses in providing STI/HIV services in $\mathrm{MCH} /$ FP clinics to put more emphasis on those skills found to be deficient. The MCH/FP unit also revised their client record forms to facilitate the providers in obtaining, recording and reporting information essential for providing STI/ HIV and family planning services using an integrated approach. Study results have been used in training workshops for supervisors in the District Health Management Teams and the development of supervision checklists. The MCH/ FP unit has used information from the studies to develop indicators to monitor the performance of their program and many of these indicators have been incorporated in the Ministry of Health Information System for use at a national level.

Zimbabwe: A new training module specifically addressing the provision of MCH/FP and STI services using an integrated approach was developed as part of the study activities and will form part of the national training curriculum. This new module has also been used by WHO to train staff in other programs with Sub-Saharan Africa. The study also helped to identify weaknesses in the current treatment algorithms given existing disease patterns. Information from the studies is being used by the national STI management committee to review the STI management guidelines in view of the study findings. The study findings are being used by the ZNFPC to revise their MIS to facilitate the provision of STI and family planning services using an integrated approach. 


\section{Resources Available from the Africa OR/TA Project II on Integration of STI/HIV and MCH/FP Information and Services}

Askew, Ian. 1998. Designing a process for developing guidelines and standards for promoting dual protection', Paper presented at the Regional Conference on Guidelines and Standards for Reproductive Health, Harare, Zimbabwe, 8-12 June.

Askew, Ian and Baker Ndugga Maggwa. 1996. Operations research on the integration of STI/ AIDS services into MCH/FP programs in East and Southern Africa: Findings from Situation Analyses and Case Studies in selected countries. Paper presented at a workshop on 'The interface between family planning and HIV/STD prevention,' co-sponsored by ILSSP, WHO, Wellcome Trust and The African Population Policy Research Centre, Nairobi, Kenya, 2-4 October.

Askew, Ian, Baker Ndugga Maggwa, and Lenni Kangas. 1998. Integrating STI and HIV/ AIDS services into MCH/FP programs in East and Southern Africa. Paper presented at the Annual Meeting of the Population Association of America, Chicago, Illinois, USA, April 2-4.

Askew, Ian, Fassihian Goli and Baker Ndugga Maggwa. 1998. Integrating STD and HIV/ AIDS services with family planning and MCH services at clinics in sub-Saharan Africa. in Clinic-based Family Planning Services in sub-Saharan Africa: Findings from Situation Analysis Studies. Africa OR/TA Project II, Population Council, New York, USA.

Baakile, Benjamin, Baker Ndugga Maggwa, Lucy Maribe, and Robert A. Miller. 1996. A Situation Analysis of the maternal and child health/family planning (MCH/FP) program in Botswana. Prepared by the Africa OR/TA Project II in cooperation with the Ministry of Health MCH/FP Unit, Family Health Division. Gaborone, Botswana, July.

Chege Jane and Askew Ian, 1997. An Assessment of Community-Based Family Planning Programmes in Kenya Africa OR/TA Project II, Population Council, Nairobi, Kenya.

Dube Hazel, Carolyn Marangwanda and Lewis Ndhlovu. 1998 An Assessment of the Zimbabwe Family Planning Programme: Results from the 1996 Situation Analysis Study. Africa OR/TA Project II, Population Council, Nairobi, Kenya.

Ghana Statistical Services. 1997. Second Round Situation Analysis Study of Family Planning Service Delivery Points in Ghana 1997. Africa OR/TA Project II, Population Council, Nairobi, Kenya.

Kariba, James, Bedan Kariuki and Baker Ndugga Maggwa. 1997. Integration of STI and HIV/ AIDS with MCH-FP Services: A case study of the Nakuru Municipal Council's Project on Strengthening STD/AIDS Control. Nakuru Municipal Council and the Africa OR/TA Project II, Nairobi, Kenya, April.

Maggwa, Baker Ndugga. 1998. A rapid assessment tool for evaluating the quality of the integrated MCH/FP and STD/HIV programs in Botswana, Paper presented at the Annual Meeting of the American Public Health Association, Washington, D.C., November 15-19.

Maggwa, Baker Ndugga. 1998. The integration of STVHIV services with MCH/FP services. Paper presented at the Regional Conference on Guidelines and Standards for Reproductive Health, Harare, Zimbabwe, 8-12 June.

Maggwa, Baker Ndugga and Ian Askew. 1997. Integrating STI/HIV management strategies into existing MCH/FP programs: Lessons from case studies in East and Southern Africa. Population Council, Nairobi, Kenya, July.

Maggwa, Baker Ndugga 1996. Sexually transmitted infections, family planning, and maternal-child health: integrating services in sub-Saharan Africa. Population Briefs 2(4):4.

Maggwa, Baker Ndugga and Ian Askew. 1997. Integrating STI/HIV management strategies into existing MCH/FP programs: Lessons from case studies in East and Southern Africa. Paper presented at workshop on 'Improved Reproductive Health: International Shared Experiences' by the Population Council, Bogor-West Java, Indonesia 4-5 December. 
Maggwa, Baker Ndugga and Ian Askew. 1997. Integrating STI/HIV management strategies into existing MCH/FP programs: Lessons from case studies in East and Southern Africa. Paper presented at the Annual Meeting of the American Public Health Association, Indianapolis, Indiana, 9-13 November.

Maggwa, Baker Ndugga, Naomi Rutenberg and Ian Askew. 1997. A challenge to integrating STI/HIV management strategies into existing MCH/FP programs in East and Southern Africa: Talking about sex and sexually transmitted diseases. Paper presented at the Annual Meeting of the American Public Health Association, Indianapolis, Indiana, 9-13 November.

Maggwa, Baker Ndugga. 1997. STD services and comprehensive primary health care: The practical implications. Paper presented at the Forum on Establishing Appropriate Services for the Management and Prevention of STDS, Department of Health, Johannesburg, South Africa, 25-26 September.

Maggwa, Baker Ndugga and Placide Tapsoba. 1996. Collecting information on other reproductive health services through the Situation Analysis approach. Paper presented at a workshop on Strengthening the Utilization of Situation Analysis for Planning, Managing and Evaluating Reproductive Health Services, Population Council, Nairobi, Kenya, 29-31 May.

Maggwa, Baker Ndugga, Ian Askew, and Andy Fisher. 1995. Integration of STI and HIVI AIDS services with MCH-FP services: Experiences from four countries in subSaharan Africa. Paper presented at the Annual Meeting of the American Public Health Association, San Diego, CA, USA 29 October-2 November.

Maggwa, Baker Ndugga, Ian Askew, Carolyn Marangwanda, Sikhozile Simba and Hazel Dube. 1999. Assessing the potential demand for and effectiveness of integrating STVHIV management services with Zimbabwe National Family Planning Council's clinic-based family planning services. Africa OR/TA Project II, Population Council, Nairobi, Kenya.

Maribe, Lucy and Scott Stewart. 1995. Botswana's national program of integrated services - what are the costs: A case study. Paper presented at the Annual Meeting of the American Public Health Association, San Diego, CA, 29 October-2 November.

Maribe, Lucy Sejo, Baker Ndugga Maggwa, Ian Askew and Kate Miller. 1997. Using a rapid assessment approach to evaluate the quality, of care in an integrated program: The experience of the Family Health Division, Ministry of Health, Botswana. Population Council, Nairobi, Kenya, November.

Miller, Robert, Karen Stein, Kate Miller, Lewis Ndhlovu, Baker Ndugga Maggwa, Diouratie Sanogo and Emmy Kondo. 1996. Measuring reproductive health care after Cairo: Findings from four Situation Analysis studies in Africa. African Journal of Fertility, Sexuality and Reproductive Health 1 (2):92-1 00.

Mukaire, Joy, Florence Kalikwani, Baker Ndugga Maggwa and Wilson Kisubi. 1997. Integration of STI and HIV/AIDS services with MCH-FP services: A case study of the Busoga Diocese Family Life Education Program, Uganda, Busoga Diocese Family Life Education Program, the Africa OR/TA Project II and Pathfinder International, Nairobi, Kenya, January.

Solo J., B N Maggwa, JW Kariba, BK Karuiki and G. Maitha 1999. Improving the management of STis among MCH/FP clients at the Nakuru Municipal Council Health Clinics Africa OR/TA Project II, Population Council, Nairobi, Kenya.

Twahir, Amina, Baker Ndugga Maggwa and Ian Askew. 1996. Integration of STI and HIV/ AIDS services with MCH/FP services: A Case Study of the Mkomani Clinic Society in Mombasa,Kenya. Mkomani Clinic Society and the Africa OR/TA Project II, Nairobi, Kenya, April.

Twahir, Arnina and Baker Ndugga Maggwa. 1995. Mkornani Clinics: Integration of MCH/ FP with STD/H IV services - what are the costs: A case study, Paper presented at the Annual Meeting of the American Public Health Association, San Diego, CA, USA 29 October-2 November. 


\section{Postabortion Care}

It is estimated that 20 million unsafe abortions take place around the world each year with about 70,000 women dying as a result. Countless other women suffer short and long term illnesses. Unsafe abortion is a leading contributor to maternal mortality and morbidity; in sub-Saharan Africa, it is estimated that unsafe abortions account for between 20-30 per cent of all maternal mortality. Since the endorsement of Postabortion Care (PAC) at the International Conference on Population and Development (ICPD) in 1994, there has been increased attention paid to $P A C$ as an intervention to reduce maternal morbidity and mortality.

Essentially, this intervention requires a more comprehensive approach to care for women who suffer complications from spontaneous or unsafely induced abortion, by providing safer treatment for evacuation, counseling on family planning services and links to other reproductive health services as needed. Better management through all three components can help to reduce the mortality and morbidity associated with complications, while providing family planning counseling and services can help women avoid unwanted pregnancies and repeat abortions.

Activities completed by the Africa OR/TA Project II

\begin{tabular}{|c|c|}
\hline Country and Collaborators & Study Description \\
\hline $\begin{array}{l}\text { BuRKINA FASO } \\
\text { - Ministry of Health } \\
\text { - Cellule de Recherche en } \\
\text { Santé de la Reproduction } \\
\text { (CRESAR) } \\
\text { JHPIEGO }\end{array}$ & $\begin{array}{l}\text { Introducing integrated treatment of abortion } \\
\text { complications and family planning counsel- } \\
\text { ing and services in two national hospitals in } \\
\text { Ouagadougou and Bobo-Dioulasso }\end{array}$ \\
\hline $\begin{array}{l}\text { KENYA } \\
\bullet \text { Ministry of Health } \\
\bullet \text { Ipas }\end{array}$ & $\begin{array}{l}\text { Testing three alternative approaches to provid- } \\
\text { ing integrated treatment of abortion complica- } \\
\text { tions and family planning in six hospitals }\end{array}$ \\
\hline $\begin{array}{l}\text { SeNEGAL } \\
\text { Center de Formation } \\
\text { et de Recherche en } \\
\text { Santé de la Reproduction } \\
\text { (CEFOREP) } \\
\text { La Clinique Gynecologique } \\
\text { et Obstetricale du CHU } \\
\text { Aristide Le Dantec } \\
\text { JHPIEGO }\end{array}$ & $\begin{array}{l}\text { Introducing integrated treatment of abortion } \\
\text { complications and family planning in three hos- } \\
\text { pitals in Dakar }\end{array}$ \\
\hline
\end{tabular}

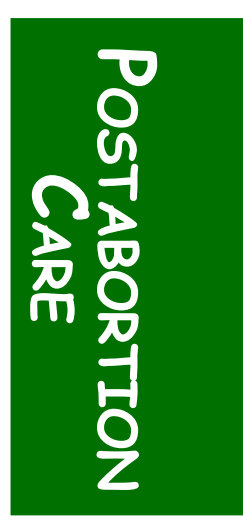




\section{How Extensive is the Problem of Incomplete Abortion?}

Incomplete abortion constitutes a major public health concern and a significant draw on facility resources. This is evident in the high proportion of gynecological ward admissions for postabortion care either as a result of spontaneous or induced abortion. This proportion ranged from 11 per cent at the two national hospitals in Burkina Faso to over 35 per cent in the six provincial hospitals in Kenya. This only represents, however, those women who actually come to the hospital to seek treatment services.

\section{What are the Characteristics of Women seeking Treatment of Incomplete Abortion?}

Though a large number of incomplete abortion patients are young (under 25 years), there is a substantial proportion that are over 30 years. The mean age in all three studies was between 25 and 29 years. In addition, the majority of clients were married (67 per cent in Burkina Faso, 71 per cent in Kenya and 85 per cent in Senegal). The profile of incomplete abortion patients does not conform, therefore, to the common perception by many providers that they are mostly single adolescents.

Most women were not using family planning at the time of the pregnancy, although a significant proportion were: 22 per cent in Kenya, 12 per cent in Senegal and 11 per cent in Burkina Faso. The majority of these women were using either the pill or rhythm, and experienced either method or user failure.

\section{Women from Kenya tell their stories}

Pre-intervention

A 20 year old unmarried woman who was a farmer came to the hospital after an induced abortion. It had been her first pregnancy. She had a regular partner but did not want to have children until she was married. When she arrived in the hospital, her cervix was torn since the "quack" had used scissors to perform the abortion.

Asked why she was not using a family planning method at the time she became pregnant, she said whenever she asked her boyfriend to use a condom he bought a sweet and asked her to eat it with the wrapper on. This, he said, is the same way he would feel if he had sex with a condom on. She was afraid to use the pill because she thought it could make her barren.

\section{Post-intervention:}

A 22 year old married woman came to the hospital after experiencing a miscarriage. She had had three pregnancies but had only one living child, having lost the other two pregnancies. This miscarriage had come only four months after the other. Before she became pregnant with this last pregnancy, she had not been using a family planning method because she wanted to get pregnant. She said she would like one more child but is not sure when because she felt very weak. She said she would want her husband also to be counseled on family planning. She went home with the combined pill. 


\section{How is Emergency Treatment Best Provided?}

Manual vacuum aspiration (MVA) has been shown to be safer and less costly than dilatation and curettage $(\mathrm{D} \& \mathrm{C})$ in the treatment of incomplete abortion, while being just as effective for cases of up to a uterine size of 12 weeks. The introduction of MVA and the accompanying restructuring of services were key components of PAC activities in all three OR studies. Prior to introduction of MVA, most facilities relied on D\&C for treatment and, in Burkina Faso and Senegal, digital curage. When introduced, MVA was both highly acceptable and quickly adopted as the primary type of treatment at sites in all three studies as shown. In Senegal, however, D\&C and curage continued to be practiced.

MVA can be provided without general anesthesia; hence women need not be treated in major operating theaters. Consequently, services can be restructured, including creating small treatment rooms directly on the ward to reduce duration of patient stay and thereby save hospital resources. At one hospital in Kenya, for example, the mean duration of patient stay decreased from 60 to 21 hours after treatment services were moved from the operating theater to a room on the gynecological ward.

MVA can be done with lower levels of pain control than D\&C, i.e., with analgesia and a para-cervical block. However, the Kenya study found that in practice this recommendation is often translated into no pain control at all; only three per cent of MVA patients received any pain medication prior to or during the procedure. Not unexpectedly, 60 per cent of the women described the pain they experienced as extreme. Providers indicated that they would like clearer guidelines on the use of pain control with MVA.

The main problem encountered in creating sustainable MVA services is maintaining a supply of MVA kits. Though kits can be reused numerous times, it is essential that health programs develop ways to ensure a continued supply of kits. In addition, hospitals need to have a regular supply of decontamination and sterilizing solutions. In many cases, patients were required to buy these solutions in order to receive services.

Training of providers in PAC was shown to improve providerpatient relations. In the words of one provider in Kenya, it "has made me change and have a good attitude towards patients who have procured an abortion whether induced or not. They all need love and care." This change is essential to offering high quality services, as negative provider attitudes were shown to be a barrier to improved care for incomplete abortion patients.

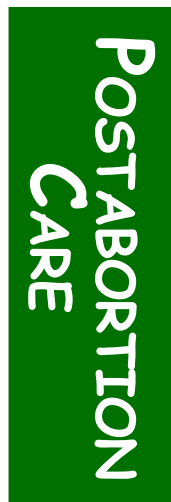


There is essential information that women should be given about the procedure before leaving the hospital, including the problems for which they should return to a health facility, and the fact that they could have an almost immediate return to fertility. As a result of the interventions, the number of women who got information about the timing of their return to fertility rose from 13 to 41 per cent in Kenya, and from 12 to 90 per cent in Burkina Faso. However, many more women still left the facilities without vital reproductive health information.

In Senegal, only 11 per cent of women were given any information at all about possible future problems. Improving the information given to women post-treatment must be further emphasized in training and supervision of PAC services.

\section{How Best can Family Planning Services be Provided to Postabortion Patients?}

Providing family planning information and services, if desired, is essential to enable women to avoid the recurrence of an unwanted pregnancy, and to allow women who have experienced a miscarriage to wait and rest before becoming pregnant again. Although routinely providing such information and services to postabortion patients was new to all the hospitals involved in these three studies, it was rapidly ac-

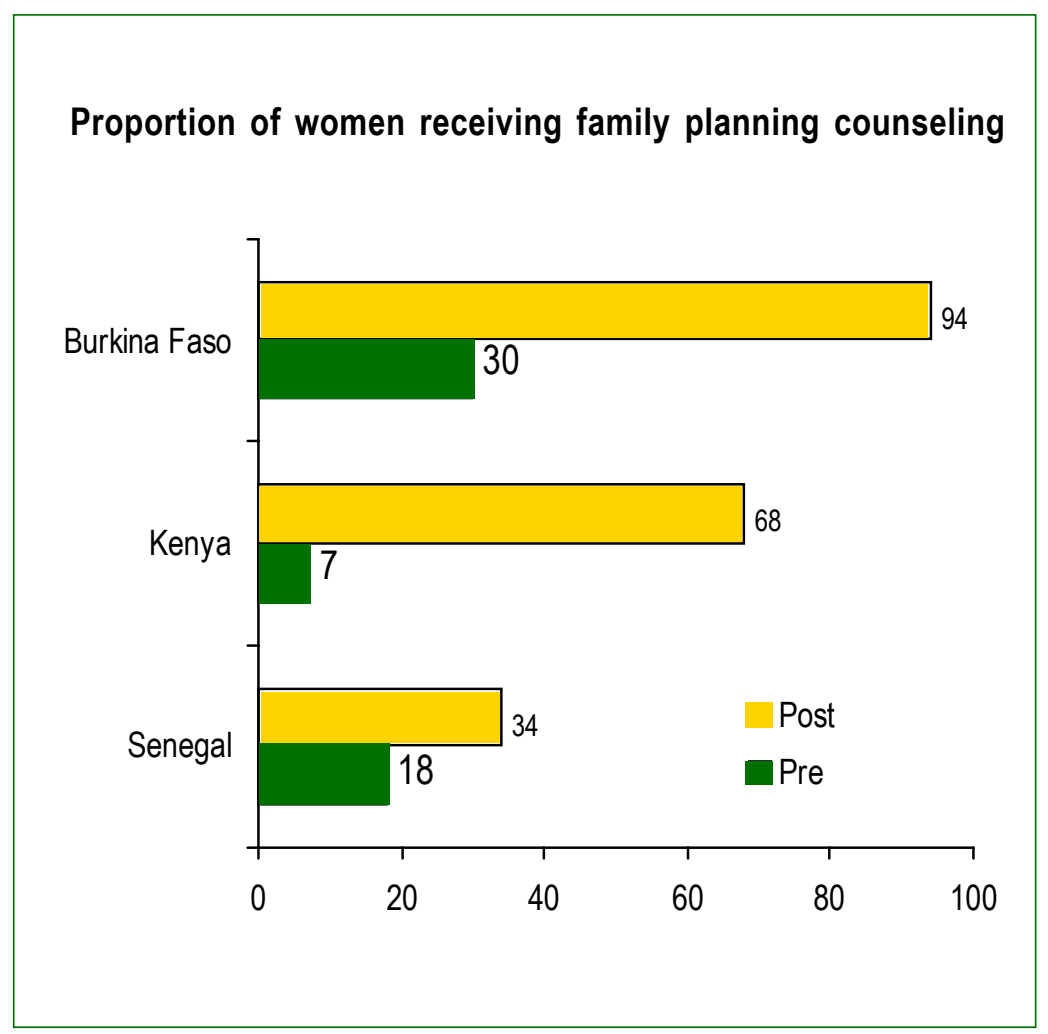
cepted into standard hospital practice in the majority of sites in Burkina Faso and Kenya, as shown on the left.Although there was also a significant increase in the Senegal sites, two-thirds of the women were still not being counseled on family planning before leaving the hospital.

The place where family planning counseling is provided is an important consideration when introducing a PAC program. In Senegal, before the intervention, most clients were either referred to the family planning clinic or given counseling in the operating theater; afterwards, the majority were counseled while recuperating on the ward. The Kenya study tested three alternative models for providing family planning:

- Having staff on the gynecological ward provide family planning to women on the ward;

- Having staff from the hospital's family planning clinic come to the gynecological ward to provide family planning;

- Escorting the women from the gynecological ward to the family planning clinic following recuperation. 
Training and supporting staff on the gynecological ward to counsel women and provide contraceptives was shown to be the most effective, acceptable and feasible model of linking treatment and postabortion family planning. With this model, almost all women (92 per cent) received family planning counseling, as compared with 62 per cent and 54 per cent for the second and third models respectively.

\section{Implications for the Routine Implementation of Postabortion Care}

Improved PAC services were clearly shown to be acceptable, feasible and effective in multiple settings. Implementation of these services requires the following:

- Training of providers in both MVA and Postabortion Family Plan ning;

- Providing necessary equipment, including MVA kits;

- Facility upgrading;

- Re-organization of services;

To ensure sustainability, it was found to be important to:

- Create supportive national policies, e.g. including MVA kits in $\mathrm{MOH}$ lists of essential supplies and in national logistics systems;

- Institute on-the-job training so that providers transfer their skills to other staff and services continue even if staff are moved;

- Instituionalize training in relevant medical schools so that all providers are knowledgeable about PAC services.

\section{Enhancing the Role of Male Partners}

Men can play an important role in the PAC process. Many women were accompanied to the hospital by their partners (42 per cent in Kenya), and these men expressed a desire to receive more information about their partner's condition; primarily in terms of what had caused the problem and how the same problem could be avoided in the future.

In addition, both men and women generally wanted the men to be involved in the family planning counseling - in Kenya 93 per cent of women and 92 per cent of their partners wanted the man to receive family planning counseling at this time. However, any PAC services that involve men should be careful to consult the woman first about including her partner - one third of women in Senegal indicated that they would not want their partner included in counseling. 


\section{How has Operations Research Helped in Improving PAC?}

Operations research has proved to be an effective means for introducing and gaining support for this innovative service under uncertain, and sometimes controversial, circumstances. The importance of using an OR approach for introducing a new intervention was particularly evident in Francophone Africa, where $P A C$ was virtually unknown prior to the two OR studies in Burkina Faso and Senegal.

As part of the OR study in Burkina Faso, national norms and standards for PAC were developed and adopted by the MOH, and the two national hospitals began to plan for including PAC supplies and commodities within their regular annual budgets to ensure sustainability of the service. As a result of the study, support for expansion of PAC services to other hospitals in the country has been made available to the $M O H$ and CRESAR from JHPIEGO, the SFPS Project, UNFPA and the World Bank.

The experience in Burkina Faso led to the creation by JHPIEGO of a regional team of PAC trainers. This team trained staff in Senegal for the OR PAC study and has subsequently trained staff in Guinea, with the expectation that it will train staff in Mali, Côte d'Ivoire and Benin in the near future.

In Senegal also, the OR study has contributed to the development of national service delivery protocols for the delivery of PAC - these draft norms and standards were validated at a workshop held in May 1999 by JHPIEGO. Support has been provided to CEFOREP by JHPIEGO and UNFPA to expand PAC services on a limited basis initially (four regional hospitals and a district hospital), with the intention that the lessons learned will contribute to a nationwide expansion in the year 2000.

Prior to the OR study in Kenya, PAC had already been introduced on a pilot basis in a number of large hospitals. The purpose of the OR study was to improve the way PAC is provided within hospitals by demonstrating to administrators the most effective and acceptable way to organize these services. The results from the OR study have been adopted by the $\mathrm{MOH}$ as the standard way in which PAC should be introduced into hospitals. The on-ward model of offering post-abortion family planning is about to be expanded to other provincial and district hospitals through a national PAC expansion program, largely funded by SIDA. The Africa OR/TA Project II supported the $\mathrm{MOH}$ in undertaking a needs assessment to guide the planning for this expansion. 


\section{Resources Available from Africa OR/TA Project II on Postabortion Care}

Askew, Ian. 1 998. Measuring the quality of postabortion care. Paper presented at the 'Global Meeting on Postabortion Care: Advances and Challenges in Operations Research,' Population Council, New York, 29-21 January.

Cellule de Recherche en Sante de la Reproduction, Direction de la Sante de la Famille, Population CouncilAfricaOR/TAProjectiland)HPIEGO. 1998 Introduction $d u$ traitement medical l'urgence ainsi que les services et conseils ulterieurs en PF pour les femmes qui souffrent de complications suite a un avortement au Burkina Faso. Final Report.

Dao, Blami, Babakar Mane, Blandine Tieba, Placide Tapsoba, Inoussa Kabore and Thierno Dieng. Treating complications of postabortion patients for Francophone Africa: The experience of Bobo-Dioulasso and Ouagadougou, Burkina Faso and Dakar, Senegal. Paper presented at the APHA Annual Conference, Washington, D.C. November 1998.

Faye, Ousseynou, Babakar Mane, Thierno Dieng, Placide Tapsoba, Cheikh Mbengue and Fadel Diadhiou. La planification familiale chez les femrnes presentant des complications liees a un avortemenl. Paper presented by CEFOREP researchers at the International Conference of Societe Africaine de Gyneco-Obsterique (SAGO), Dakar, Senegal. December 14-18, 1998.

Ghosh, Anita, Bibiane Kone, Jean Lankoande and Placide Tapsoba. 1997. Introducing improved postabortion care into maternity services in Burkina Faso. Paper presented at the 'Global Meeting on Postabortion Care: Advances and Challenges in Operations Research,' Population Council, New York, 29-21 January.

Huntington Dale. Advances and Challenges in Postabortion Care Operations Research: Summary Report of a Global Meeting. 19-21 January 1998. New York. Population Council.

Mane, Babakar, Thierno Dieng, Cheikh Mbengue (Centre de Formation et de Recherche en Sante de la Reproduction), Ousseynou Faye, Fadel Diadhiou (Clinique Gynecologique et Obstetricale CHU Aristide le Dantec), Placide Tapsoba (Population Council Africa OR/TA Project II), Kathy Jesencky and Theresa Deans (JHPIEGO). Introduction des soins obstetricaux durgence et dela planification familiale pour les patientes presentant des complications liees a un avortement Dakar, Senegal. May 1998.

Moussa, Cheikh. Revue de la litterature sur les avortements A risque au Senegal

Orninde, Achola, Margaret Makumi, Deborah Billings, and Julie Solo. 1997. Postabortion care services in Kenya: Baseline findings from an operations research study. The Africa OR/TA Project II, Nairobi, Kenya, March.

Solo, Julie, Deborah Billings, Colette Aloo-Obunga, Achola Ominde and Margaret Makumi. "Creating Linkages Between Incomplete Abortion Treatment and Family Planning Services in Kenya'. Studies in Family Planning, March 1999.

Solo, Julie and Deborah Billings. 1996. Testing alternative approaches to providing integrated treatment of abortion complications and family planning in Kenya. Paper presented at the annual meeting of the American Public Health Association, New York, New York, 17-21 November.

Solo, Julie and Deborah Billings. 1997. An analysis of the resources needed to create linkages between incomplete abortion treatment and family planning services in Kenya. Paper presented at the Annual Meeting of the American Public Health Association, Indianapolis, Indiana, 9-13 November.

Solo, Julie, Achola Ominde, Margaret Makumi, Deborah Billings and Colette Aloo-Obunga. 1998. "Creating linkages between incomplete abortion treatment and family planning services in Kenya' The Division of Primary Health Care, MOH, lpas and the Africa OR/TA Project II, Nairobi, Kenya, January.

Solo, Julie, Achola Ominde, Margaret Makumi, Deborah Billings and Colette Aloo-Obunga 1998. Creating linkages between incomplete abortion treatment and family planning services in Kenya: What works best? Paper presented at the 'Global Meeting on Postabortion Care: Advances and Challenges in Operations Research,' Population Council, New York, 19-21 January.

Solo, Julie, Deborah Billings and Achola Ominde. 1997. Improving postabortion care services in Kenya: what works best? Paper presented at the Annual Meeting of the American Public Health Association, Indianapolis, Indiana, 9-13 November.

Solo, Julie, Esther Muia, and Khama Rogo. 1995. Testing alternative approaches to providing integrated treatment of abortion complications and family planning in Kenya: Findings from Phase 1. The Africa OR/TA Project II, Nairobi, Kenya, August. 


\section{Reaching Adolescents with Information and Services}

\section{In recent years, the reproductive health status and service needs of adolescents in developing countries have become a priority for policymakers and program managers, alike.}

Adolescents constitute a significant proportion of the population, particularly in developing countries, where their contribution to population increase is considerable due to population momentum, or the sheer numbers of young people in their reproductive years. Perhaps more importantly, adolescents suffer disproportionately from negative reproductive health outcomes and their sequelae, such as early and unwanted pregnancies, unsafe abortion and STIs, including HIV/AIDS.

The physiological and social disadvantages young people face concerning their reproductive health status are exacerbated by added psychosocial, policy and service barriers associated with reproductive health services in sub-Saharan Africa. Programs for adolescents in sub-Saharan Africa are now moving into a second generation, and taking valuable lessons from previous experiences.

This section presents lessons learned from the following OR studies of adolescents themselves and of programs offering information and services to adolescents supported through the Africa OR/TA Project II.

- A study in Zambia, implemented by CARE compared two community-based approaches for promoting safer sex behaviors adolescent peer educators who were also condom sales agents and by micro-finance credit schemes ".. Research and programs focusing on adolescent reproductive health in sub-

Saharan Africa are a relatively new phenomenon, with the majority of programs being less than twenty years old. This first generation of youth programs has largely relied on lessons learned from outside the region. for youth.

- An assessment was completed in Ghana of the performance, utilization and effectiveness of Planned Parenthood Association of Ghana's Youth Centers.

- A survey was conducted of adolescents' knowledge, attitudes and behavior concerning reproductive health issues in three urban areas of the Volta Region in Ghana; this survey provides the baseline for an on-going longitudinal OR study to compare the effectiveness of peer educators and youth centers in reaching youth. 
- The "Youth Empowerment Project' in Botswana was implemented to strengthen the management and service delivery capabilities of youth-serving NGOs to take on greater responsibility for adolescent reproductive health and education. As part of this project, four "mini-OR studies" were undertaken to strengthen the NGOs research capacities:

1. Assessing the coverage and adequacy of services provided by the Association of Medical Missionaries in Botswana to care givers of HIV/AIDS+ youth;

2. Accessibility, availability, and use of condoms among youth;

3. Utilization of IEC material on HIV/AIDS by adolescents with disabilities;

4. Effectiveness of peer education training programs in Gaborone.

In addition, staff from the Africa OR/TA Project II also provided extensive technical assistance to other organizations implementing adolescent reproductive health programs in the region, notably:

To IPPF/London and to the Family Planning Associations of Burkina Faso, the Gambia, Ghana and Tanzania for the DFIDfunded 'Sexual Health Project'

To the Family Planning Association of Kenya and the Zimbabwe National Family Planning Council for their Rockefeller Foundation-funded OR studies to design and test models for reaching youth;

- To the IPF affiliate in Burkina Faso for an assessment of its GTZ-funded "Youth-to-Youth" program;

- To the Pacific Institute for Women's Health program on 'Adolescent Health and Sexuality' in West Africa, funded by the Rockefeller Foundation.

\section{What do we know about the Sexual and Reproductive Behavior of Adolescents?}

".. The study in Ghana also revealed that

a significant proportion of girls had experienced force during early sexual encounters - 21 per cent of girls reported that their first sexual encounter resulted from rape..."
The majority of young people become sexually active before marriage, and the age of first intercourse appears to be decreasing over time. In Ghana, by age 16 , about 50 per cent of adolescents were found to have had sexual intercourse.

Sex in exchange for money or gifts is also common among adolescents. In Zambia, for example, almost two thirds of the sexually active girls reported receiving money or gifts for sex, while in Ghana, 36 per cent of sexually active boys reported using money and gifts to obtain sex from girls. 
For girls, age differences between them and their partners reflects important power imbalances with regard to sexual negotiation and family planning use. In Ghana, girls' sexual partners are, on average, 3 to 4 years older, compared to adolescent boys being only about one year older than their partners.

These findings emphasize that program planners need to take into account the high proportion of non-consensual sex and sex within unequal relationships when designing programs for adolescents.

\section{Contraceptive Use: Do Adolescents Protect Themselves?}

Use of contraceptive methods among unmarried adolescents is low considering that premarital pregnancies are, more often than not, unwanted. Among sexually active adolescents in Botswana, 65 per cent reported ever using a method. In urban Ghana, 51 per cent of sexually experienced adolescents used contraception during their most recent intercourse.

Condoms are perhaps the most suitable method for adolescents as they prevent transmission of STIs, including HIV/AIDS, provide protection against pregnancy, and are appropriate for those in unstable relationships and/or having unplanned sex.

While virtually all adolescents interviewed in Ghana are aware of condoms, they describe shyness in obtaining condoms and psychosocial barriers to carrying condoms as reasons for difficulties in actually using them; 63 per cent of boys and 80 per cent of girls report that they feel too embarrassed to obtain condoms. Programs need to create mechanisms to facilitate adolescents acquiring condoms anonymously and without embarrassment.

In the study in Zambia, many adolescents considered condoms unnecessary or inappropriate for their age. Some felt that young boys cannot impregnate girls as their sperm are not strong enough, and some boys also complained that condoms are too big and easily slip off.

\section{What are the outcomes of unprotected sex?}

- Over one third of sexually experienced nevermarried females in the Ghana study had experienced a pregnancy.

91 per cent of the pregnancies were unwanted.

89 per cent of the girls who had an unwanted pregnancy reported having attempted abortion.

- 21 per cent of sexually active girls in Zambia had experienced at least one pregnancy.

- Four per cent of sexually experienced girls and nine per cent of sexually experienced boys reported having had sexually transmitted diseases. 


\section{Alternative Approaches to Reaching Adolescents}

\section{Youth Centers}

Evidence from the study in Ghana (supported by evidence from the studies undertaken in Kenya and Zimbabwe) suggests that youth centers might not be the most appropriate or effective way to reach adolescents with reproductive health information and services. Why?

One reason is that chemist shops, kiosks and friends are the most common source of condoms for adolescents. Seventy-eight per cent of adolescents in the Ghana urban youth study obtained condoms from chemists. Despite the clear evidence of their preference for non-formal outlets, most programs for the youth focus on strengthening facility-based delivery of family planning information and services, often through youth centers, instead of expanding access to non-formal outlets

Multi-purpose youth centers were found to be only marginally effective in reaching girls and younger adolescents with reproductive health information and services. In centers in Kenya and Zimbabwe, boys outnumbered girls at the centers by as much as 4 to 1 , and a negligible number of adolescents aged 10 to 14 visited the centers. Youth Centers run by family planning organizations in Ghana, Kenya and Zimbabwe have been stigmatized as places for the sexually active or for those with sexually transmitted infections. As such, these youth centers were seen as unappealing, particularly for girls for whom premarital sexual activity is not culturally accepted. Youth programs operated by family planning organizations should distance themselves from the parent organization in order to avoid this stigma.

Moreover, the hours and days of operation were often not convenient to youth; these are often regular business hours when most young people are in school or involved in income-generating activities. Only a small minority of clients of the youth centers was aware that reproductive health services were available at the facilities because they were often viewed as recreational centers. Such multipurpose centers need to take a "no missed opportunity" approach to integrating reproductive health messages with recreational activities or other activities used to attract adolescents to facilities.

In addition, youth center approaches have been found to be extremely expensive and unsustainable, given the small number of young people and the level of occupancy and training costs.

Because most young people are concerned with education, employment and livelihood opportunities and not primarily with recreation, the youth centers run by the Planned Parenthood Association of Ghana are using library and career services to draw young people to the centers. Preliminary evidence from these centers reveals that parents of adolescents are also more amenable to adolescents going to centers for these services rather than for recreation. 


\section{Peer Educators}

Peer educators in Kenya were often found to be judgmental and conservative in their attitudes toward premarital sex and provision of contraceptives to young people. While they were quite knowledgeable about HIV/AIDS and STIs, they lacked communication skills and knowledge of fertility and family planning. Given that many youth programs utilize lay people to deliver information and services, special attention needs to be paid to addressing attitudes and quality of information provided by peer educators.

Peer educators in the IPPF-affiliate program in Botswana felt that they had not been adequately prepared to handle critical situations arising during their daily work. They also indicated a need for more training in being able to organize their peers, for example, in inter-personal communications and group dynamics.

The central role of the peer educators in the Zambia program was the sale of condoms to youth. The evaluation of this approach showed that one third of the agents did not like doing this. Because of the lack of disposable income of most youth, the agents resorted to giving condoms for free (thereby forsaking their profit) rather than allowing their clients to have unprotected intercourse.

Peer educator programs seem to have significant impact on the behavior of the educators themselves. In Zambia, 94 per cent of peer educators reported that they are practicing safer sex since they became involved in the program.

\section{Micro-credit}

An innovative approach to reaching out-of-school adolescents was tested in Zambia. More than 220 youth were formed into credit and savings groups, given a 14-hour course in small business skills and sexual and reproductive health, and given a loan of 100,000 kwacha (approximately US\$67) to invest in a new or existing business, mostly small-scale vending activities. The objective of this intervention was to encourage safer sex behavior through the introduction of skills that promote a more positive view of one's self and one's future.

For a variety of reasons, the intervention was only partially successful. Repayment rates were extremely low, and frequently the loan was spent on non-business activities (such as relatives' school fees and funerals) or was stolen by family or friends.

However, almost half of the recipients felt that the experi-

"..While young people in Kenya generally had confidence in the knowledge of peer educators, less than half of the adolescents interviewed (42 per cent) felt that the peer educator would keep information confidential and only a slight majority of the clients in Zimbabwe felt that counselors would keep information confidential..." ence had changed their plans for the future, and valuable lessons were learned that have been incorporated by CARE into its on-going youth micro-credit schemes.

The intervention appears to have had some limited effect in encouraging the practice of safer sex (i.e. through fewer sexual partners, more condom use and better health seeking behavior), but 
the differences between experimental and control groups were not significant.

\section{Reaching adolescents more effectively}

Youth involvement in the design and implementation of programs has long been considered an important element in the success of youth programs; unfortunately, their involvement has rarely been meaningful. In Zambia, however, the Participatory Learning Approach (PLA) has been used successfully as means of including youth in the designing, planning and evaluation of programs.

Adolescent reproductive health information and services is a sensitive issue in most communities. As such, gatekeepers (including parents, communities and religious bodies) need to be involved in program planning and to develop program "ownership" to the greatest extent possible. This has not been the case in most programs and, as a result, they risk opposition and rejection in the communities in which they operate.

Adolescent boys and girls experience very different social pressures and expectations associated with sexual behavior. Efforts to consider the distinctive social context and needs of boys and girls have been limited. Program planners need to re-orient thinking to take into account the gender specific social context of sexual activity and reproductive behavior for adolescents.

The few programs for adolescents that have been systematically evaluated reveal that they are sorely lacking in quality of care. Special attention needs to be paid to both defining what constitutes quality care for adolescents and ensuring that programs meet these standards.

Situation Analysis studies have shown that many service providers disapprove of providing RH services to youth. For example, many providers take it upon themselves to restrict access to different family planning methods by age and marital status, even when these restrictions are not part of national guidelines. 


\section{Resources Available from the Africa OR/TA Project II on Reaching Adolescents}

Fetters, Tamara and Gladys Nkhama. 1997. Using peer support to encourage contraceptive method use and continuation in Zambia. Paper presented at the $125^{\text {th }}$ annual meeting of the American Public Health Association, Indianapolis, Indiana, 9-13 November.

Fetters, Tamara, Evans Mupela, and Naomi Rutenberg. 1998. Youth Talk About Sexuality. A Participatory Assessment of Adolescent Sexual and Reproductive Health in Lusaka, Zambia. CARE/Zambia and Population Council. Nairobi, Kenya. August.

Fetters, Tamara, Fines Mukonze, and Julie Solo 1999. Investing in Youth: Testing Community Based Approaches for Improving Adolescent Sexual and Reproductive Health. CARE/Zambia and Population Council. Lusaka, Zambia. January.

Glover, Evam Kofi, Angela Bannerman, Robert Miller, Heidi Jones, Eugene Weiss and Joanna Nerquaye-Tetteh. 1997. Adapting Reproductive Health Strategies to Adolescent Needs: Findings from Three Ghanaian Towns. Paper presented at the $125^{\text {th }}$ annual meeting of the American Public Health Association, Indianapolis, Indiana, 9-13 November.

Glover, Evam Kofi, Annabel S. Erulkar, Joana Nerquaye - Tetteh, 1998, Youth Centers in Ghana: The Planned Parenthood Association of Ghana Program. Planned Parenthood Association of Ghana and the Population Council. Population Council, Nairobi. November.

Khulumani, Pilate and Bernard Pakes. 1996. Strengthening NGOs management and service delivery capabilities: Research component of the YEP project. Health Research Unit, Ministry of Health, and the Botswana

Montsi, Mercy Rapelesega and Naomi Rutenberg. 1997. The Youth Empowerment Project: Strengthening NGO management, research and service delivery capabilities in Botswana. Population Council, Nairobi, Kenya, June.

Ouédraogo, Boukary, Inoussa Kaboré, Youssouf Ouédraogo, and Idrissa Ouédraogo. 1996. Identification des besoins spécifiques des jeunes dans le domaine de la santé sexuelle. A report of Technical Assistance provided by the Africa OR/TA Project II to the Association Burkinabè pour le Bien-Etre Familial (ABBEF), CFDS/GTZ Projet, Formation et Recherche Action. Ouagadougou, Burkina Faso, August

Pakes, Bernard. 1996. Strengthening NGOs management and service delivery capabilities: Management component of the YEP project. Botswana National Productivity Center, Gaborone, Botswana, November. 


\section{Strengthening the Role of Men as Partners in Reproductive Health}

Men's reproductive choices and sexual behaviors affect both their own health and that of their partners. A man's views of fertility and family planning can influence his partner's attitudes and her access to services thereby determining the timing and number of pregnancies that she may have. A man's sexual practices may not only put him but also his partner at risk of sexually transmitted infections, including HIV. Whether or not he seeks and obtains treatment for his own infection usually determines whether or not his partner also receives treatment.

In order to address both men's and women's reproductive health needs, it is essential for program managers to understand the many factors influencing men's attitudes and behavior, and their use of reproductive health services. Men-like women-have a right to high quality services which respond to their needs. Addressing men's needs is also important as a way of meeting women's reproductive health needs because men can create barriers or opportunities for women seeking health care services. Ensuring that reproductive health services are "male-friendly" may result also in better services for women.

The following activities concerning the role of men were supported by the Africa OR/TA Project II:

- A study undertaken in Kenya by the Africa Population and Health Policy Research Centre collected information from men and women and from clinic staff on men's perceptions of family planning, STIs/HIV and including men in reproductive health services.

- A study in Tanzania with Marie Stopes International evaluated the effect of four vasectomy promotion interventions on knowledge, attitudes and behavior among men in Dar-es-Salaam.

- In Burkina Faso, the role of men in antenatal and infant care practices was assessed through qualitative research ". a man's views of fertility and family planning can influence his partner's attitudes and access to services. A man's sexual practices may not only put him but also his partner at risk of sexually transmitted infections, including HIV.." methods. 
- In Zambia, a study used qualitative methods to better understand the way in which the HIV epidemic influences reproductive and contraceptive decision-making.

\section{Male Involvement in Family Planning}

When asked, the majority of men interviewed in all of the studies maintain that they should decide on reproductive issues within the family. However, they also frequently believe that family planning is a woman's responsibility because:

- Men do not have sufficient information about family planning methods, how they work, their side effects and how they affect future fertility;

- Men lack a choice of methods that they can use. The condom is often seen as a method for use outside of regular partnerships, and vasectomy is viewed by many as a loss of manhood. Moreover, some female methods are thought to make women "hot", which causes them to be promiscuous, or "cold" which leads to a loss of interest in sex;

- Men are generally excluded from existing reproductive health services, including family planning, antenatal care or postabortion care;

- Some men recognize that, because it is the woman who suffers method side effects and/or too closely spaced or too many pregnancies, allowing her to choose the method that works best for her empowers her to control these associated problems.

"... You will give your wife the priority to decide which way to choose because she is the one who understands her body well". (participant at a focus group discussion with married men, Kakamega, Kenya).

Perceptions among men concerning their role in practicing family planning vary widely, however. In particular, urban-rural differences were apparent in these stud-

Use of Family Planning by men and their partners in Dar es Salaam

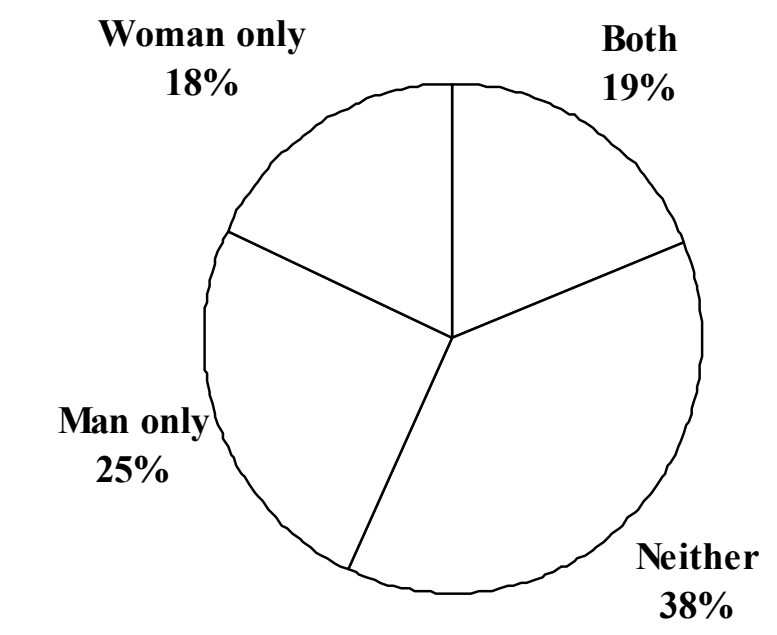
ies.

For example, many men in Dar es Salaam, Tanzania, reported currently using a family planning method themselves, whereas most men interviewed in rural western Kenya were opposed to family planning, associating its use with infidelity and loss of control over their wives. 


\section{Men and STIs/HIV}

Men interviewed in rural western Kenya were not particularly concerned about STIs other than HIV. They appear to know that STIs are treatable and the threat of STIs to their health is overshadowed by the risk of acquiring HIV/AIDS. Concern about STIs appears to be related also to the availability of treatment. Thus men in Kakamega town who had relatively easy access to treatment were less concerned about STIs than men in rural areas of Kakamega who had limited options for treatment.

Men and women recognize that it is generally the male partner who is responsible for STIs in women. While most men know that they should seek diagnosis and treatment for an STI, many do not. They report that this is because providers in public facilities have a negative attitude and can be abusive, and the costs of private facilities are unaffordable to many.

Men are generally reluctant to tell their partners that they are infected, although some men infected with STIs recognize the obligation to get treatment and will broach the subject for discussion. Infection with an STI means infidelity, and raising the issue is seen as synonymous with announcing lack of trust. It also opens the door for retaliation. However, sometimes the infidelity is already known, and so admitting to an STI and seeking treatment is acceptable.

In some cultural settings, sexuality (and thus STIs) is not seen as a "respectable" topic for discussion by a couple. It is also recognized that couples discuss STIs more easily when there is a loving, trusting relationship. Such discussions are more likely to be about prevention through mutual faithfulness.

Some common responses to dealing with STIs as reported by men and women in Kakamega District of western Kenya include:

- Not disclosing the STD to the partner;

- Feigning a more acceptable illness;

- Seeking treatment secretly;

- Getting treatment for the partner, but packaging the medication as for a different disease;

- Avoiding sex until cured.

As would be expected, men's perceptions of the prevalence of and their risk of infection HIV/AIDS varies in different settings. Men in Kakamega District were unsure of the prevalence of HIV/AIDS and of their own risk of infection. They tended to be fatalistic about contracting the disease because "one has to die of something".

Men who knew or believed that they were infected with HIV often denied their status. There were anecdotal reports of men who increased their sexual activity to hide their status or to "create company in death". 
Moreover, many men feared that their wife would desert them if they found out they were HIV-positive; they indicated that they would be reluctant to inform their partners. When asked, however, most women said that they would stay with their partners. In contrast, men interviewed in Ndola, Zambia, did perceive HIV as a threat to almost everyone because of the perceived high levels of promiscuity in their community (Ndola is in the copper mining area of the country and has a large population of commercial sex workers).

\section{How Can "Male-Friendly" Reproductive Health Services be Organized?}

Men interviewed in Kenya and Zambia, male adolescents interviewed in Lusaka, Zambia, and male 'mystery clients' visiting clinics in Dar es Salaam, Tanzania, all listed a number of difficulties they encountered when accessing reproductive health services.

These included:

- Poor access to services, being physically inaccessible or inconveniently located;

- Service hours usually inconvenient for employed men;

- Lack of privacy at facilities;

- $\mathrm{MCH} / \mathrm{FP}$ clinics are seen as places for women only;

- Unfriendly and unhelpful providers;

- High cost of consultations, treatment and vasectomy services and condoms;

- Lack of information and choice of services;

- Inadequate information about family planning and STIs for men;

- Lack of choice of methods for men to use;

- Concern about side effects.

The study in Dar-es-Salaam, Tanzania focused on providing vasectomy. The results indicated that a mass media campaign through radio, newspapers, and talks given to men at their workplace effectively reached a large proportion (60 per cent) of the male population. The campaign could reduced somewhat the general misperception that vasectomy was equivalent to castration.

It also showed that, with sufficient and appropriate information, some men would be willing to have the procedure. However, the study also showed that it is essential to complement such a campaign with an improvement in access to and quality of the vasectomy services offered.

Many providers had not been adequately trained in counseling, and were found to be giving misinformation or had prejudiced views. Moreover, most facilities lacked privacy and a conducive atmosphere for discussing what is still a very sensitive topic. 


\section{Making Services "Male-friendly"}

Data collected from men and women in these studies suggest that a program offering male-friendly information and services should seek to do the following:

- Provide information to men about contraceptive methods, signs and symptoms of STIs and which helps them assess their risk of HIV infection;

- Be youth-friendly as well, to reach male adolescents;

- Offer services not only for men and women independently, but also for couples:

- Expand availability of male methods;

- Offer services to diagnose and treat STIs and prevent HIV:

- Reach wives for STD treatment through their partners;

- Promote condom use at all times, at least with partners other than spouse:

- Address stigma around HIV that blocks efforts at HIV prevention and prevents infected people from getting care;

- Help infected individuals live positively with HIV.

A COPE exercise undertaken in clinics in western Kenya revealed the following activities that providers indicated they would need to be able to offer quality services reproductive health services for men as well as women:

- Updates on developments in men's reproductive health service delivery:

- More male providers;

- More space in existing clinics to accommodate male clients;

- Training and support to provide vasectomy;

- Regular condom supplies:

- IEC materials aimed at men;

- Counseling skills for dealing with couple conflict resolution. 


\section{Resources Available from the Africa OR/TA Project on Strengthening the Role of Men as Partners}

Fapohunda, Bolaji and Rutenberg, Naomi. 1999. Enhancing The Role of Men's Participation In Reproductive Health In Kenya, Africa Population Policy Research Center and Africa OR/TA Project II, Population Council, Nairobi, Kenya. January.

FPAK and Africa OR/TA Project II. 1995. Increasing Male Involvement in FPAK's Family Planning Program, Kenya.

Kaboreé, Inoussa, Placide Tapsoba, Diouraté Sanogo, Paul Nebié, and Ernest Dabiré. 1998. Implication des hommes dans les services de santé de la reproduction dans la zone du Laboratoire de Santé Communautaire du Bazega, Burkina Faso. Paper presented at the "Premiére Conférence de l'Afrique Francophone sur la Participation des Hommes ^ la Santé de la Reproduction.” Ouagadougou, Burkina Faso, 30 March-3 April.

Laboratoire de Santé Comunautaire. 1998. Evaluation de la prise en charge de la Maternité Sans Risque et de la Survie de l'Enfant au niveau communautaire du Bazéga, Series Documentaire No. 20, Laboratoire de Santé Communautaire du Bazéga, Ouagadougou, Burkina Faso. December.

Muhondwa, Eustace and Naomi Rutenberg. 1997. Effects of the Vasec Tomy Promotion Project On Knowledge, Attitudes, And Behaviour Among Men In Dar Es Salaam, Tanzania. Africa OR/TA Project II, Population Council, Nairobi, Kenya. September.

Muhondwa, Eustace, Naomi Rutenberg, and Grace Lusiola. 1996. The effects of a vasectomy promotion project on knowledge, attitudes, and behavior among men in Dar-esSalaam. Paper presented at the annual meeting of the American Public Health Association, New York, New York, 17-21 November.

Ndeti, Cecilia, Gilbert Magiri, Jacqueline Mundy, et al. 1995. Increasing male involvement in a CBD program in Kenya. Paper presented at the annual meeting of the American Public Health Association, San Diego, CA, 29 October-2 November.

Rutenberg, Naomi, Ann Biddlecom, Fred Kaona and Kathleen Siachitema. 1997. Reproductive decision-making in the context of HIV/AIDS in Zambia.Paper presented at the annual Population Association of America Meeting, Washington, D.C., 27-29 March.

Rutenberg, Naomi, Ann Biddlecom, and Fred Kaona. 1999.

Reproductive decision making in the context of HIV/AIDS in Ndola, Zambia. Africa OR/TA Project II, Population Council, Nairobi, Kenya. February. 


\section{Introducing Emergency}

\section{Contraception to Expand Method Choice}

The last five years have witnessed a dramatic upsurge in interest over the potential role of emergency contraception (EC) as a means of reducing unwanted pregnancy, limiting the need for unsafe abortion, and providing better services for rape victims. Though in use since the 1960's, the last three years have seen the establishment of an international consortium on $\mathrm{EC}$, the development of innovative training curricula and IEC materials, the implementation of more aggressive strategies for marketing emergency contraceptive pills (ECP) and the publication of a plethora of articles and newsletters on the delivery of EC services.

While these developments have contributed greatly to our knowledge about EC, applying this new knowledge to developing country situations has been difficult. Most research on EC has been derived from experience gathered in the developed world. Few developing countries have dedicated EC products, and provider knowledge of EC is limited.

Developing countries also present numerous operational constraints that limit their ability to use as a blueprint, service delivery models developed in Europe or North America. Perhaps most critical of all, the post-coital nature of EC makes it difficult to develop new service delivery models based solely on the experience of traditional family planning programs.

The Africa OR/TA Project II supported an operations research approach in Zambia that allowed the country to 1) gain first-hand experience with the delivery of EC services; 2) identify operational issues most relevant to the country's particular needs and service delivery environment; 3) propose strategies for overcoming these difficulties and 4) test problem solving strategies through individual $O R$ studies.

\section{Introducing Emergency Contraception in Zambia}

Introducing EC into a service delivery setting can present many uncertainties. One of these is knowing how best to enhance accessibility, not only to the contraceptive product itself, but also to the information a user must have before she will seek out the product. Another is product administration and dispensing, specifically, the implications on accessibility and efficacy of prophylactic distribution of emergency contraceptive pills; as well as the 
consequences of dispensing dedicated products rather than the cutting up of existing pill cycles.

Other issues include the identification of appropriate strategies for managing side effects, encouraging the transition from EC to routine use of family planning methods and training a potentially wide range of service providers.

A 1995 WHO-sponsored assessment of contraceptive needs in Zambia concluded that EC could play a critical role in reducing the need for unsafe abortion and in lowering rates of maternal mortality and morbidity. With no previous experience in the delivery of EC services, the potential difficulties facing Zambia were unclear. Consequently, Lusaka's University Teaching Hospital launched an OR study to explore more closely the range of issues relating to EC within a developing country context. The study comprised two phases:

- An exploratory phase in which family planning providers accumulated enough first-hand experience to identify strategies for overcoming potential difficulties associated with the introduction or delivery of EC services.

- An experimental phase of targeted interventions designed to test specific problem-solving strategies identified during the exploratory phase.

Data were collected through: interviews with clients attending the hospital for legal abortions; surveys among health care providers and clients of $\mathrm{MCH} / \mathrm{FP}$ services; focus group discussions among university students; and from client history records established for all women receiving EC. The key findings are as follows.

\section{Access to Emergency Contraception Services}

Physical access to EC varies greatly with factors such as age, conjugal status and even prior use of family planning methods. Women receiving EC in clinic-based settings had a mean age of 29 years, an average of 2.9 previous pregnancies. Furthermore, 59 per cent reported using some form of contraception at the time they had unprotected sex. This suggests that potential demand for EC is broad and is not restricted to young people, unmarried women or non-users of family planning.

Most messages advertising the availability of EC assume that women will readily identify the risk associated with a single act of unprotected sex and respond in an appropriate manner. However, of 263 abortion clients interviewed, over three-quarters had had absolutely no idea they might become pregnant at the time, and 14 per cent could not identify the act of sexual intercourse that led to their pregnancy. Those most likely to suspect pregnancy were women who had used family planning at some point in the past, but not on the particular occasion they had had unprotected sex.

Women need to have access to ECP within 72 hours of unprotected sex for it to be effective. During the second, experimental 
phase of the study, two approaches to maximizing access within 72 hours were tested and compared:

- Prophylactic distribution: Commonly used in developed countries, ECP is provided to the woman at the time she obtains her regular contraceptive method, before it is ever needed.

Advanced prescription: Prescriptions for the pills are provided at the time of obtaining the regular method, which can be redeemed anonymously when needed.

Both strategies were found to be equally likely to enhance recall of the time frame within which emergency contraception must be initiated; the number of ECPs needed; the frequency with which they should be taken; the brand-name of the emergency contraception pill and the location where it could be obtained.

What these findings suggest, therefore, is that fears over inadequate client knowledge or potential recall should not serve as a basis for doubting the safety or practicality of dispensing ECPs, either prophylactically or under advanced prescription.

For prophylactic distribution, loss by individuals was fairly minimal: only 10 per cent of the women who did not use their ECPs had lost them. But because fewer than half of the women provided ECPs in advance had used them within three months, loss to the system of unused packets could be considered significant.

Advanced prescription saw higher losses of the prescription cards themselves, but because those women who redeemed their prescriptions actually used the product, the loss to the system was minimal.

Providing pills prophylactically dramatically increased timely access. Nearly 80 per cent of EC users who received their pills ahead of time, took their first dose within 24 hours compared to only 40 per cent of those women who received the prescription card.

This is an important finding in light of new research suggesting that the effectiveness of EC is greater the earlier it is begun after unprotected sex.

\section{Time Interval Between Unprotected Sex and Administration of Emergency Contraception}

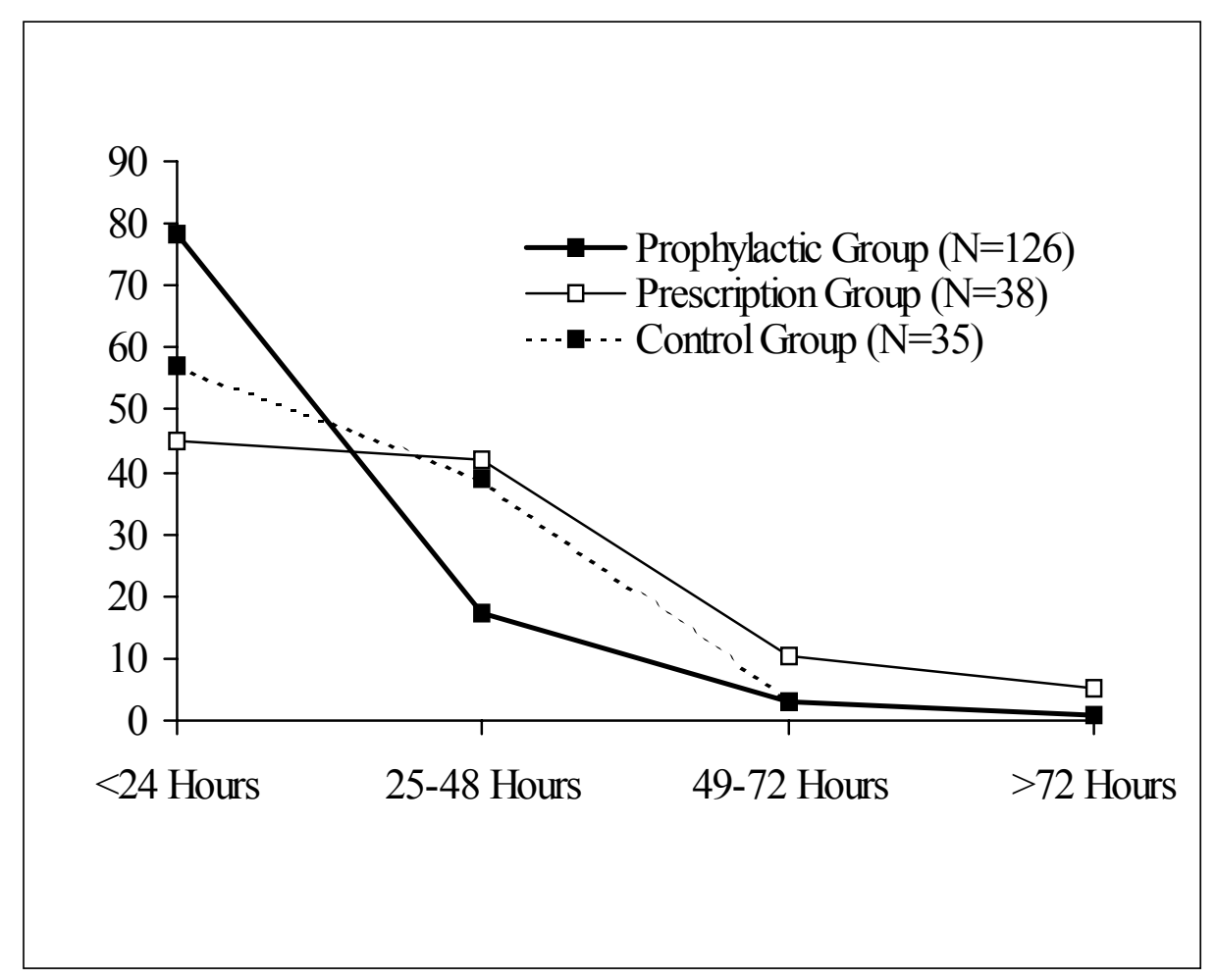




\section{Does Use of Emergency Contraception Encourage Women to Abandon Routine Family Planning Methods?}

Initially, service providers were skeptical of "prophylactic" provision, arguing that it would encourage women to abandon their regular family planning methods. As can be seen, women receiving ECP prophylactically did indeed end up using them more often than did either those who re-

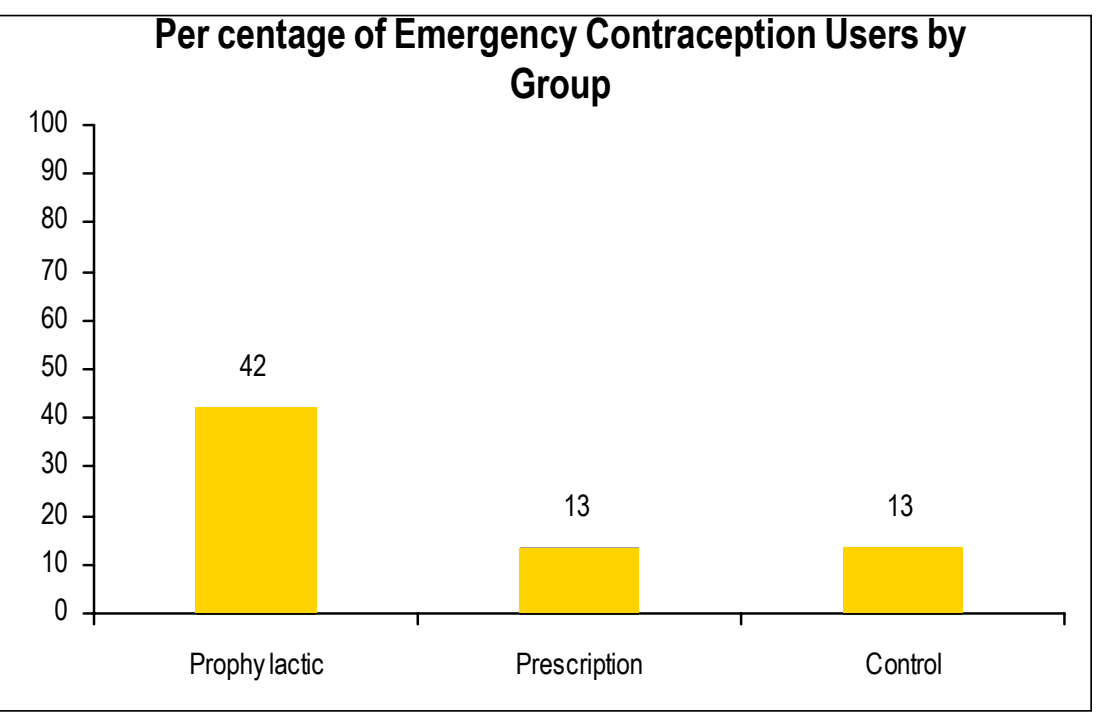
ceived prescriptions or those in a control group who received only general counselling.

But it appears, based on focus group discussions, that a number of factors contributed to their higher use of EC. Some women clearly did abandon more routine methods; they cited pressure from their partners; the perception that EC was "stronger" (and/or "less fallible") than their routine method or simple curiosity. Others however, used EC because of method failure or misuse - a seemingly common phenomenon across all three groups. Under these circumstances, those in the prophylactic group were more likely to use emergency contraceptive pills because they were the only ones in a position to benefit from already having them on hand.

\section{Does use of Emergency Contraception Encourage the Adoption of more Effective Family Planning Methods?}

While many routine family planning users seem attracted to the apparent convenience of EC, non-routine family planning users who have used EC are virtually unanimous in wanting to begin using family planning immediately after. Of the non-family

Rejection of barrier methods by family planning users after use of PC-4

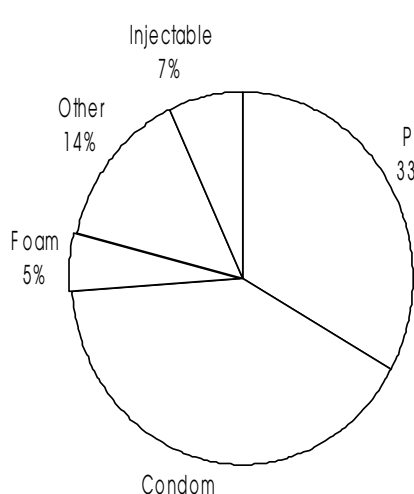

$41 \%$ planning users who received EC, over 90 per cent eventually chose to adopt a routine family planning method.

Moreover, the methods they chose were notable for their efficacy: pills, the IUD, injectables and Norplant $\AA$ implants represented over 92 per cent of the methods used. Even among regular family planners, the use of EC is strongly associated with the adoption of a more effective contraception after the experience. 
As encouraging as these trends may be from a fertility regulation perspective, concern is growing over the fact that the switch to more effective pregnancy avoidance may be occurring at the expense of barrier methods that prevent infections. Given the importance of condom use and other barrier methods for the prevention of STIs and HIV, these findings suggest that efforts to promote dual protection should be reinforced.

\section{Is Routine Follow-up of Emergency Contraception Users Necessary?}

There is no indication that the side effects associated with use of emergency contraception warrant routine follow-up. Consequently, doubts or concerns over the feasibility of client follow-up should not, at least on medical grounds, play a role in hindering or limiting the provision of emergency contraception services.

Though the range and severity of side effects associated with the use of EC in Zambia were comparable to findings cited elsewhere, in the eyes of many participating health care providers, they were still high. Indeed, over 85 per cent of all EC users experienced at least some side-effect. Consequently, an OR study was implemented to compare the service delivery implications of providing a progestin-only pill known to reduce levels of side-effects (Postinor-2), versus the combined pill (PC-4). As can be seen, the use of Postinor-2 reduced the level of side-effects by halving levels of nausea and virtually eliminating vomiting altogether.

Although the results of this study highlighted important distinctions in side effects between the two products, from a service delivery level, the similarities far outweighed any differences between them. Family planning users adopted both products at comparable rates and, after having used them, manifested few if any differences in their appreciation of either one, in their decision to adopt a family planning method or in their choice of method.

Whichever product Zambia's regulatory agencies eventually choose to adopt, they can at least build confidence on a common body of service delivery information accumulated since the introduction of $P C-4$.

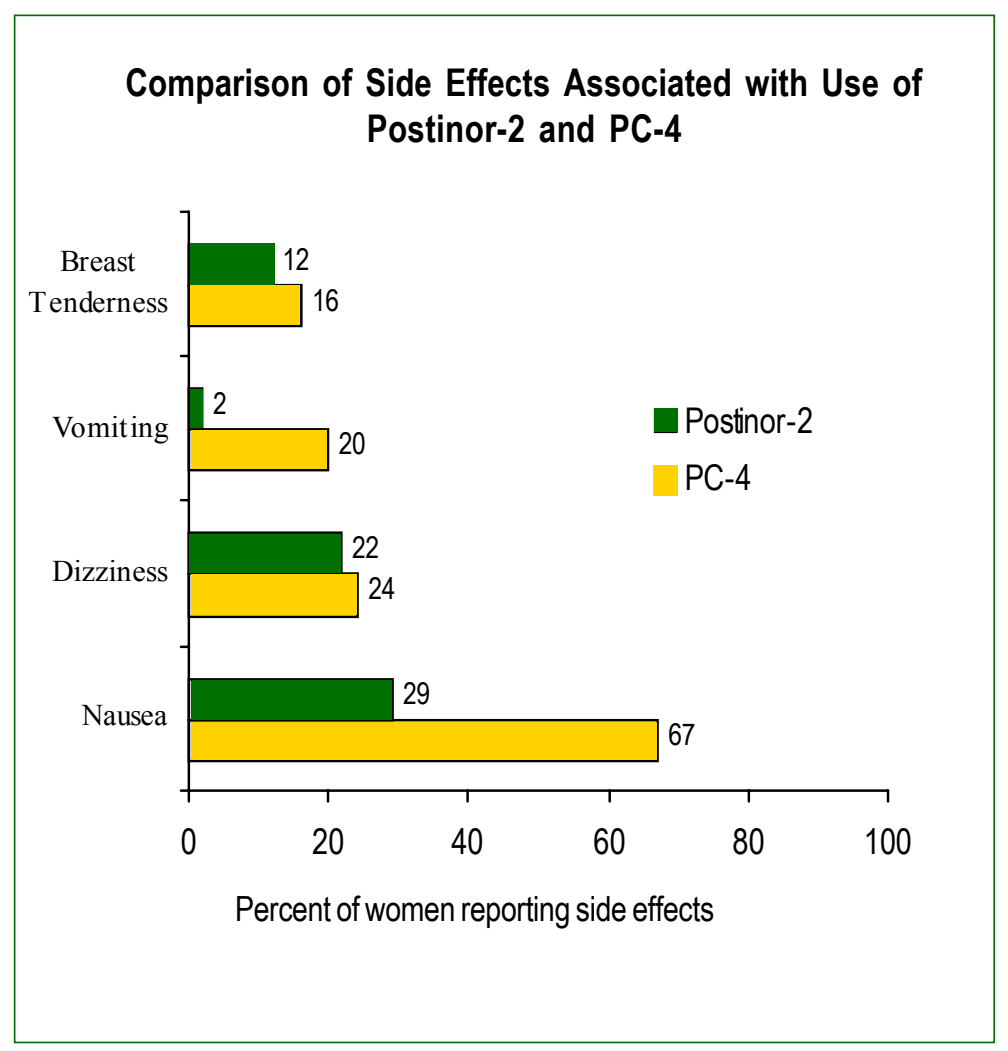




\section{How has Operations Research facilitated the Introduction of Emergency Contraception?}

In the short time since the start-up of this study, emergency contraception has been introduced in more than 25 health care facilities across Lusaka and the rural Copperbelt. To date, over 1,500 women have received emergency contraception pills (ECPs) and many thousands more have been informed about it as the only means available to prevent unwanted pregnancies after unprotected intercourse.

Although no effort was ever made to publicize the availability of emergency contraception beyond the original 25 clinics, distribution of ECPs has clearly increased over the last 16 months. The method has even established itself within the marketplace, with reports of pharmacies and drug venders charging up to 10,000 Kwacha per packet (approximately US\$4.25) - nearly 20 times the price of the leading socially marketed brand of oral contraceptives. Even at the health center level, distribution of ECPs has expanded beyond the sites originally affiliated with this project. Accounts of emergency contraception usage have been reported as far away as Livingstone and Kabwe.

In addition to greater utilization of emergency contraception, knowledge about the product has particularly expanded among health care providers. Prior to the introduction of the method, 89 providers were trained in emergency contraception at three separate one-day workshops. All of these individuals returned to their respective health centers where many, through routine procurement channels, obtained ECPs and began providing them to their clients.

\section{Resources Available from the Africa OR/TA Project on Introducing Emergency Contraception}

Ahmed, Y., M Ketata and J P Skibiak 1998. Emergency Contraception in Zambia: Setting a New Agenda for Research and Action, Africa OR/TA Project II, Population Council, Nairobi, Kenya.

Ahmed Y., M. Ketata, and J.P. Skibiak. 1999. Comparing Alternative Products in the Provision of Emergency Contraception, Africa OR/TA Project II, Population Council, Nairobi, Kenya.

Skibiak, John P. et al. 1997. Emergency Contraception: Searching For New Solutions. Paper presented at the 125th Annual Meeting and Exhibition of the American Public Health Association. Indianapolis, USA, November.

Skibiak, John P., Y. Ahmed and M. Ketata. 1999. Testing Strategies to Improve Access to Emergency Contraception Pills: Prescription vs. Prophylactic Distribution. Africa OR/TA II Project, Population Council, Nairobi, Kenya. 


\section{Female Genital Cutting}

Female Genital Cutting (FGC) describes a group of practices that involves the partial or complete removal of the clitoris and/or external female genital organs for cultural or other nontherapeutic reasons. The terms Female Genital Mutilation (FGM) or female circumcision are also used. These practices are prevalent in many African ethnic and religious groups.

The reasons justifying FGC are based on various traditional beliefs such as the preservation of cultural and female identities through principles of twinning of human beings and as protection against curses; religion, through a perceived Islamic recommendation; the control of sexuality by preserving a girl's virginity and ensuring women's faithfulness; and social conformity.

The repercussions of this practice are numerous, particularly the potential health-related consequences. To counter the practice, women's associations and NGOs have organized IEC interventions among communities, traditional circumcisors and medical personnel. United Nations agencies, as well as USAID, other donors and numerous NGOs have made FGC one of their priority concerns. Many African governments have developed policies and laws aimed at the elimination of FGC. The Africa OR/TA Project II was requested to develop a program of activities that would increase understanding of the practice in West Africa, and of some of the interventions that are being taken to reduce it.

\section{Activities Under the Africa OR/TA Project II}

\begin{tabular}{|c|c|}
\hline Country & Study Description \\
\hline \multirow[t]{4}{*}{ Burkina Faso } & $\begin{array}{l}\text { Measuring the prevalence, typology and complications associated with } \\
\text { FGC among clients attending clinics in Bazega, Burkina Faso }\end{array}$ \\
\hline & $\begin{array}{l}\text { A participatory approach to designing a community-based } \\
\text { intervention to address } F G C\end{array}$ \\
\hline & A qualitative study on attitudes towards female circumcision \\
\hline & $\begin{array}{l}\text { A quantitative survey in Bazega Province on practices and } \\
\text { attitudes }\end{array}$ \\
\hline Ghana & $\begin{array}{l}\text { A quantitative survey in Kassena-Nankana district on practices } \\
\text { and attitudes }\end{array}$ \\
\hline \multirow[t]{4}{*}{ Mali } & $\begin{array}{l}\text { Testing the effectiveness of training health facility staff in client } \\
\text { education about FGC and clinical treatment of FGC } \\
\text { complicatons }\end{array}$ \\
\hline & Evaluation of a strategy to "convert" traditional circumcisors \\
\hline & Literature review of FGC in Mali \\
\hline & National seminar for defining a strategy to eradicate $F G C$ \\
\hline Senegal & Description of NGO anti-FGC intervention \\
\hline
\end{tabular}


In addition, in January 1997, Project staff collaborated with the international organization, Rainbow, to organize and implement a regional workshop in Ouagadougou, Burkina Faso, on research and advocacy activities in the region. The workshop was attended by participants from countries throughout the Sahelian region.

The key points emerging from this four-day workshop included:

- The need for an assessment of the reliability of available statistics on the practice of FGC in the region;

- A strong commitment by all participants to combating any kind or type of FGC;

- The desire of all participants to develop a "concerted strategy" for eradicating FGM;

- The need to develop a manual on women's rights regarding such harmful practices;

- A strong interest in creating a "bulletin" to link those working within the region.

Priority was given to a request for a regional training workshop on operations research as applied to FGM for staff from the participating institutions. A need was also expressed to encourage more research on evaluating the impact of interventions conducted for behavior change.

\section{Prevalence of FGC in Sahelian Countries}

Two OR studies measured the presence of genital cutting for all women having a pelvic examination during their visits to the 21 health centers of Bazèga province in Burkina Faso, and in seven health centers in the regions of Bla and Bamako in Mali. In both studies, over 90 per cent of all women examined had been cut.

Results from population surveys, such as the DHS, have shown that FGC is practiced by a significant proportion of the population in Sahelian countries:

- Mali - 94\%:

- Guinea - 90\%:

- Burkina Faso - 80\%:

- Northern Ghana - 77\%;

- Côte d'Ivoire - 43\%:

- Senegal - $20 \%$
In countries where prevalence of FGC is not universal, the likelihood of a women having undergone the procedure is usually associated with her ethnic background. For example, in Burkina Faso, the probability of being circumcised is three times higher among the Mossi, and twice as high for Muslim girls. In northern Ghana, the highest rates are found among practitioners of traditional animist religions. Schooling beyond the primary level appears to reduce the likelihood of a girl being cut.

The age at which girls are cut varies, depending to a large extent on the reasons for the practice. In northern Ghana, girls are cut at around age 17 years as a rite of passage to woman- 
hood, whereas in Burkina Faso the mean age is around nine years, and in Mali it is around six years. As can be seen, the age at which girls are cut is getting lower in Mali, a trend found also in northern Ghana and in Kenya, but not in Burkina Faso.

\section{Complications Associated with FGC}

In addition to the immediate trauma suffered by girls undergoing FGC, it is frequently asserted that many women suffer longer-term complications as a result of the procedure. The two OR studies in Burkina Faso and Mali that included observations of women's genitalia and interviews with the women were able to provide empirical evidence of the types of longer-term complications that may be suffered by women who have been cut.

\section{Visible complications}

Visible complications associated with genital cutting were found among 14 per cent of women who had been cut in the Burkina Faso study. The most common complications were keloids (62 per cent) and stenosis (20 per cent); 6 per cent of these women had vaginal

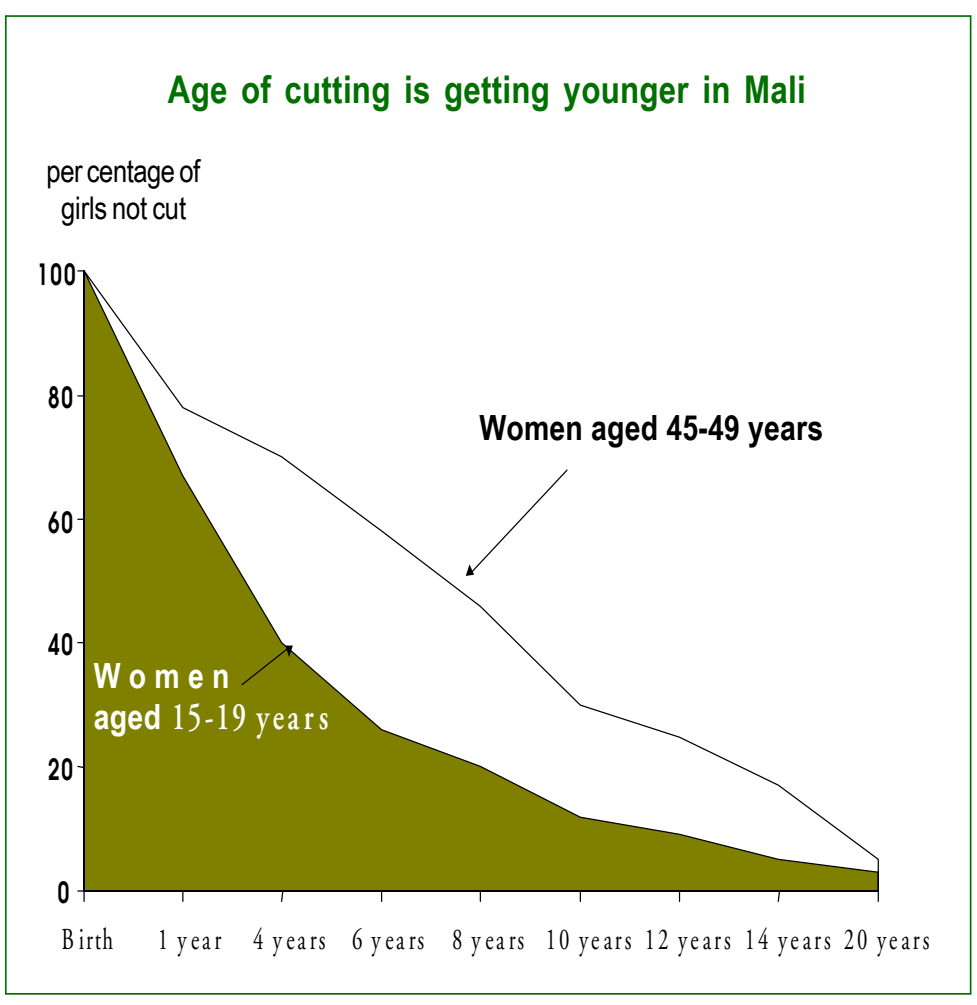
obstructions. In Mali, 5 per cent of the women who had been cut had visible complications, the most common being hemorrhaging (52 per cent), stenosis (13 per cent), vaginal obstructions ( 8 per cent) and keloids ( 7 per cent).

Women with 'type III' cutting in Mali and Burkina Faso were over two times more likely to have a visible complication than those with a 'type II' cut, and those with a 'type I' cut were significantly less likely to have a visible complication.

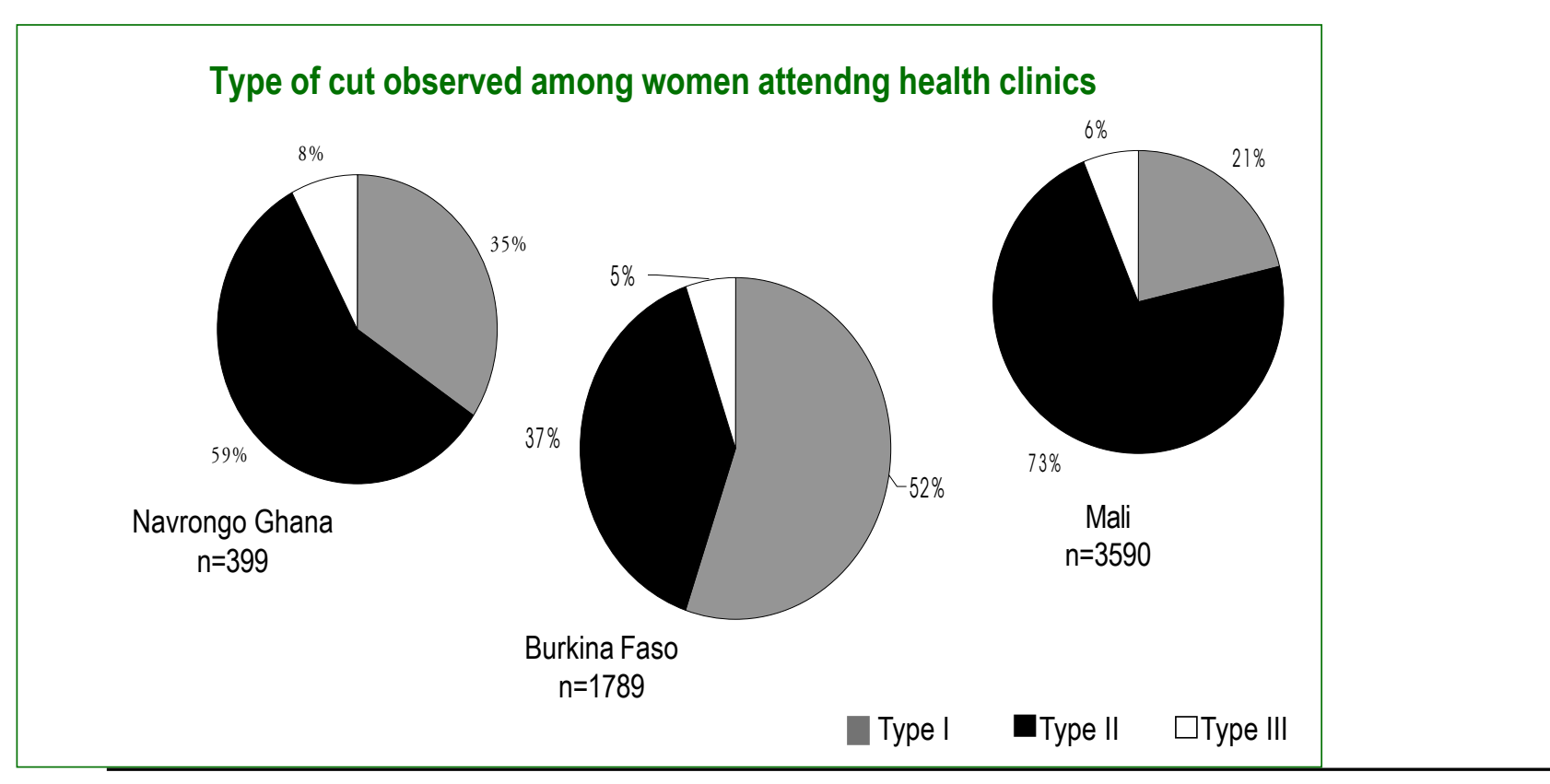


In Burkina Faso, women who were cut were over one and a half times more likely to have a genital infection than women who were not cut.

\section{Difficulties during childbirth}

Among the 2,088 women observed giving birth at clinics in Mali, 27 per cent experienced a difficulty. However, those who had been cut were more than six times more likely to experience a delivery complication, and those who had a Type II or Type III cut were 1.72 - 1.88 times more likely to have a complication than those with a Type I cut. In Burkina Faso, women were asked about their experience with previous deliveries; their responses gave simi-

Women with Type III cutting in Mali and Burkina Faso were over two times more likely to have a visible complication than those with a Type II cut, and those with a Type I cut were significantly less likely to have a visible complication. lar results to those found in Mali: being cut significantly increased the likelihood of reporting a difficulty and the severity of cut also increased (by three times) the likelihood. However, no association was found among women in Burkina Faso between being cut and having experienced a stillbirth.

\section{Attitudes and Behaviour of Clinic and Community Health Workers Concerning FGC}

Most clinic staff interviewed in Mali reacted positively towards suggestions that efforts be made to eliminate FGC. Even though 93 per cent of the female staff were circumcised themselves, 33 per cent of their daughters were not circumcised. The vast majority (87 per cent) of both male and female medical staff stated that they would not circumcise their daughters.

Many staff still support the practice, however. For example, onequarter of the clinic staff interviewed think that the Koran recommends the practice; 39 per cent think that circumcised girls are more libertine; 32 per cent that men prefer marrying circumcised women and 21 per cent that FGC is a rite of passage that makes girls more responsible. However, two-thirds of the service providers also think that FGC violates the rights of women and children.

Female genital cutting has usually been undertaken by traditional practitioners. In Mali, however, 13 per cent of clinic staff interviewed stated that FGC is practiced in their clinics, but only 4 per cent admitted having carried out at least one operation themselves. Moreover, more than a third of these clinic staff believe that if FGC is practiced in a hygienic environment, it will not affect the girl's health, and that there are no health risks when the clitoris is cut. Furthermore, 71 per cent of the women attending the clinics in Mali think that practicing circumcision in health centers is good because it can diminish health risks for the girl. 


\section{Community Views on FGC}

The studies conducted in Burkina Faso, Ghana and Mali used qualitative research methods to ascertain the main reasons to justify FGC. These included preserving one's cultural identity, respecting Islamic norms or those laid down by the ancestors; for maintaining hygiene as the clitoris is considered as a source of illness, and to control female sexuality.

A fundamental and almost universal reason is conformity to social norms, aimed at ensuring the continuation of ancestral traditional practices that confer cultural identity. In many societies, the practice has traditionally been carried out on girls of the same age-group and was followed by a period of isolation during which initiation rites were practiced. Today, female circumcision is practiced at a younger age, thus losing its value as an initiation rite.

Despite many sensitization campaigns and other interventions, the studies conducted in Burkina Faso and Mali show that most people do not recognize the harmful aspects of female circumcision, and many men and women still approve the practice. For example, in Burkina Faso, 41 per cent of men and 51 per cent of women interviewed support female circumcision despite the fact that it was recently declared illegal in the country.

Moreover, 18 per cent of the women interviewed explicitly stated that they intended to have their daughters circumcised in the future. In Mali, where the practice is not illegal, 60 per cent of the women explicitly stated that they intended to have their daughters cut in the future.

In Mali and Burkina Faso, men have not been the target of IEC campaigns. If the practice is ever to be abandoned, programs must include men in sensitization campaigns. In Burkina Faso, for example, fathers play the most important role in deciding whether to circumcise a girl, a situation recognized by both men and women.

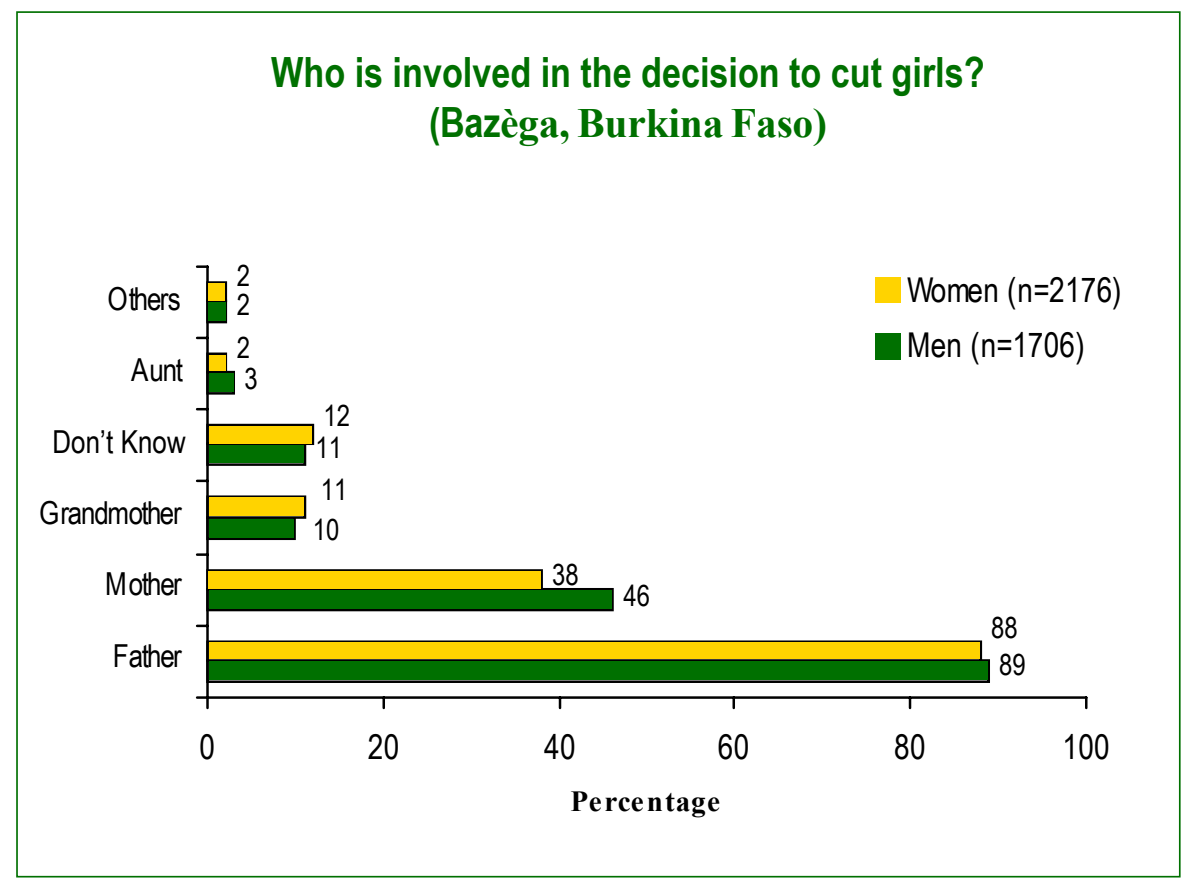




\section{To What Extent Have Interventions Currently in Place Been Able to Bring about Change?}

\section{Involvement of medical personnel in FGC education}

Following a training course for clinic staff in Mali, most health personnel dramatically increased their knowledge of FGC and its complications. They also supported the idea of IEC campaigns within their clinics for discouraging the practice. However, their communication skills remain insufficient. Even after attending a formal training course staff in only three out of seven health centers were giving group health talks on the subject, and only three per cent of providers were counseling individual clients on FGC after the intervention. Health providers are an important potential resource in any campaign to educate the public about the health complications of FGC because they have credibility when discussing health issues. A concerted effort is needed to ensure that they can become effective behavior change agents.

\section{Motivating traditional FGC practitioners to stop the practice}

Several NGOs in Mali have tried persuading traditional FGC practitioners to stop the practice through training them in alternative income-generation skills. However, this strategy appears not to have been successful as many practitioners who had claimed to have abandoned the practice were found to have taken it up again later. Many reasons contribute to the failure of this strategy, but the key reason appears to be that these traditional practitioners belong to the lowest caste in Malian society (the blacksmith caste). Consequently, they have little control over their role and are simply responding to requests for their services. Sensitization of the whole community and a general decision to abandon the practice, thus reducing demand for their services, is therefore a prerequisite to convincing traditional practitioners to abandon their activities.

\section{Legislation making the practice illegal}

Burkina Faso, Ghana and Guinea (and shortly Senegal) have passed laws that prohibit FGC, with stiff penalties for those found guilty. However, these laws have rarely, if ever, been enforced and they seem to have encouraged clandestine circumcision and cutting at an earlier age so that the practice can continue. Thus, whether a law can effectively contribute to reducing this practice is unknown, and further research is needed.

\section{Sensitization and educational campaigns on the health consequences}

IEC campaigns have been the main type of anti-FGC interventiontested by NGOs. It has been difficult to determine, however, the most important target groups. 
While efforts have been made to sensitize women through women's groups and meetings, research shows that men generally, and male opinion leaders in particular, play a key role in making decisions. In addition, IEC messages have generally not been well thought out nor sufficiently tested. Adolescents have been left out of the sensitization process, although they could prove to be the most effective target group in the long run. More attention needs to be paid to systematically testing alternative IEC strategies.

\section{Public declarations against female circumcision}

Evidence from several countries points to the importance of public statements against the practice made by opinion leaders, especially religious leaders. Such statements reinforce educational messages and give social support for a reconsideration of the practice.

In rural Senegal, this principle has been taken a step further. Female villagers, who had learned about human rights and the health consequences of FGC through a basic education program, decided that they wanted to end the practice. They then initiated a series of public discussions to extend and reinforce acceptance of the idea throughout the village. Finally, together with the men in their community, they made a public declaration that they would no longer continue the practice, a pledge that was agreed to by all members of the village.

In rural Kenya, where FGC is a rite of passage for many adolescent girls, an educational program with a special focus on mothers and their adolescent daughters led to the development of an alternative ritual to mark the transition. This ritual replaces genital cutting with other symbolic activities; in effect, a public declaration is made that the girl has successfully become a woman but has not been circumcised. 


\section{How Has Operations Research Contributed To Reducing The Practice Of FGC?}

In Mali, the Africa OR/TA Project II organized and supported a national seminar to present evidence of $F G C$ and its harmful consequences to key government and social leaders. This seminar resulted in the development of a national program of action and the following statement:

"The Commissariat à la Promotion de la Femme (CPF) has pledged today to take the fight for the sexual and reproductive health of women in Mali forward by working alongside parliamentarians and non-governmental organizations (NGOs). The widespread violation of women's bodily integrity, especially female genital mutilation (FGM), is a compelling cause for immediate and bold action."

The OR study conducted in public health facilities in Mali demonstrated that female circumcision was being undertaken in public health facilities. Immediately following the dissemination of these findings, the Minister of Health issued a circular letter to all regional directors of public health. In the letter, she ordered them to use all means available to stop the practice being carried out in their health facilities, citing it as their moral and technical responsibility. This was followed shortly afterwards by a circular letter from the Minister for the Promotion of Women, Children and the Family to all regional coordinators in the ministry and to all NGOs involved in women's rights. This letter encouraged them to communicate the Minister's instruction as widely as possible and to support the health services in implementing this policy.

A second outcome of this OR study was that the Ministry of Health created a new training curriculum and module specifically on FGC. The module is based on the training developed during the OR study and has been integrated into the Ministry's inservice reproductive health training programme for clinic staff. 


\section{Resources available from Africa OR/TA Project II on Female Genital Cutting}

Adongo, Philip, Patricia Akweongo, Fred Binka and Cheik Mbacké. 1998. Female Genital Mutilation: Socio-cultural factors that influence the practice in the KassenaNankana District. Paper presented at the annual meeting of the Population Association of America, Chicago, Illinois, 2-4 April.

Adongo, Philip, James Phillips, Beverly Kajihara, Clara Fayorsey, Cornelius Debpuur and Fred Binka. 1997. Cultural factors constraining the introduction of family planning among the Kassena-Nankana of Northern Ghana. Social Science and Medicine 45(12): 1789-1804.

Association pour le Développement des Activités de Population (ASDAP), and Direction de la Santé Familiale et Communautaire, Ministère de la Santé. 1998. Efficacité de la Formation du Personnel de Santé dans l'Education des clientes sur l'excision et la prise en charge des complication. ASDAP and Africa OR/TA Project II, Population Council, Bamako, Mali. December.

Centre National de Recherche Scientifique et Technique (CNRST). 1998. Evaluation de la Stratégie de Reconversion des Exciseuses pour l'Eradication des Mutilations Genitales Feminines au Mali. CNRST and Africa OR/TA Project II, Population Council, Bamako, Mali. December.

Commissariat à la Promotion Feminine (CPF) et Population Council. 1997. Rapport du Seminaire National pour la Definition diune Strategie d'Eradication de l'Excision au Mali. CPF and Africa OR/TA Project II, Population Council, Bamako, Mali. June

Diallo Assitan. 1998. Les Mutilations Genitales Feminines: Revue de la Litterature et des Actions menees au Mali. Africa OR/TA Project II, Population Council, Bamako, Mali. March

Diop, Nafissatou J., Annamaria Cerulli, and Diouratié Sanogo. 1996. Female circumcision in West Africa: A socio-cultural dilemma revolving around health, religion, culture and women's perceptions. Paper presented at the annual meeting of the American Public Health Association, New York, New York, 17-21 November.

Gouédé, Nicholas. 1998. Mali works to end Female Genital Mutilation. Populi 25(1): 2.

Jones, Heidi, Nafissatou Diop, Inoussa Kaboré and Ian Askew. 1999. The typology of Female Genital Cutting in Burkina Faso and Mali: Can type be linked to negative health outcomes? Paper presented at the annual meeting of the Population Association of America, New York, 25-27 March.

Heidi Jones, Nafissatou Diop, Ian Askew, Inoussa Kaboré. 1999. Studies in family planning forthcoming: Types of female genital cutting in Burkina Faso and Mali and their relationship with negative health outcomes. Originally submitted to Studies in Family Planning, March 16.

Kaboré, Inoussa, Placide Tapsoba, Diouratié Sanogo, Paul Nebié, Ernest Dabiré, Baya Banza, Georges Gueilla, Télesphore Kaboré, and Clotilde Ky. 1997. An innovative community based approach to eradicate Female Genital Mutilation in West Africa, Burkina Faso. Paper presented at the 125th annual meeting of the American Public Health Association, Indianapolis, Indiana, 9-13 November.

Kaboré, Telesphore, Inoussa Kaboré, Placide Tapsoba, and Ernest Ouedraogo. 1998. Which approach best addresses the issue of FGM in rural communities of Burkina Faso? Paper presented at the annual meeting of the American Public Health Association, Washington D.C., 15-18 November.

Kaboré, Telesphore, Inoussa Kaboré and Heidi Jones. 1999. The participatory learning approach: Designing community-based interventions to address Female Genital Mutilation in Burkina Faso. Poster presented at the annual meeting of the Population Association of America New York, 25-27 March.

Laboratoire de Santé Communautaire. 1996. Enquete Quantitative de Base. Serie documentaire No. 13, Laboratiore de Santé Communautaire du Bazèga, Ouagadougou, Burkina Faso. June.

Laboratoire de Santé Communautaire. 1998. Evaluation de la prévalence, de la typologie et des complications liées à l'excision chez les patientes fréquentant les formations sanitaires du Bazéga., Serie Documentaire No. 21, Laboratoire de Santé Communautaire du Bazèga, Ouagadougou, Burkina Faso. December. 
Laboratoire de Santé Communautaire. 1998. Etude participative pour l'Identification des Strategies Communautaires de Lutte contre la pratique de líexcision dans le Bazega. Serie Documentaire No. 22, Laboratoire de Santé Communautaire du Bazèga, Ouagadougou, Burkina Faso. December.

Ouédraogo, Ousmane, Boubacar Héma, Dénis Zongo, Batébié Zio, Soahibou Danté and Youssouf Ouédraogo. 1996. La pratique de l'excision: Données qualitatives collectées dans 19 provinces sur 15 groupes ethniques auprès de clientes et prestataires de services des formations sanitaires. Report prepared by the Africa OR/TA Project II in cooperation with the Ministère de la Santé, de l'Action Sociale et de la Famille, Ouagadougou, Burkina Faso, May.

Sanogo, Diouratié. 1997. Présentation du module MGF de l'Enquête Démographique et de Santé (EDS II). Presentation at FGM workshop, "Programme de l'Atelier National pour la Definition de Strategies d'Eradication des MGF au Mali," Commissariat à la Promotion des Femmes, Bamako, Mali, 17-19 June.

Tapsoba, Placide, Alex Nazzar, Inoussa Kabore and Jim Phillips. 1998. FGM: What are the determinants to behavior change? Findings from various appraisal techniques in Bazega, Burkina Faso and Navrongo Ghana. Paper presented at the annual meeting of the American Public Health Association, Washington D.C., 15-18 November.

Tokindang Joel et Assitan Diallo. 1997. L'excision au Mali: Une vision prospective des pratiques. Africa OR/TA Project II, Population Council, Bamako, Mali. June (unpublished paper).

Tostan. 1999. Breakthrough in Senegal: A report on the process used to end Female Genital Cutting in 31 villages. Tostan, Thies, Senegal. January. 


\section{Building Capacity for Operations Research}

Strengthening the capabilities of managers to undertake and use operations research for diagnosing and solving service delivery problems has been a major theme of the Africa OR/TA Project II. Within the region, there remains a scarcity of human and institutional resources (in both service delivery organizations and in universities) with the capacity to undertake operations research on reproductive health services.

Moreover, many reproductive health programs in the region are now beginning to use operations research as a way of informing their planning processes so that decisions can be based on empirical evidence of better practices for service delivery. Given this need both to increase the capacity of managers and researchers for undertaking operations research on reproductive health services, and to enhance the capacity of programs to perceive and to use operations research as an integral part of their planning, management and evaluation processes, the Africa OR/TA Project II supported 24 subprojects that addressed these capacity-building objectives.

The capacity-building activities supported through the Africa OR/TA Project II can be broadly categorized into two types. First, there were a number of activities that sought to strengthen the way in which operations research is carried out, by developing and improving the data collection and analysis methods used. These activities focused on the following:

- Strengthening the Situation Analysis methodology, so that it can be used to assess a broader range of reproductive health services and so that the results are communicated directly to key decision-makers;

- Applying participatory research methods to designing and evaluating reproductive health programs;

- Refining existing methods to better measure the cost-effectiveness of integrated reproductive health programs;

- Developing and testing a rapid assessment mechanism for monitoring the quality of integrated reproductive health services

- Developing and strengthening field station research capacities in Burkina Faso and Ghana.

Second, the Africa OR/TA Project II supported activities that sought to enhance the capacity of program managers and staff to take a data-based approach to decision-making, and specifically to incor- 
porate operations research as a way of generating and using such data. This category included two types of activities:

- Training in operations research and in program planning, management and evaluation through more than 25 workshops in nine countries;

- Organizational development to increase efficiency through technical assistance to individual programs in six countries.

\section{Development and Improvement of Research Methods}

\section{Strengthening the Situation Analysis methodology}

The first Africa OR/TA Project was responsible for the initial development of the Situation Analysis approach to assessing facilitylevel service delivery, and the Africa OR/TA Project II continued to play the leading role in further developing and refining the methodology.

Standardization of the approach: Standardization of the approach culminated in the Population Council publishing "The Situation Analysis Approach to Assessing Family Planning and Reproductive Health Services: A Handbook". This handbook contains an introduction to the methodology, the core data collection instruments, guidelines for training, question-by-question guides, and an analysis plan. It is intended to be used by program managers and researchers wishing to carry out a standard Situation Analysis study. About 2,400 copies of the handbook have been distributed in over 25 countries, and translations completed to make the handbook available in French and Spanish (in collaboration with the INOPAL III Project).

Synthesis of key findings: A monograph has also been produced that describes and analyzes the provision of clinic-based family planning services in sub-Saharan Africa through synthesizing and preparing comparative analyses of data collected through Situation Analysis Studies in 12 African countries.

The Population Council has published the monograph under the title "Clinic-Based Family Planning and Reproductive Health Services in Africa: Findings from Situation Analysis Studies". It is intended for program managers, donors, technical assistance organizations and researchers concerned with strengthening reproductive health services in the region.

Dissemination of the Situation Analysis approach throughout the region: An international conference was held in Nairobi, Kenya in May 1996 entitled "Strengthening the Utilization of Situation Analysis for Planning, Managing and Evaluating Reproductive Health Services" (jointly supported by the Council's Ebert Program and Programmatic Grant from USAID).

Attended by more than 70 pro gram managers, donors and researchers from several anglophone African countries, the conference sought to share and document managers' experiences with using the results from Situation Analysis studies. It also sought 
to review the concepts and definitions of quality from several perspectives, to prepare draft program-specific plans for strengthening the utilization of Situation Analysis data for management and evaluation purposes, and to review new and future directions for the Situation Analysis approach. A report of the conference is available, and many of the papers presented were published in a special edition of the African Journal of Fertility, Sexuality and Reproductive Health.

An international conference for francophone program managers on the analysis and utilization of data from Situation Analysis studies was held in Dakar, Senegal, in June 1997. The conference drew about 90 program managers, donors and researchers from ten countries and addressed the methodological approach of Situation Analysis, the treatment and analysis of data, dissemination of results and ways to increase their utilization. The conference allowed for useful region-wide discussions and resulted in several plans to carry out such studies in numerous countries. A report of the meeting is available.

Availability of data collection instruments and data sets: Repositories of the datasets and instruments for all completed Situation Analysis studies in the African region have been established. These repositories have been placed in the Project's Nairobi, Dakar and Washington offices, and with USAID/Washington and Tulane University. The data sets are in the public domain and so are available on request to anyone interested in undertaking secondary or comparative analyses.
Contents of "Clinic-Based Family Planning and Reproductive Health Services in Africa: Findings from Situation Analysis Studies" monograph:

- Indicators of readiness and quality: Basic findings: Presents the overall findings of approximately 100 indicators of the readiness and quality of family planning services in 12 countries.

- Using Situation Analysis to improve reproductive health programs: Examines how Situation Analysis is being used to assess program strengths and weaknesses, but also to evaluate changes in programs over time, and to measure the impact of interventions.

- Determinants of quality of family planning services: A case study of Kenya: Provides a detailed look at the relationship between the readiness of a facility to deliver family planning services and the quality of services received by clients.

- Unrealized quality and missed opportunities in family planning services: Examines how existing resources could be utilized more effectively to improve the quality of family planning services.

- Urban and rural family planning services: does service quality really differ? Presents findings that challenge the common expectation that urban family planning services are superior to rural services.

- How providers restrict access to family planning methods: Results from five African countries: Details the extent to which providers impose various restrictions - such as marital status, parity, and age - on women seeking family planning services, and compares these restrictions against national service protocols.

- Tests and procedures required of clients in three countries of West Africa: Reviews the requirements for laboratory tests and other medical procedures - such as blood pressure, weight taking, and pelvic exams - imposed on clients and compares these requirements against international standards.

- Integrating STI and HIV/AIDS services at MCH/FP clinics: Reviews the extent to which STI and HIV/AIDS services have been integrated with MCH/FP services, and examines the feasibility of expanding integration of services.

- Changes in quality of services over time: Compares the findings of successive studies conducted in four countries to determine how these family planning and reproductive health programs have changed in the interim.

\section{Applying Participatory Research Methods to Designing and Evaluating Reproductive Health Programs}

Operations research studies that test interventions with quasiexperimental designs have conventionally relied on questionnaire surveys to provide quantitative measures of the effect of interventions on the population receiving the services. Diagnostic studies have also relied heavily on questionnaire surveys.

Although there has been an increasing use of qualitative methods (especially focus group discussions, in-depth interviews and observations) to collect information, it is only recently that use has been made by OR studies of methods undertaken with the participation of those for whom the services are intended to benefit.

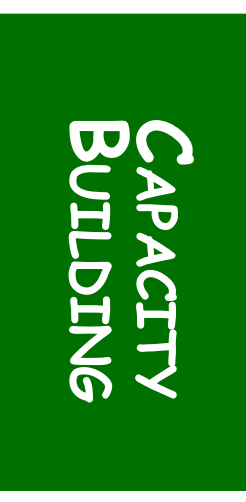


The two large-scale community-based projects implemented in Navrongo, Ghana, and Bazéga, Burkina Faso, have used participatory methods to collect information and to design their interventions so that they are acceptable to the communities, and so that communities are motivated to participate in their implementation. For a fuller description of the participatory design process followed in Navrongo, see Nazzar et al. (1995), and in Bazèga see LSC (1997).

The study to test approaches to reaching out-of-school youth in Zambia used Participatory Learning and Action (PLA) methods to develop interventions based on adolescents' perceptions of sexual and reproductive health concepts and practices. Two workshops were held in Zambia to train managers and researchers from a range of NGOs and the MOH in PLA data collection, analysis and presentation methods. These methods included area mapping, social mapping, body mapping, transect walks, ranking and scoring, diagrams, wealth/well-being ranking, sketch stories, focus group discussions and sex census by secret ballots.

Participatory methods have been used frequently for designing community-based programs, but the study in Zambia was one of the few occasions in which PLA was used to measure the effectiveness of the interventions over time. A similar approach was taken when the Africa OR/TA Project II provided technical assistance to IPPF in applying participatory evaluation methods for designing and assessing sexual health interventions with its affiliate organizations in Ghana, Tanzania, the Gambia and Burkina Faso. Unfortunately, the donor prematurely ended funding for this initiative before the interventions could be evaluated; hence it was not possible to apply lessons learned from this experience.

In addition, a study in Bazèga, Burkina Faso, used the PLA approach to better understand community members' perceptions of the practice of FGC and to elicit their suggestions for how best to motivate people to stop the practice. The results from this study will be used by FRONTIERS to design and test a communitybased intervention in Bazèga to reduce the practice. In addition, the methodology developed is going to be used by CARE International (with technical assistance from FRONTIERS) to develop and test community-based FGC interventions in Ethiopia, Somalia and Sudan.

\section{Refining existing methods to better measure the cost-effec- tiveness of integrated reproductive health programs}

Through a partnership with FHI, the Africa OR/TA Project II adopted existing resource analysis methods for measuring the cost-effectiveness of strengthening reproductive health service programs. Working with the ZNFPC in Zimbabwe, the cost of adding STI detection and management procedures to routine consultations for family planning clients was measured.

This included a time motion study and observations of the ways in which providers offered an integrated service. The results indicated that risk assessment did not add additional time to the client-provider interaction, that a pelvic examination added about 
15 minutes and that there was sufficient unused time in the average provider's day to be able to offer an integrated approach.

The study also showed that providers are not accurate when asked to estimate how they spend their time: there is a tendency to underestimate the time spent with a client. Thus a time motion study rather than staff interviews should be used when estimating staff time utilization. A similar study undertaken with the Nakuru Municipal Council in Kenya, found similar results, that is, staff time was under-used. There is scope for offering a more comprehensive service to clients.

In Tanzania, a study was undertaken at the request of USAID to compare the cost-effectiveness of three CBD programs that have different schemes for remunerating their agents. This study tested, and proved, the hypothesis that CBD agents who are salaried perform more cost-effectively than volunteers. Cost analysis methods used elsewhere (in Kenya and Bangladesh) were adapted for assessing how to cost and compare the work done by nonsalaried and salaried workers.

For each program the cost per agent visit was calculated. It was felt that cost per CYP was an inappropriate measure because it is affected by more than agent remuneration. The study also recommended that analyses of remuneration policies generally should be examined in the context of how programs allocate their funding among remuneration, training and supervision because all three have been shown to influence a person's performance.

\section{A Rapid Assessment Mechanism for Monitoring the Quality of Integrated Reproductive Health Services}

The Africa OR/TA Project II worked with the Division of Family Health in Botswana to develop and test a rapid assessment mechanism for routinely monitoring the quality of services provided through its integrated MCH/FP and STI/HIV program. The mechanism collects data from a representative sample of clinics through a short checklist based on the Situation Analysis approach.

Lot Quality Assurance Sampling (LQAS) is used to generate statistically valid measures for 50 key indicators from a small sample of observations of provider-client interactions. Many of the indicators measured through this mechanism (which were defined through a consultative process involving managers from all levels of the health care system) have now been incorporated by the $\mathrm{MOH}$ information system for use at the national level.

The rapid assessment mechanism was found to be acceptable to staff and managers because it gave valid information on the readiness of health facilities to provide integrated family planning and STI services. This information has been used by the Central Training Section of the MCH/FP Unit to revise its curriculum for future courses, putting more emphasis on general and breast examination procedures, and on STI and HIV/AIDS risk assessment and counseling procedures. 
The MCH/FP Unit is also planning to revise its family planning client record forms to routinely record and report information that measures some of these key indicators. A report describing the development and field-testing of the mechanism is available (Maribe et al., 1997).

\section{Developing and Strengthening Field Station Research Capacities}

The Population Council is supporting the development of two governmental health research field stations, one at Navrongo in northern Ghana and one in Bazéga, central Burkina Faso.

The Navrongo Health Research Centre (NHRC) is one of three field stations being supported by the Ghana $\mathrm{MOH}$ to implement its program of health systems research. Its research capacity is built around a Demographic Surveillance System that maintains a database (updated every three months) of the entire population in the Kassena-Nankana district. The NHRC has also developed an annual panel survey of 1,800 compounds, a computerized MIS for monitoring activities by community-based service providers and the four clinics in the district, an annual series of focus group discussions to monitor attitudinal changes, and a computerized financial accounting system.

These systems enable data on a wide range of topics to be collected fairly routinely from users, non-users and providers of health and family planning services. Strengthening these research capabilities and adapting them to the needs of different family planning and reproductive health research studies is an on-going activity. It was undertaken in close collaboration with colleagues in the Population Council's Policy Research Division and through funding and/or technical assistance from the Council's Programmatic Grant with USAID, the Rockefeller Foundation, FINNIDA, the Mellon Foundation, the Hewlett Foundation and other donors. The Navrongo Health Research Centre has been established for almost ten years, and most assistance is now directed towards developing more fully the already impressive capacity that exists.

The Laboratoire de Santé Communautaire (LSC) in Burkina Faso has only recently been established, so the Africa OR/TA Project II helped the $\mathrm{MOH}$ to develop the capacity to organize the field station itself. An organizational structure has been created in which the MOH's Direction de la Santé de la Famile has established collaborative links with organizations that can contribute differently to the needs of the field station. These are the Direction Regionale de la Santé in Bazèga, the University's Unité d'Enseignement et de Recherche en Demographie, Mwangaza (an NGO specializing in community mobilization) and the Population Council's Ouagadougou office.

This group meets routinely and all activities planned for the LSC are done so jointly. The LSC has been able to attract funding from sources such as the Rockefeller Foundation and UNFPA and is planning collaboration with Family Care International and the USAID-funded FOCUS, HORIZONS and FRONTIERS Projects. 


\section{Strengthening the Capacity to Plan, Manage and Evaluate Service Delivery Programs}

\section{Training}

Training in operations research and in program planning, management and evaluation was a major component of the Project's efforts to transfer knowledge to build collaborating organizations' capacity to strengthen their service delivery programs. Over 25 training workshops for managers and researchers were held during the course of the Project, and these are listed in Appendix 6. These training workshops covered a wide range of subjects, including operations research, proposal writing, research methods, data analysis, computing skills, gender issues, strategic planning and management, and policy guidelines.

\section{Organizational development}

A second approach to building capacity was to work closely with an organization to help it develop appropriate structures and procedures for working more efficiently. The Africa OR/TA Project II provided technical assistance to the following organizations for this purpose:

Burkina Faso: With the Direction de la Santé Familiale to establish the field research station at Bazèga (see earlier).

Ghana: With the Evaluation and Research Unit (ERU) of the Planned Parenthood Association of Ghana. This assistance has included providing computer hardware and software training for ERU staff in OR methods through attendance at international training workshops joint development of data collection instruments, analysis of data, and presentation of results; and one-onone training in research design and questionnaire development.

Senegal: With the Programme National de Planification Familiale (PNPF), with the USAID Mission and with Management Sciences for Health (MSH). This assistance focused on operationalizing the objectives and evaluation plan for the bilateral "Child Survival and Family Planning Project, assisting the USAID Mission's re-engineering process, assisting the Mission to revise its objectives and strategies and developing 33 evaluation indicators.

Tanzania: With the Family Planning Unit of the $\mathrm{MOH}$ (since renamed the Reproductive Health Unit). Technical assistance was requested for three activities: reviewing research proposals submitted in response to the publication of the family planning program's research agenda and request for proposals, assistance to NGOs in formulating research proposals and developing research instruments and the preparation of a paper for the annual meeting of the $\mathrm{MCH} / \mathrm{FP}$ program. Also with the IPPF-affiliate, UMATI, to prepare its strategic planning documents.

Zimbabwe: With the Zimbabwe National Family Planning Council's Evaluation and Research Unit (ERU). A number of smallscale training sessions were held for selected staff in various computing programs; the training was provided through a combination of Project staff and commercial companies in Harare. 
Project staff worked with ERU staff to develop various management and administrative skills (e.g., defining scopes of work and terms of reference for hiring consultants, the management of multiple research studies) and to develop a draft strategic plan for the ERU's activities over the next five years. This draft plan has been used subsequently by the ERU within the wider context of the ZNFPC's five-year strategic planning process, which commenced in July 1996.

In Botswana, the Project responded to a request from the USAID Mission to support activities that would strengthen those NGOs working in adolescent reproductive health. The Government of Botswana was keen to enhance the role played by the non-governmental sector in social service provision. This project used a two-pronged strategy to address NGO needs.

A local parastatal management training and consulting organization, the Botswana National Productivity Centre (BNPC), assisted the NGOs to identify and address organizational and managerial problems, while the Health Research Unit of the MOH provided training and technical assistance to the NGOs in how to use operations research to improve the delivery of reproductive health services to youth.

A full-time project coordinator provided daily management and monitoring of the activities and a project office was established within the BNPC. The main activities and achievements of this capacity-building activity, which came to be known as the Youth Empowerment Project - (YEP), are described in the box (opposite page).

The final workshop, held in September 1996, was used as a platform for participating NGOs to share their experiences and mobilize further support (both technical and financial) from the government, private sector and international donor community in order to sustain and continue to improve on the gains made through the project (USAID ceased being active in Botswana in October 1996). The workshop was attended by nearly 80 participants from various government sectors, donors, university and the private sector. An ad hoc committee composed of NGO representatives presented recommendations for follow-up action. The country's First Lady was a key participant at this workshop.

The principal recommendation of the committee was to solicit BNPC and HRU technical support beyond the life of YEP to gain more experience in applying the skills acquired and to utilize the results of the research projects for improving and revising their programs. They recommended that a second phase include "Training of Trainers" so that management training could be more widely shared within each NGO, thus creating a common approach and supportive environment towards the application of new management techniques.

Consensus was reached on an appropriate role for the NGOs in relation to government ministries; for example, the Department of Youth and Sports is actively seeking to commission NGOs to undertake OR studies on its behalf. 


\section{Activities of the Botswana Youth Empowerment Project (YEP)}

Project activities were initiated with the "Project Kick-off Workshop" in November, 1995 where the project was introduced to interested NGOs who confirmed their commitment. Information was collected on each NGO to establish a baseline position. The participants selected the name "Youth Empowerment Project (YEP)" for the project. Eleven NGOs participated in the management development activities and eight NGOs attended the OR training and participated in the OR studies, including:

- National, youth-oriented NGOs linked with international networks (the Botswana Scouts Association, Girl Guides and the YWCA);

- Indigenous youth NGOs (The Botswana Youth Centre);

- NGOs with a reproductive health but not necessarily a youth focus (BOFWA - the IPPF affiliate in Botswana, and Population Services International);

- NGOs with mandates relating to community development, health and education (The Red Cross, Association of Medical Missions in Botswana, AIDS Action Trust - ACT, and Mambo Arts Commune);

- An NGO established to serve as a clearinghouse of information and central net work point for all NGO activities in Botswana (BOCONGO).

The initial program of activities under the management component of YEP was a series of eight two-day retreats facilitated by the BNPC where representative staff from each NGO used a participatory methodology to assess the characteristics of their NGO which had the potential to affect individual and/or organizational performance.

The next activity was two management-training workshops that covered the following topics: Strategic Management; Change Management, Time Management; Performance Management; and Project Management. These management workshops addressed the training needs identified through the Kick-off workshops and retreats. Overarching all of this was intensive technical assistance by BNPC staff to individual NGOs to enhance performance on an as-needed basis.

The Health Research Unit coordinated a parallel set of activities in which staff from eight NGOs received three weeks training on how to use and design operations research to increase NGO performance. The NGOs formed teams, each with a facilitator from the HRU, and prepared four research proposals for small-scale studies. The topics (and implementing NGOs) were:

- Assessing the Coverage and Adequacy of Services Provided by AMMB to Care Givers of AIDS/HIV Positive Youth" (Association of Medical Missionaries in Botswana);

- Effectiveness of Peer Education Training Programs in Gaborone" (BOFWA, YWCA and BOCONGO);

- Accessibility, Availability and Use of Condoms among Youth" (Botswana Scouts Association and Botswana Youth Centre);

- Utilization of Information, Education and Communication Material on HIV/AIDS by Adolescents with Disabilities" (Botswana Red Cross Society and Population Services International).

Africa OR/TA Project staff worked closely with staff from the NGOs to revise the proposals, and eventually all were approved for funding each study entailed a few weeks of fieldwork and cost $\$ 3,000$ - 8,000. The research teams brought their data to a second training workshop that focused on data analysis, report writing and preparation for dissemination of the results to the managers of their respective NGOs.

The Kick-off workshop revealed a need for a centralized data base and geographic information system on NGO activities to facilitate collaboration and networking as well as to provide access to information about NGOs to government and donor agencies. By the end of the project period, the Botswana Council of NGOs had completed a database with information on almost all NGOs in the country as well as maps showing the locale and type of activity for the YEP NGOs and registered members of the Council. 
The YEP project was originally conceived to last aproximately 18 months but had to be implemented in less than 10 months due to administrative delays in preparing the buy-in. It is too soon to tell what long-term effects the activities will have on the participating NGOs. However, there is abundant evidence of positive changes in the short term.

For example, the project raised awareness and appreciation of the need for strategic planning as an important tool in performance management, and by the end of the project seven NGOs were developing, reviewing or taking greater steps to implement strategic plans. Also, the participants in the operations research training and studies gained skills and experience in the implementation of research studies, from problem identification to mobilizing management to support the use of the research results.

Their organizations have already demonstrated their appreciation of the use of OR as a management tool by implementing changes in the organization of services as a result of the research results. The challenge now is to ensure that the changes and progress made in the past year are sustained. 


\section{Resources Available from the Africa OR/TA Project II on Capacity Building}

Strengthening the Situation Analysis approach

Africa OR/TA Project II \& Asia and the Near East OR/TA Project. 1996. Strengthening Situation Analysis methodology: A coordinated interregional approach. Population Council, New York, January.

Gouédé, Nicholas (ed.) 1998. Analyse Situationnelle: Un outil de recherche en santé de la reproduction. Rapport de l'Atelier sur l'analyse et l'utilisation des études d'Analyse Situationnelle, Dakar, Sénégal, 9-12 juin, 1997. Population Council, New York.

Huntington, Dale, Kate Miller and Barbara Mensch. 1996. The reliability of the Situation Analysis observation guide. Studies in Family Planning 27(5):277-282.

Leonard, Ann (ed.) 1997. Situation Analysis: How can we use it better? Report of a workshop on strengthening the utilization of Situation Analysis for planning, managing, and evaluating reproductive health services, Nairobi, Kenya, May 2931, 1996. Population Council, Nairobi, Kenya.

Miller, Kate, and Diouratié Sanogo. 1997. Analyse Secondaire: Développement des indicateurs pour les managers. Presentation at francophone Africa program managers' workshop on "Analysis and Utilization of Situation Analysis studies," Population Council, Dakar, Senegal, 9-14 June.

Miller, Kate, and Diouratié Sanogo. 1997. Méthodologie pour le développement des indicateurs. Presentation at francophone Africa program managers' workshop on "Analysis and Utilization of Situation Analysis studies," Population Council, Dakar, Senegal, 9-14 June.

Miller, Kate, Lewis Ndhlovu and Diouratié Sanogo. 1996. ”Using Situation Analysis to evaluate programme changes over time". Paper presented at a workshop on Strengthening the Utilization of Situation Analysis for Planning, Managing and Evaluating Reproductive Health Services, Population Council, Nairobi, Kenya, 2931 May.

Miller, Robert, Andrew Fisher, Kate Miller, et. al. 1997. The Situation Analysis Approach to Assessing Family Planning and Reproductive Health Services: A Handbook. Population Council, New York.

Miller, Robert. 1996. "Description and evolution of the Situation Analysis approach”. Paper presented at a workshop on Strengthening the Utilization of Situation Analysis for Planning, Managing and Evaluating Reproductive Health Services, Population Council, Nairobi, Kenya, 29-31 May.

Ndhlovu, Lewis. 1998. Lessons learned from Situation Analysis Studies in Zambia. Paper presented at the session "Facility Surveys in Developing Countries: Lessons Learned and New Directions," Annual Meeting of the Population Association of America April 2-4, Chicago, Illinois

Sanogo, Diouratié. 1997. Définition de l'Analyse Situationnelle. Presentation at francophone Africa program managers' workshop on "Analysis and Utilization of Situation Analysis studies," Population Council, Dakar, Senegal, 9-14 June.

Tapsoba, Placide. 1997. Evolution de l'Analyse Situationnelle. Presentation at francophone Africa program managers' workshop on "Analysis and Utilization of Situation Analysis studies,” Population Council, Dakar, Senegal, 9-14 June.

Using Situation Analysis to assess program readiness and service quality

Askew, Ian, Barbara Mensch, and Alfred Adewuyi. 1994. Indicators for measuring the quality of family planning services in Nigeria. Studies in Family Planning 25(5): 268-283.

Askew, Ian, Kate Miller, and Barbara Mensch. 1995. Key indicators for measurement of quality of family planning services. Paper presented at The EVALUATION Project's Service Delivery Working Group meeting, Washington, D.C., 5 October.

Askew, Ian. 1994. Distinguishing between quality assurance mechanisms and quality assessment techniques. Health Policy and Planning 9(3): 274-277.

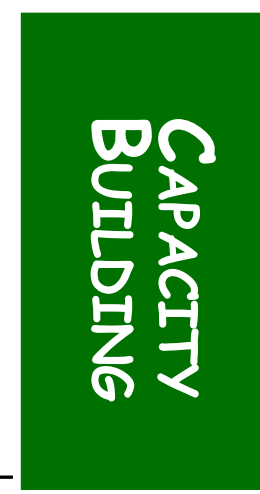


Fisher, Andrew, Kate Miller, and Robert Miller. 1997. Situation Analysis: Assessing the functioning and quality of the service delivery environment. Paper presented at the IUSSP/Evaluation Project Seminar on Methods for the Evaluation of Family Planning Program Impact, Jacó, Costa Rica 14-16 May.

Fisher, Andrew, Robert Miller, Ian Askew, Barbara Mensch, Anrudh Jain and Dale Huntington. 1996. The Situation Analysis approach to assessing the supply side of family planning programmes. African Journal of Fertility, Sexuality and Reproductive Health. 1(2):121-135.

Mensch, Barbara, Andrew Fisher, Ian Askew, et al. 1994. Using Situation Analysis data to assess the functioning of family planning clinics in Nigeria, Tanzania, and Zimbabwe. Studies in Family Planning 25(1): 18-31.

Applying participatory research methods to designing and evaluating programs

Fetters, Tamara and Kathleen Siachitema. 1997. Reproduction health": Adolescents appraise their own reproductive health problems in peri-urban Lusaka, Zambia. Paper presented at the Annual Meeting of the American Public Health Association, Indianapolis, Indiana, 9-13 November.

Laboratoire de Santé Communautaire. 1997. Mobilisation sociale pour la mise en place d'un programme à base communautaire en matière de Santé de la Reproduction (S.R.) dans le Bazèga: Premiers éléments de bilan. Série Documentaire \#5, Juillet.

Nazzar, Alex, Philip Adongo, Fred N. Binka, et al. 1994. The Navrongo Community Health and Family Planning Project phase I trial: Developing community participation in community health. Paper presented at the Annual Meeting of the American Public Health Association, Washington, D.C., 30 October-3 November.

Nazzar, Alex, Philip Adongo, Fred N. Binka, et al. 1995. Involving a traditional community in strategic planning: The Navrongo Community Health and Family Planning Project pilot study. Paper presented at the annual meeting of the Population Association of America, San Francisco, California, 6-8 April.

Nazzar, Alex, Philip Adongo, Fred Binka, James Phillips and Cornelius Debpuur. 1995. Developing a culturally appropriate family planning program for the Navrongo experiment. Studies in Family Planning 26(6): 307-324.

Rapid appraisal mechanism for assessing service quality

Maribe, Lucy Sejo, Baker Ndugga Maggwa, Ian Askew and Kate Miller. 1997. Using a rapid assessment approach to evaluate the quality of care in an integrated program: The experience of the Family Health Division, Ministry of Health, Botswana. Population Council, Nairobi, Kenya, November.

Maribe, Lucy and Baker Ndugga Maggwa. 1996. Using a modified Situation Analysis approach for routine monitoring of quality. Paper presented at a workshop on Strengthening the Utilization of Situation Analysis for Planning, Managing and Evaluating Reproductive Health Services, Population Council, Nairobi, Kenya, 2931 May. 


\title{
Project Staff
}

\author{
Nairobi, Kenya
}

Ian Askew, Project Director (1994-1998)

Andrew Fisher, Project Director (1993-1994)

Naomi Rutenberg, Deputy Director, East/Southern Africa (1995-1998)

Ndugga Maggwa, International Resident Advisor (1995-1998)

Cecilia Ndeti, International Resident Advisor (1993-1995)

Lewis Ndhlovu, International Resident Advisor (1993-1998)

Julie Solo, Michigan Fellow and International Resident Advisor (1995-1998)

John Skibiak, Associate (1995-1998)

Jane Chege, National Fellow (1995-1997)

Benter Oluoch, Administrative Assistant (1993-1996)

Violet Bukusi, Administrative Assistant (1996-1998)

\section{Dakar, Senegal}

Diouratié Sanogo, Deputy Director, West/Central Africa (1993-1998)

Placide Tapsoba, International Resident Advisor (1993-1998)

Nafissatou Diop, National Fellow and International Resident Advisor (1995-1998)

Mounir Touré, Host Country Social Scientist (1997-1998)

Annamaria Cerulli, Michigan Fellow (1995-1996)

Marthe Bruce Dieng, Administrative Assistant (1993-1998)

\section{Gaborone, Botswana}

Mercy Montsi, Resident Coordinator (1995-1996)

\section{Ouagadougou, Burkina Faso}

Inoussa Kaboré, National Fellow and Host Country Social Scientist (1995-1998)

Youssouf Ouédraogo, Host Country Social Scientist (1994-1996)

Jeanne Marie Zongo, Administrative Assistant (1994-1997)

Pauline Zoundi, Administrative Assistant (1997-1998) 
Bamako, Mali

Assitan Diallo, National Fellow (1996-1997)

\section{Dar es Salaam, Tanzania}

Eustace Muhondwa, Host Country Social Scientist (1994-1996)

Eunice Odunga, Administrative Assistant (1996)

Lusaka, Zambia

Kathleen Siachitema, Host Country Social Scientist (1996-1998)

Winnie Lubasi, Administrative Assistant (1997-1998)

\section{New York, USA}

Joanne Gleason, Program Manager (1993-1998)

Robert Miller, Senior Research Associate (1993-1998)

Katherine Miller, Staff Associate (1995-1998)

Nicholas Gouedé, Communications Specialist (1994-1998)

Ben Bilbao, Staff Assistant (1993-1997)

Heidi Jones, Staff Assistant (1997-1998)

Emmy Kondo, Staff Assistant (1995-1996)

Elizabeth Motyka, Staff Assistant (1997)

Elizabeth Pearlman, Staff Assistant (1998)

Brian Pence, Staff Assistant (1998) 


\section{Collaboration with National Organizations}

\begin{tabular}{|c|c|}
\hline Country & Collaborating Agencies \\
\hline Botswana & $\begin{array}{l}\text { Botswana National Productivity Centre } \\
\text { Association of Medical Missions for Botswana } \\
\text { Botswana Family Welfare Association } \\
\text { Botswana Red Cross Society } \\
\text { Population Services International } \backslash \text { Botswana } \\
\text { Botswana Scouts Association } \\
\text { Botswana Youth Centre } \\
\text { Botswana Council of Non-Governmental } \\
\text { Organizations } \\
\text { Division of Family Health, Ministry of Health }\end{array}$ \\
\hline Burkina Faso & $\begin{array}{l}\text { Burkina Faso Cellule de Santé de la Reproduction } \\
\text { Centre Hospitalier National } \\
\text { Direction de la Santé de la Famille, Ministére } \\
\text { de la Santé } \\
\text { Unité d'Enseignement et de Recherche en } \\
\text { Démographie } \\
\text { Mwangaza } \\
\text { GTZ/Burkina Faso } \\
\text { National Centre for Scientific Research } \\
\text { Association Burkinabé pour le Bien-Etre de la } \\
\text { Famille } \\
\text { Comité National de Lutte Contre la Pratique de } \\
\text { L'Excision }\end{array}$ \\
\hline Cameroon & $\begin{array}{l}\text { Direction de la Santé Communautaire, Ministry } \\
\text { of Health }\end{array}$ \\
\hline Gambia & Save the Children/USA \\
\hline Ghana & $\begin{array}{l}\text { Navrongo Health Research Centre, Ministry } \\
\text { of Health } \\
\text { Ghana Statistical Service } \\
\text { Planned Parenthood Association of Ghana } \\
\text { Kassena-Nankana District Health Management } \\
\text { Team }\end{array}$ \\
\hline Guinea & $\begin{array}{l}\text { Direction de la Santé de la Reproduction, Ministére } \\
\text { de la Santé } \\
\text { USAID/Guinea }\end{array}$ \\
\hline Kenya & $\begin{array}{l}\text { Division of Primary Health Care, Ministry of Health } \\
\text { Family Planning Association of Kenya } \\
\text { African Population Policy Research Center } \\
\text { Nakuru Municipal Council } \\
\text { USAID/Kenya } \\
\text { Nairobi City Council } \\
\text { IPAS/Kenya }\end{array}$ \\
\hline
\end{tabular}




\begin{tabular}{|c|c|}
\hline $\begin{array}{l}\text { Cont ... } \\
\text { Country }\end{array}$ & Collaborating Agencies \\
\hline Mali & $\begin{array}{l}\text { Association de Soutien au Developpement des } \\
\text { Activités de Population } \\
\text { Center National de Recherche Scientifique et } \\
\text { Technique du Mali } \\
\text { Commissariat à la Promotion Feminine } \\
\text { Centre de'Etudes et de Recherche sur la } \\
\text { Population pour le Developpement }\end{array}$ \\
\hline Senegal & $\begin{array}{l}\text { Program National de Planification Familiale, Ministére } \\
\text { de la Santé } \\
\text { Centre de Formation et de Recherche en Santé de la } \\
\text { Reproduction } \\
\text { Clinique Gynecology et Obstetricale, Hospital Le Dantec } \\
\text { USAID/Senegal } \\
\text { Programme pour la Lutte contre le Paludisme, Ministére } \\
\text { de la Santé }\end{array}$ \\
\hline Tanzania & $\begin{array}{l}\text { Family Planning Unit, Ministry of Health } \\
\text { Population Health Services - Marie Stopes } \\
\text { International } \\
\text { Family Planning Association of Tanzania } \\
\text { Department for International Development, UK } \\
\text { AVSC International }\end{array}$ \\
\hline Zambia & $\begin{array}{l}\text { CARE International/Zambia } \\
\text { Planned Parenthood of Zambia } \\
\text { Makeni Ecumenical Centre } \\
\text { Central Statistics Office } \\
\text { Tropical Disease and Research Centre } \\
\text { University Teaching Hospital }\end{array}$ \\
\hline Zimbabwe & $\begin{array}{l}\text { Zimbabwe National Family Planning Council } \\
\text { USAID/Zimbabwe }\end{array}$ \\
\hline
\end{tabular}




\section{Collaboration with International Organizations}

\begin{tabular}{|c|c|}
\hline Collaborating Organization & Location of collaboration \\
\hline Africa Population Policy Research Centre & Kenya \\
\hline AIDSCAP Project & East and Southern Africa \\
\hline AVSCI & Ghana, Kenya, Senegal, Tanzania \\
\hline BASICS Project & Guinea, Zambia, East and Southern Africa \\
\hline British Council & Tanzania \\
\hline CAFS & East and Southern Africa \\
\hline Cambridge Consulting Corporation & Botswana \\
\hline Canadian Public Health Association & Zambia \\
\hline CARE International & Zambia, Regional \\
\hline Commonwealth Health Secretariat & East and Southern Africa \\
\hline CEDPA & Ghana, Kenya \\
\hline CERPOD & West and Central Afhca, Mali \\
\hline CLUSA & Burkina Faso \\
\hline Data for Decisionmaking Project & East and Southern Aftica \\
\hline EVALUATION Project & Regional \\
\hline Family Health and AIDS Prevention & Burkina Faso, Cameroon, West and Central Africa \\
\hline Project FHI / Population Program & Regional, East and Southern Africa \\
\hline FINNIDA & Ghana \\
\hline FPMD Project & Zimbabwe \\
\hline GTZ & Burkina Faso, Kenya \\
\hline INTRAH & West and Central Africa \\
\hline IPAS & Kenya \\
\hline IPPF & Ghana, Kenya, Regional \\
\hline JHPIEGO & Burkina Faso, Ghana, Senegal \\
\hline PCS/JHU & Kenya, Zambia, Regional \\
\hline JSI & Zambia \\
\hline Marie Stopes International & Kenya, Tanzania \\
\hline Mellon Foundation & Ghana \\
\hline MSH & Guinea, Senegal \\
\hline DFID & Kenya, Tanzania, Zambia \\
\hline Pacific Institute for Women's Health & Burkina Faso, West and Central Africa \\
\hline Pathfinder International & East and Southern Africa, Kenya, \\
\hline Population Council Policy Research Division & Tanzania, Uganda Ghana, Zambia \\
\hline Population Council ECC Program & Burkina Faso, Kenya, Senegal, Zambia, Regional Botswana, \\
\hline PSI & Zambia \\
\hline Rainb 9 & Burkina Faso, Senegal, Zambia \\
\hline Rockefeller Foundation & Burkina Faso, Ghana, Kenya, Zimbabwe \\
\hline Save the Children/USA & Gambia \\
\hline SEATS Project & Senegal, Zambia, East and Southern Aftica \\
\hline UNFPA & Burkina Faso, Botswana, Kenya, Mali, Zanzibar, Zambia \\
\hline UNPD & Regional \\
\hline University of Exeter, UK & Ghana, Tanzania \\
\hline Wellstart International & Regional \\
\hline WHO & Senegal, Zambia, International \\
\hline World Bank & Regional \\
\hline
\end{tabular}




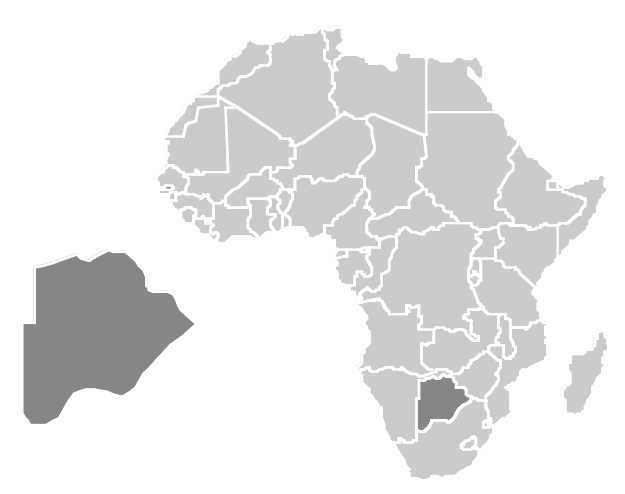

\section{BOTSWANA}

\section{Subprojects}

Duration / budget

Strengthening NGOs' management and service delivery capabilities to provide reproductive health services to November 1995 - Sept 1996 adolescents $\$ 231,850$

Baseline study for evaluation of the effect on service quality of integrating STI/HIV/AIDS services into the national $\mathrm{MCH} / \mathrm{FP}$ program

April 1995 - July 1996 $\$ 100,587$

Development and testing of rapid appraisal mechanism for assessing quality of integrated services in the national program

June 1996 - April 1997 $\$ 37,490$

Creation of database and maps of all NGOs in Botswana

May 1996 - July 1996

$\$ 10,688$

Accessibility, availability and use of condoms among July 1996 - September 1996 adolescents $\$ 10,125$

Evaluating the effectiveness of adolescent peer education June 1996 - September 1996 training programs $\$ 5,994$

Assessing the coverage and adequacy of services provided to June 1996 - September 1996 care givers of $\mathrm{HIV}+$ youth $\$ 5,935$

Utilization of IEC materials on HIV/AIDS by adolescents July 1996 - September 1996 with disabilities $\$ 2,242$ 
An assessment of the current and potential actions taken pregnant women, new mothers and their families in February 1998 - July 1998 by managing safe motherhood and child survival 


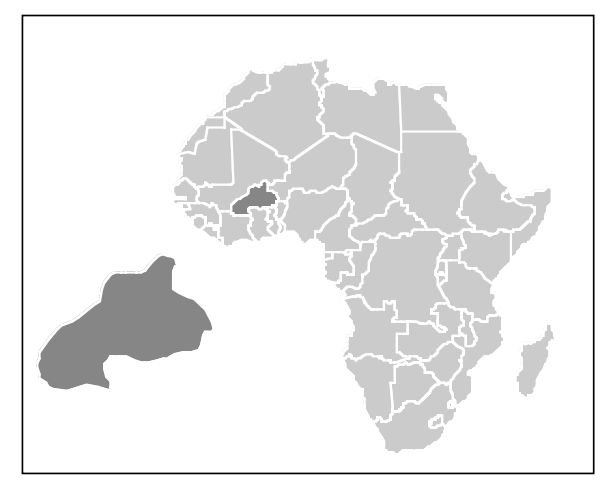

\section{BURKINA FASO}

Technical Assistance

Development of a Community Health Field Station

Design of OR study on FGM for National anti-FGM committee

aseline survey in five provinces for $\mathrm{MOH}$ program to expand role of TBAs as family planning providers

Implementation of a sexual health project by IPPF-affiliate

Assessment of IPPF-affiliate's Youth-to-Youth program

Training in Operations Research for NGO health managers from several Francophone countries

Development of national five-year health research agenda
January 1995 -

March 1996

12 days

Dec. 1995 -

November 1996 110 days

Dec. 1995 -

December 1996

55 days

August 1994 -

March 1996

44 days

December 1995 -

July 1996

30 days

March - June 1996

15 days

February 1995

5 days 


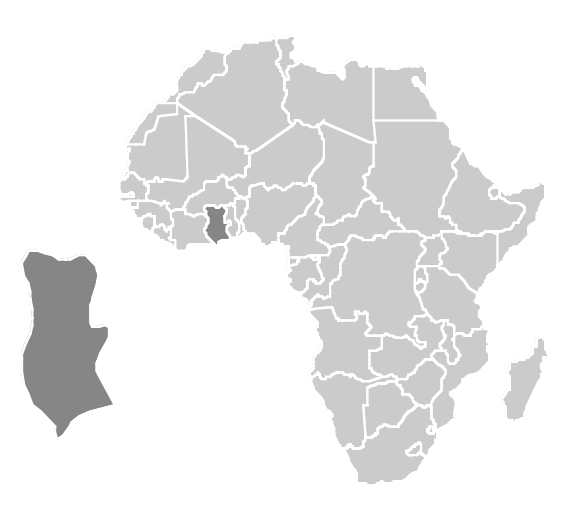

\section{GHANA}

Subprojects

Testing a community-based health care and family planning program and cost-recovery scheme at Navrongo

Diagnosis of the demand for family planning services and micropilot testing community-based nurses and volunteers in Navrongo, northern Ghana

Situation Analysis study to assess program strengthening activities of the national $\mathrm{MOH} \mathrm{MCH} / \mathrm{FP}$ program

Strengthening the operations research and program evaluation 1998 capacity of PPAG, the IPPF-affiliate

Testing the feasibility of using community-based volunteers as providers of oral contraceptives at Navrongo

Testing the effect of training community-based voluntary health 1998 workers in STD/HIV prevention at Navrongo

The characteristics of Norplant ${ }^{\circledR}$ implant users at Navrongo

Testing the effect of integrating STD/HIV services at MCH/FP clinics in Navrongo

An assessment of current perceptions and practices for identifying and treating reproductive tract infections at Navrongo

Technical Assistance

Designing a study to introduce the female condom at Navrongo

Workshop held at Navrongo to train journalists in reporting reproductive health issues in the national media
Duration / budget

\section{Duration / budget}

May 1995 - Sept. 1998 $\$ 802,899$

May 1994 - April 1995 $\$ 244,624$

August 1996 - June 1998 $\$ 211,211$

May 1996 - September $\$ 25,000$

February - July 1998 $\$ 23,403$

January - September $\$ 13,800$

January - July 1998 $\$ 11,168$

January - June 1998 $\$ 8,810$

July - October 1997 $\$ 5,350$

March 1996 - June 1997 20 days

December 1997

14 days 


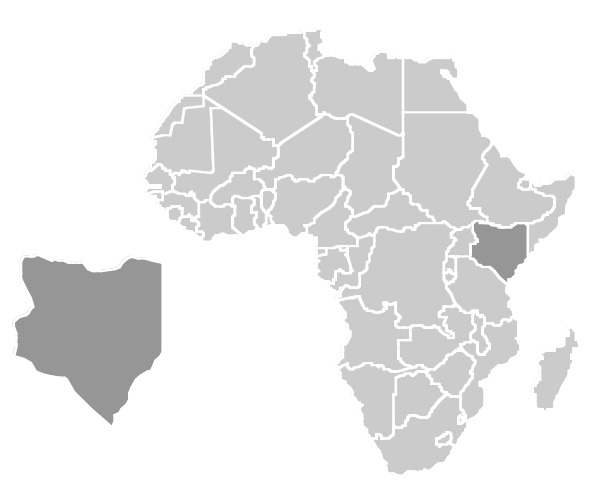

\section{KENYA}

\section{Subprojects}

Testing alternative strategies for providing an integrated service for treating abortion complications and offering family planning counseling and services in hospitals

\section{Duration / budget}

January 1995 - June 1998

$\$ 265,973$

March 1995 - September 1997 $\$ 195,181$

March 1995 - December 1996 $\$ 148,885$

October 1997 - September 1998 $\$ 80,043$

September 1997 - August 1998 $\$ 32,254$

April 1994 - September 1995 $\$ 30,949$

February - March 1998 $\$ 11,350$ 


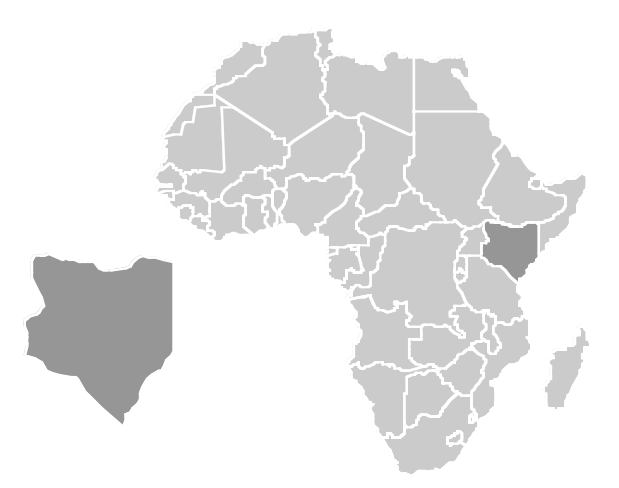

KENYA

Technical Assistance

Developing research designs for testing alternative models of providing reproductive health services to men

Preparation of briefing paper on CBD programs for USAID/ Kenya Mission

Developing a proposal for testing the feasibility and effect of CBD agents providing the injectable

Interpretation and utilization of data from Situation Analysis and CBD impact studies by Nairobi City Council

Training NGO program managers in quality of care
Duration / budget

February 1995 - July 1998 45 days

June - September 1994 35 days

February - July 1994 20 days

February - October 1996 14 days

December 1993

5 days 


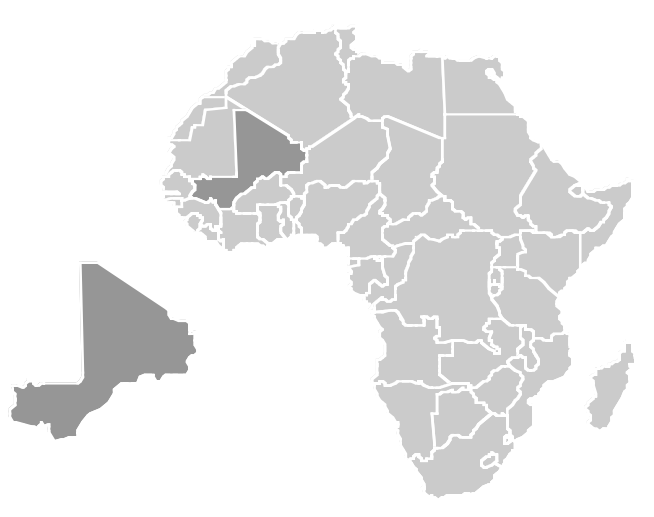

\section{MALI}




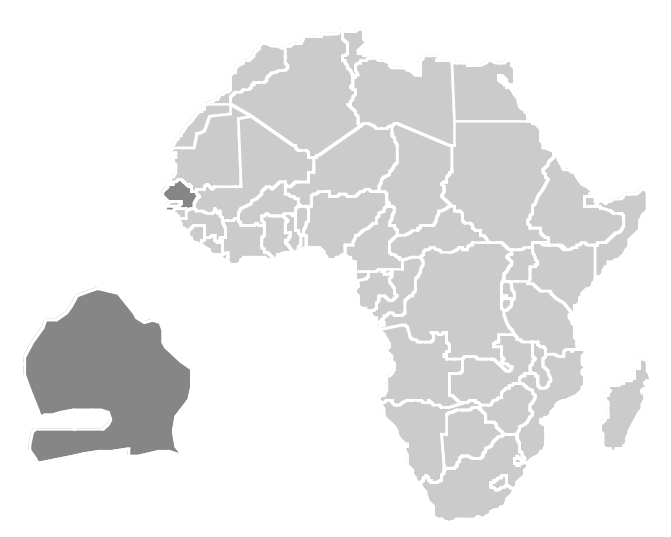

\section{SENEGAL}

\section{Subprojects}

Duration / budget

End-term Situation Analysis study to assess changes in delivery of reproductive health services following USAID-supported March - September 1998 interventions $\$ 200,555$

Baseline Situation Analysis study to determine levels of subsystem functioning and quality of care in every family planning clinic in the country prior to introduction of USAID-supported program strengthening interventions

April 1994 - Dec. 1995

$\$ 108,140$

Testing the effect of improving the quality of clinical services

Feb. 1997 - August 1998 through model clinics on contraceptive use dynamics $\$ 92,600$

Testing the introduction of MVA with family planning counseling and services for treating post-abortion complications in three hospitals in Dakar

April 1997 - July 1998 $\$ 64,000$

Mid-term Situation Analysis study to assess changes in subsystem functioning and quality of care in clinics receiving USAID-supported programmatic interventions after one year 


\section{SENEGAL}

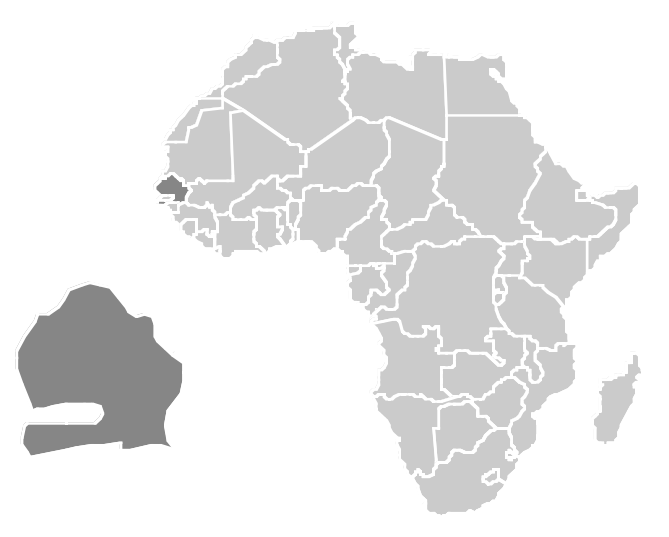

Development of evaluation indicators for USAID-supported Child Survival and Family Planning program

Measure indicators for evaluating achievements under USAID/ Senegal's Strategic Objective No. 1

Training of Regional Medical Officers in OR for developing malaria control interventions

National workshop on IEC activities concerning integration of STD/HIV services at MOH clinics

Re-engineering of the USAID/Senegal strategic planning process
March - June 1995 27 days

February - July 1997 25 days

June - October 1995 23 days

May 1997 - June 1998 15 days

March - May 1996

12 days 


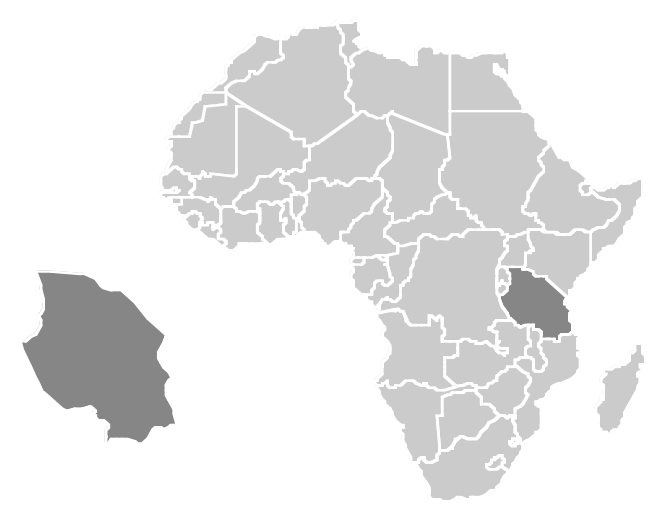

TANZANIA

Subprojects

Duration / budget

Baseline Situation Analysis study to assess levels of subsystem functioning and quality of care in every family

December 1995 - March 1996 planning clinic in Zanzibar $\$ 45,166$

An assessment of the cost-effectiveness of three alternative February 1997 - March 1998 family planning CBD models $\$ 24,700$

Training workshop on OR and proposal writing for staff December 1995 - March 1996 from the National Family Planning Program $\$ 16,006$

Evaluation of the effects of a vasectomy promotion campaign on the knowledge, attitudes and behavior of men January - September 1996 in Dar es Salaam $\$ 13,783$

\section{Technical Assistance}

Duration / budget

Development and implementation of OR studies by the $\mathrm{MOH}$ Reproductive Health Unit January 1995 - September 1998 50 days

Evaluation of UMATI's sexual health and other programs

January 1995 - September 1998 45 days

Implementation of a baseline Situation Analysis study to assess readiness of clinics in Mbeya Region to integrate STI/HIV services into existing MCH/FP services through an DfID-supported project

March - September 1995 33 days

Development of an evaluation plan for the AVSCI Quality Management Approach 


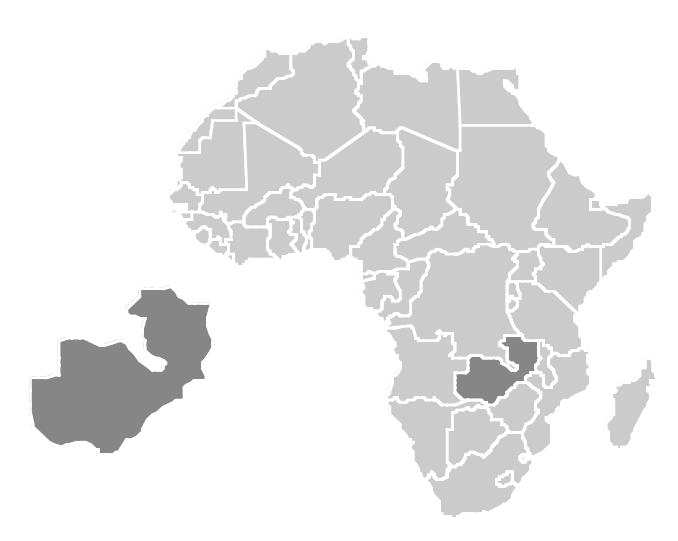

\section{ZAMBIA}

\section{Subprojects}

National baseline Situation Analysis study to assess levels of subsystem functioning and quality of care in clinics receiving USAID-supported and UNFPA-supported interventions

February 1997 - February 1998 $\$ 171,287$

Testing and comparing two community-based strategies for improving reproductive health amongst out-of-school youth in Lusaka

Determining the most appropriate strategies for introducing emergency contraception in $\mathrm{MOH}$ and other clinics

Sept. 1997 - September 1998 $\$ 54,641$

Training $\mathrm{MOH}$ and NGO staff in the Participatory Learning Approach

August 1996 - November 1996 $\$ 19,756$

Comparing the acceptability and administration of two regimes of hormonal emergency contraception: $\mathrm{PC}-4$ May 1998 - December 1998 and Postinor-2

A comparison of prophylactic distribution and prophylactic prescription strategies for increasing access to emergency contraception

May 1998 - December 1998 $\$ 9,710$

Study of contraceptive decision-making behavior March 1997 - Sep. 1998 among couples with HIV/AIDS $\$ 9,111$

Revisit to a selection of clinics from the Situation Analysis study to obtain more in-depth information about delivery of reproductive health services 


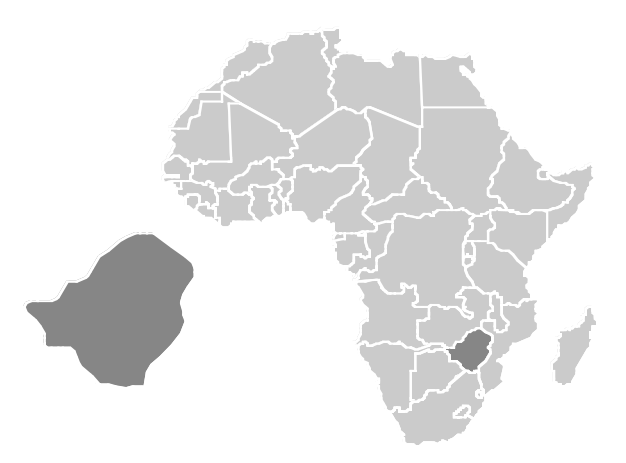

\section{ZIMBABWE}

\section{Subprojects}

Duration / budget

A national Situation Analysis study to assess changes since 1991 in subsystem functioning and quality of care in the national family planning program

June 1996 - July 1998

$\$ 116,201$

January - September 1998 $\$ 115,783$

January 1996 - July 1998

$\$ 26,763$

March - September 1998

$\$ 12,500$
Measuring the cost of adding STI management services to the existing family planning services at ZNFPC clinics
Assessing the potential demand for and effectiveness of integrating STI/HIV management services within ZNFPC's Strengthening the research and research management capacity of the ZNFPC Evaluation and Research Unit 


\section{Activities in non-Focus Countries}

Guinea

Baseline Situation Analysis study to assess levels of January - September subsystem functioning and quality of care in clinics $\$ 148,529$

\section{Cameroon}

Baseline Situation Analysis study to assess clinic-based reproductive health and family planning services
October 1997 - September 1998 $\$ 145,382$

\section{- The Gambia}

Evaluating the relative effects of community-based demand mobilization and service improvement strategies on contraceptive prevalence

April 1995 - September 1996 $\$ 72,775$ 
Regional workshop on developing and implementing standards and guidelines for reproductive health services in east and southern Africa

\section{Technical Assistance}

\section{Duration / budget}

Regional workshop on FGM for NGOs and researchers in west Africa with Rainbé

October 1996 - May 1997 31 days

Identifying and developing research studies on adolescent reproductive health in west Africa with the Pacific Institute for Women's Health 
Presentation of papers on OR studies at the USAIDsupported Regional Conference on Maximizing Access and February - March 1995 Quality of Services in Francophone Africa 40 days

Preparation of three background papers on measuring quality of family planning services for the UNPD Task Force September - October 1995 on the Measurement of Quality 32 days

Advice and training on OR methods for the IPPF Sexual January 1994 - March 1996 Health Project 25 days

Training materials and resource person at OR Regional Training Workshop for West and Central Africa with August - October 1996 CERPOD and Tulane University 20 days

Developing study designs and research proposals on adolescent reproductive health services in Kenya and Zimbabwe for funding by the Rockefeller Foundation 15 days

Analysis of services provided to breastfeeding clients attending for family planning at clinics in Senegal and January - February 1996 Nigeria for the Wellstart Project 12 days 10 days

Training materials and resource person for gender and OR at the UNFPA Anglophone Regional Training Workshop for Population Program Managers 


\title{
Indication of Readiness and quality of family planning services in sub Saharan Africa
}

\author{
R - 1 READINESS TO PROVIDE SERVICES: INFRASTRUCTURE AND FACILITIES \\ $\%$ of clinics with an adequate waiting area \\ $\%$ of clinics with working electricity \\ $\%$ of clinics with piped running water \\ $\%$ of clinics with working toilet for clients \\ $\%$ of clinics with adequate light in exam room \\ $\%$ of clinics with clean exam room \\ $\%$ of clinics with adequate water in exam room
}

\section{R - 2 READINESS TO PROVIDE SERVICES: ACCESSIBILITY}

$\%$ of clinics open on time

$\%$ of clinics with sign announcing family planning services inside or outside the clinic

\section{R - 3 READINESS TO PROVIDE SERVICES: METHODS OFFERED}

$\%$ of clinics that offer Combined Pills

$\%$ of clinics that offer injectables

$\%$ of clinics that offer Progestin-Only Pills

$\%$ of clinics that offer NORPLANT ${ }^{\dagger}$ implants

$\%$ of clinics that offer condoms

$\%$ of clinics that offer dual-method counseling

$\%$ of clinics that offer IUDs

$\%$ of clinics that offer tugal ligation

$\%$ of clinics that offer vasectomy

$\%$ of clinics that offer natural family planning

$\%$ of clinics that offer LAM

\section{R - 4 READINESS TO PROVIDE SERVICES: CONTRACEPTIVE SUPPLIES AND LOGISTICS}

$\%$ of clinics that have experienced a stockout of condoms in the previous 6 months

$\%$ of clinics that have experienced a stockout of Combined Pills in the previous 6 months

$\%$ of clinics that have experienced a stockout of Progestin-Only Pills in the previous 6 months

$\%$ of clinics that have experienced a stockout of IUDs in the previous 6 months

$\%$ of clinics that have experienced a stockout of injectables in the previous 6 months

$\%$ of clinics that have experienced a stockout of NORPLANT ${ }^{\dagger}$ implants in the previous 6 months

$\%$ of clinics that have experienced atleast one stockout of an offered method in the last 6 months

$\%$ of clinics with a commodity inventory

$\%$ of clinics with adequate storage facilities for commodities

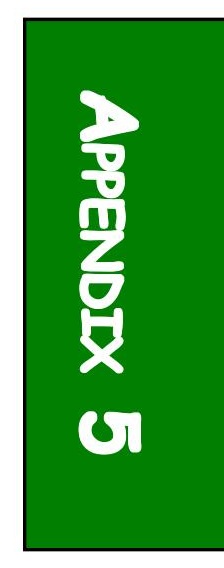




\section{R - 5 READINESS TO PROVIDE SERVICES: EQUIPMENT}

$\%$ of clinics with enough adult weighing scales

$\%$ clinics with enough blood pressure machines

$\%$ of clinics with enough stethoscopes

$\%$ of clinics with access to sterilizing equipment

$\%$ of clinics with enough exam couches

$\%$ of clinics with enough angle poise lamps or flashlights

$\%$ of clinics with enough gloves

$\%$ of clinics with enough sterilizing lotion

$\%$ of clinics with enough tenacula

$\%$ of clinics with enough uterine sounds

$\%$ of clinics with enough specula

$\%$ of clinics with enough needles and syringes

$\%$ of clinics with enough NORPLANT ${ }^{\dagger}$ implants kits

\section{R - 6 READINESS TO PROVIDE SERVICES: STAFFING}

$\%$ of clinics with at least one nurse on duty on the day of the study visit $\%$ if clinics with at least one doctor on duty on the day of the study visit Mean years staff have been offering family planning services $\%$ of staff whose basic training included family planning Mean years ago basic training took place $\%$ of staff who have had training in clinical family planning Mean years ago clinical training took place $\%$ of staff who have had refresher training in family planning $\%$ of staff who have had basic or refresher training in family planning $\%$ of staff who provide STD/HIV services at this SDP $\%$ of staff who have had refresher training in STD/HIV Mean years ago refresher STD/HIV training took place $\%$ of staff who have had basic or refresher training in STD/HIV $\%$ of staff who have had training in family planning counseling or IEC Mean years ago training on family planning counseling or IEC took place $\%$ of staff who have had training in IUD insertion and removal Mean years IUD took training place $\%$ of staff who have had training in tubal ligation Mean years ago tubal ligation training took place 


\section{R - 7 READINESS TO PROVIDE SERVICES: IEC MATERIALS AND ACTIVITIES}

$\%$ of clinics with a poster on family planning on the walls

$\%$ of clinics with a brochure on family planning

$\%$ of clinics with a flip chart on family planning

$\%$ of clinics with a poster on HIV on the walls

$\%$ of clinics with a poster on STDs on the walls

$\%$ of clinics with a brochure on HIV

$\%$ of clinics with a brochure on STD

$\%$ of clinics a flip chart on HIV

$\%$ of clinics with flip chart on STDs

$\%$ of health talks that included family planning

$\%$ of health talks that included STDs

$\%$ of health talks that included HIV

\section{R - 8 READINESS TO PROVIDE SERVICES: RECORDING AND SUPERVISION}

$\%$ of clinics with client record cards in good condition

$\%$ of clinics that have received a supervisory visit in the previous 6 months 
$\%$ of all clients given a friendly greeting

$\%$ of clients who asked a question

Among clients who asked a question, \% satisfied with the response

$\%$ of clients who found the provider easy to understand

$\%$ of pelvic exams in which client was informed about the procedure beforehand

$\%$ of pelvic exams in which client was informed about the results afterward

$\%$ if IUD insertions in which the client was given moral support

\section{QUALITY OF SERVICES: INFORMATION TAKEN FROM CLIENTS}

$\%$ of new clients asked about their reproductive intentions

$\%$ of new clients asked their breast-feeding status

$\%$ of Progestin-Only Pills acceptors asked their breast-feeding status

$\%$ of new clients asked their method preference

$\%$ of new clients asked about previous method use

$\%$ of revisit clients asked about problems with their method

$\%$ of clients asked if they discuss family planning with partner

$\%$ of new clients asked the nature of their sexual relations

$\%$ of revisit clients asked the nature of their sexual relations

$\%$ of new clients asked about unusual bleeding

$\%$ of revisit clients asked about unusual bleeding

$\%$ of new clients asked about unusual discharge

$\%$ of revisit clients asked about unusual discharge

$\%$ of IUD clients asked about unusual bleeding

$\%$ of IUD clients asked about unusual discharge

\section{Q-3 QUALITY OF SERVICES: CHOICE OF METHODS}

$\%$ of new clients told about at least two methods

$\%$ of new clients to whom Combined Pills were mentioned

$\%$ of new clients to whom Progestin-Only Pills were mentioned

$\%$ of new clients to whom injectables were mentioned

$\%$ of new clients to whom condoms were mentioned

$\%$ of new clients to whom IUDs were mentioned

$\%$ of new clients to whom tubal ligation was mentioned

$\%$ of new clients to whom one method was over emphasized 
$\%$ of new acceptors told how to use their method

$\%$ of new acceptors told the side effects of their method

$\%$ of new acceptors told how to use their method and it side effects

$\%$ of new acceptors told about their method's ability to protect against STD/HIV

$\%$ of new clients specifically told that condoms protect against STD/HIV

$\%$ of new clients with whom flip chart was used

$\%$ of new clients with whom a brochure was used

$\%$ of new clients with whom a poster was used

QUALITY OF SERVICES: TECHNICAL COMPETENCE

$\%$ of new clients who were weighed

$\%$ of new clients whose LMP was taken

$\%$ of new clients whose blood pressure was taken

$\%$ of new clients whose medical history was taken

$\%$ of new clients who were given a general physical exam

$\%$ of pelvic exams before which the provider washed hands

$\%$ of pelvic exams after which the provider washed hands

$\%$ of pelvic exams during which clean/sterile speculum was used

$\%$ of pelvic exams during which clean/sterile gloves were used

$\%$ of IUD insertions during which the uterus was sounded

$\%$ of IUD insertions during which the provider used sterile instruments

$\%$ of injections during which a sterile needle was used

$\%$ of injections before which the injection site was disinfected

$\%$ of injections before which the vial was vigorously taken

$\%$ of injections after which the injection site was not massaged

$\%$ of new acceptors told that they can switch methods

$\%$ of clients given a date of return

Q-7 QUALITY OF SERVICES: APPROPRIATENESS AND ACCEPTABILITY OF SERVICES

$\%$ of clients who received all the information and services they desired

Client satisfaction with time of consultation:

$\%$ too long

$\%$ just right

$\%$ too short

$\%$ of clients who found the wait reasonable

$\%$ of clients who found the cost of services acceptable 


\begin{tabular}{|c|c|c|c|c|}
\hline Location & Coverage & Dates & Topic & Participants \\
\hline Nairobi, Kenya & National & Dec, 1993 & Quality of care & NGO staff \\
\hline Dakar, Senegal & Regional & July, 1994 & Situation Analysis & Regional training team \\
\hline Nairobi, Kenya & Regional & Aug, 1994 & Situation Analysis & Regional training team \\
\hline Ouagadougou, Burkina Faso & National & Oct, 1994 & Computing training & $\mathrm{MOH}$ staff \\
\hline Harare, Zimbabwe & National & Feb, 1995 & Qualitative research & ZNFPC researchers \\
\hline Ouagadougou, Burkina Faso & Regional & $\begin{array}{l}\text { March, } 1995 \\
\text { March, } 1996\end{array}$ & Operations research & NGO managers \\
\hline Dakar, Senegal & National & June, 1995 & Operations research & Regional MOH staff \\
\hline Dakar, Senegal & National & Sep, 1995 & Proposal development & $\mathrm{MOH}$ staff \\
\hline Arusha, Tanzania & National & Jan, 1996 & Operations research & $\begin{array}{l}\text { Proposal development } \\
\text { MOH \& NGO staff }\end{array}$ \\
\hline Harare, Zimbabwe & National & Jan, 1996 & Computing skills & ZNFPC staff \\
\hline Gaborone, Botswana & National & Feb, 1996 & Operations research & $\begin{array}{l}\text { Proposal development } \\
\text { NGO staff }\end{array}$ \\
\hline Dakar, Senegal & National & March, 1996 & Operations research & $\begin{array}{l}\text { Proposal development } \\
\text { PNPF and NGO staff }\end{array}$ \\
\hline Nairobi, Kenya & Regional & March, 1996 & Gender issues & UNFPA managers \\
\hline Harare, Zimbabwe & National & April, 1996 & Strategic planning & ZNFPC staff \\
\hline $\begin{array}{l}\text { Gaborone, Botswana } \\
\text { (5 x 3-day workshops) }\end{array}$ & National & April-August1996 & Strategic management & NGO staff \\
\hline Livingstone, Zambia & National & August, 1996 & Participatory appraisal & $\mathrm{NGO}, \mathrm{MOH}$ staff \\
\hline Gaborone, Botswana & National & August, 1996 & Data analysis & NGO staff \\
\hline Bamako, Mali & Regional & August, 1996 & $\begin{array}{l}\text { Operations research; } \\
\text { proposal development }\end{array}$ & Program managers \\
\hline Nairobi, Kenya & Municipal & October, 1996 & Data analysis & NCC staff \\
\hline Ouagadougou, Burkina Faso & Regional & January, 1997 & FGC interventions & NGO staff \\
\hline Mombasa, Kenya & Regional & April, 1997 & Quality improvement & Program managers \\
\hline Harare, Zimbabwe & National & October, 1997 & Strategic planning & ZNFPC staff \\
\hline Navrongo, Ghana & National & December, 1997 & Mass media & National journalists \\
\hline Nairobi, Kenya & National & February, 1998 & Policy guidelines & $\mathrm{MOH}$ staff \\
\hline Francistown, Botswana & National & May, 1998 & Integration & $\mathrm{MOH}$ staff \\
\hline Harare, Zimbabwe & Regional & June, 1998 & Quality improvement & Program managers \\
\hline Lusaka, Zambia & National & December, 1998 & Participatory appraisal & $\mathrm{NGO}, \mathrm{MOH}$ staff \\
\hline
\end{tabular}


